\title{
Personalised risk communication for informed decision making about taking screening tests (Review)
}

\author{
Edwards AGK, Evans R, Hood K, Elwyn GJ
}

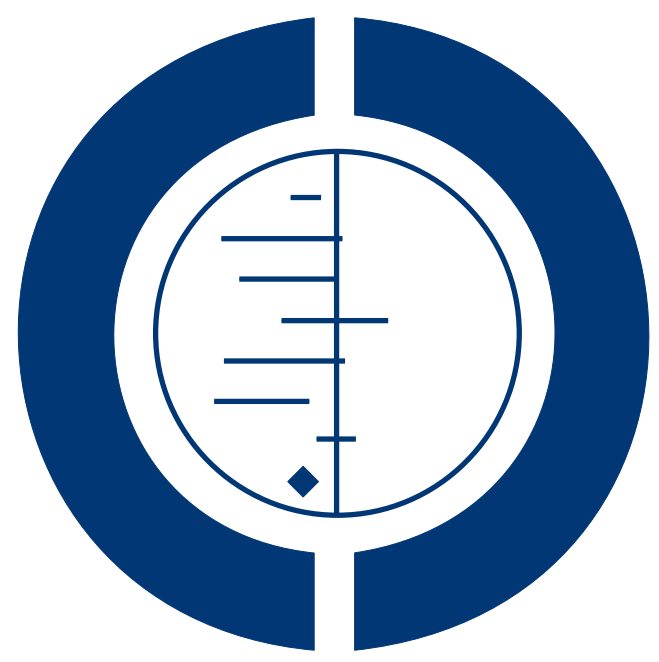

\section{THE COCHRANE COLLABORATION $^{\circledR}$}

This is a reprint of a Cochrane review, prepared and maintained by The Cochrane Collaboration and published in The Cochrane Library 2011, Issue 12

http://www.thecochranelibrary.com



Personalised risk communication for informed decision making about taking screening tests (Review)

Copyright @ 201 I The Cochrane Collaboration. Published by John Wiley \& Sons, Ltd. 
TABLE OF CONTENTS

HEADER . . . . . . . . . . . . . . . . . . . . . . . . . . . . . . . . . . . . . . . 1

ABSTRACT . . . . . . . . . . . . . . . . . . . . . . . . . . . . . . . . . . . . . . . . . . . . . 1

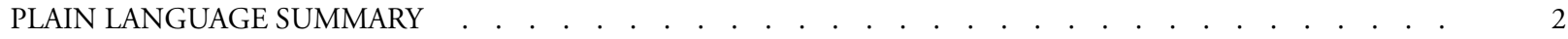

BACKGROUND . . . . . . . . . . . . . . . . . . . . . . . . . . . . . . . . . . . . . 2

OBJECTIVES . . . . . . . . . . . . . . . . . . . . . . . . . . . . . . . . . . . . . . 4

METHODS . . . . . . . . . . . . . . . . . . . . . . . . . . . . . . . . . . . . . . 44

RESULTS . . . . . . . . . . . . . . . . . . . . . . . . . . . . . . . . . . . . . . . 6

DISCUSSION . . . . . . . . . . . . . . . . . . . . . . . . . . . . . . . . 10

AUTHORS' CONCLUSIONS . . . . . . . . . . . . . . . . . . . . . . . . . . . . . . . 12

ACKNOWLEDGEMENTS . . . . . . . . . . . . . . . . . . . . . . . . . . . . . . . . . . . . . . . . . 12

REFERENCES . . . . . . . . . . . . . . . . . . . . . . . . . . . . . . . . . . . . . 13

CHARACTERISTICS OF STUDIES . . . . . . . . . . . . . . . . . . . . . . . . . . . . . 17

DATA AND ANALYSES . . . . . . . . . . . . . . . . . . . . . . . . . . . . . . . . . . . . . . . . . . . . . $\quad 29$

Analysis 1.1. Comparison 1 personalised risk communication versus general risk information, Outcome 1 knowledge regarding screening test / condition concerned. $\quad . \quad$. . . . . . . . . . . . . . . . . . . . . . . . . . . . .

Analysis 1.2. Comparison 1 personalised risk communication versus general risk information, Outcome 2 knowledge



Analysis 1.3. Comparison 1 personalised risk communication versus general risk information, Outcome 3 perceived risk perceiving self as appropriate candidate for test. . . . . . . . . . . . . . . . . . . . . . . . . . . .

Analysis 1.4. Comparison 1 personalised risk communication versus general risk information, Outcome 4 accurately perceived risk.

Analysis 1.5. Comparison 1 personalised risk communication versus general risk information, Outcome 5 anxiety (Cancer related anxiety and helplessness scale; IES breast cancer distress).

Analysis 1.8. Comparison 1 personalised risk communication versus general risk information, Outcome 8 intention to take screening test.

Analysis 1.9. Comparison 1 personalised risk communication versus general risk information, Outcome 9 uptake of screening test. . . . . . . . . . . . . . . . . . . . . . . . . . . . . . . . . . .

Analysis 1.10. Comparison 1 personalised risk communication versus general risk information, Outcome 10 appropriate use of cholesterol test. . . . . . . . . . . . . . . . . . . . . . . . . . . . . . . .

Analysis 1.11. Comparison 1 personalised risk communication versus general risk information, Outcome 11 smoking.

Analysis 1.13. Comparison 1 personalised risk communication versus general risk information, Outcome 13 improvement in risk comprehension/perception. . . . . . . . . . . . . . . . . . . . . . . . . . . .

Analysis 1.14. Comparison 1 personalised risk communication versus general risk information, Outcome 14 making a recommended behaviour change. . . . . . . . . . . . . . . . . . . . . . . . . . . .

Analysis 2.1. Comparison 2 personalised risk communication versus general risk information for PAP SMEARS, Outcome 1 intention to take screening test. . . . . . . . . . . . . . . . . . . . . . . . . . . . . . . .

Analysis 2.2. Comparison 2 personalised risk communication versus general risk information for PAP SMEARS, Outcome 2 uptake of screening test. . . . . . . . . . . . . . . . . . . . . . . . . . . . . . . . 50

Analysis 3.2. Comparison 3 personalised risk communication versus general risk information for MAMMOGRAPHY, Outcome 2 knowledge regarding screening test / condition concerned. . . . . . . . . . . . . . . .

Analysis 3.3. Comparison 3 personalised risk communication versus general risk information for MAMMOGRAPHY, Outcome 3 accuracy of perceived risk.

Analysis 3.7. Comparison 3 personalised risk communication versus general risk information for MAMMOGRAPHY, Outcome 7 intention to take screening test.

Analysis 3.8. Comparison 3 personalised risk communication versus general risk information for MAMMOGRAPHY, Outcome 8 uptake of screening test.

Analysis 4.1. Comparison 4 personalised risk communication versus general risk information for CHOLESTEROL TESTS, Outcome 1 uptake of screening test. . . . . . . . . . . . . . . . . . . . . . . .

Analysis 4.2. Comparison 4 personalised risk communication versus general risk information for CHOLESTEROL TESTS, Outcome 2 appropriate use of cholesterol test. 
Analysis 5.1. Comparison 5 personalised risk communication versus general risk information for 'HIGH RISK' PEOPLE,

Outcome 1 knowledge regarding screening test / condition concerned. . . . . . . . . . . . . . .

Analysis 5.2. Comparison 5 personalised risk communication versus general risk information for 'HIGH RISK' PEOPLE,

Outcome 2 perceived risk - perceiving self as appropriate candidate for test. . . . . . . . . . . . . . . . .

Analysis 5.3. Comparison 5 personalised risk communication versus general risk information for 'HIGH RISK' PEOPLE,

Outcome 3 accurately perceived risk. . . . . . . . . . . . . . . . . . . . . . . . . . .

Analysis 5.4. Comparison 5 personalised risk communication versus general risk information for 'HIGH RISK' PEOPLE,

Outcome 4 anxiety. . . . . . . . . . . . . . . . . . . . . . . . . . . . . . . . .

Analysis 5.7. Comparison 5 personalised risk communication versus general risk information for 'HIGH RISK' PEOPLE,

Outcome 7 intention to take screening test. . . . . . . . . . . . . . . . . . . . . . . .

Analysis 5.8. Comparison 5 personalised risk communication versus general risk information for 'HIGH RISK' PEOPLE,

Outcome 8 uptake of screening test. . . . . . . . . . . . . . . . . . . . . . . . . . . . . . . . . . . . .

Analysis 6.1. Comparison 6 personalised risk communication versus general risk information for COLORECTAL

SCREENING, Outcome 1 uptake of screening test. . . . . . . . . . . . . . . . . . . . . . . . . . . . . .

Analysis 7.1. Comparison 7 personalised risk communication versus general risk information for PROSTATE CANCER

SCREENING, Outcome 1 uptake of screening test. . . . . . . . . . . . . . . . . . . . . . . . . 64

APPENDICES . . . . . . . . . . . . . . . . . . . . . . . . . . . . . . . . . . . . . . . 64

FEEDBACK . . . . . . . . . . . . . . . . . . . . . . . . . . . . . . . . . . . . . . 69

WHAT'S NEW . . . . . . . . . . . . . . . . . . . . . . . . . . . . . . . . . . . . 70

HISTORY . . . . . . . . . . . . . . . . . . . . . . . . . . . . . . . . . . . . . . . 70

CONTRIBUTIONS OF AUTHORS . . . . . . . . . . . . . . . . . . . . . . . . . . . . . . . . . . . . . . . 71

DECLARATIONS OF INTEREST . . . . . . . . . . . . . . . . . . . . . . . . . . . . . . . . . . . . . . . . 71

SOURCES OF SUPPORT . . . . . . . . . . . . . . . . . . . . . . . . . . . . . . . . . . . . . . . . . . . . . . . . . 71

INDEX TERMS . . . . . . . . . . . . . . . . . . . . . . . . . . . . . . . . . . . . 72

Personalised risk communication for informed decision making about taking screening tests (Review) 


\title{
Personalised risk communication for informed decision making about taking screening tests
}

\author{
Adrian GK Edwards ${ }^{1}$, Rhodri Evans ${ }^{1}$, Kerry Hood ${ }^{1}$, Glyn J Elwyn ${ }^{1}$ \\ ${ }^{1}$ Department of Primary Care and Public Health, School of Medicine, Cardiff University, Cardiff, UK \\ Contact address: Adrian GK Edwards, Department of Primary Care and Public Health, School of Medicine, Cardiff University, 2nd \\ Floor, Neuadd Meirionnydd, Heath Park, Cardiff, Wales, CF144YS, UK. edwardsag@cardiff.ac.uk. adriangkedwards@btinternet.com.
}

Editorial group: Cochrane Consumers and Communication Group.

Publication status and date: Edited (no change to conclusions), comment added to review, published in Issue 12, 2011.

Review content assessed as up-to-date: 30 December 2005.

Citation: Edwards AGK, Evans R, Hood K, Elwyn GJ. Personalised risk communication for informed decision making about taking screening tests. Cochrane Database of Systematic Reviews 2006, Issue 4. Art. No.: CD001865. DOI: 10.1002/14651858.CD001865.pub2.

Copyright (C) 2011 The Cochrane Collaboration. Published by John Wiley \& Sons, Ltd.

\section{A B S T R A C T}

\section{Background}

There is a trend towards greater patient involvement in healthcare decisions. Adequate discussion of the risks and benefits associated with different choices is often required if involvement is to be genuine and effective. Achieving both the adequate involvement of consumers and informed decision making are now seen as important goals for any screening programme. Personalised risk estimates have been shown to be effective methods of risk communication in general, but the effectiveness of different strategies has not previously been examined.

\section{Objectives}

To assess the effects of different types of personalised risk communication for consumers making decisions about taking screening tests.

\section{Search methods}

We searched the Cochrane Central Register of Controlled Trials (CENTRAL) (The Cochrane Library Issue 4, 2004), MEDLINE (1985 to December 2005), EMBASE (1985 to December 2005), CINAHL (1985 to December 2005), and PsycINFO (1989 to December 2005). Follow-up searches involved hand searching Preventive Medicine, citation searches on seven authors, and searching reference lists of articles. For the original version of this review (Edwards 2003c) we also searched CancerLit (1985 to 2001) and Science Citation Index Expanded (searched March 2002).

\section{Selection criteria}

Randomised controlled trials addressing the decision by consumers of whether or not to undergo screening, incorporating an intervention with a 'personalised risk communication element' and reporting cognitive, affective, or behavioural outcomes. A 'personalised risk communication element' is based on the individual's own risk factors for a condition (such as age or family history). It may be calculated from an individual's risk factors using formulae derived from epidemiological data, and presented as an absolute or relative risk or as a risk score, or it may be categorised into, for example, high, medium or low risk groups. It may be less detailed still, involving a listing, for example, of a consumer's risk factors as a focus for discussion and intervention. 


\section{Data collection and analysis}

Two authors independently assessed each trial for quality and extracted data. We extracted data about the nature and setting of the intervention, and relevant outcome data, along with items relating to methodological quality. We then used standard statistical methods of the Consumers and Communication Review Group to combine data using MetaView, including analysis according to different levels of detail of personalised risk communication, different condition for screening, and studies based only on high risk participants rather than people at 'average' risk.

\section{Main results}

Twenty-two studies were included, nine of which were added in the 2006 update of this review. There was weak evidence, consistent with a small effect, that personalised risk communication (whether written, spoken or visually presented) increases uptake of screening tests (odds ratio (OR) 1.31 (random effects, 95\% confidence interval (CI) 0.98 to 1.77). In three studies the interventions showed a trend towards more accurate risk perception (OR 1.65 (95\% CI 0.96 to 2.81), and three other trials with heterogenous outcome measures showed improvements in knowledge with personalised risk interventions. There was little other evidence from these studies that the interventions promoted or achieved informed decision making by consumers about participation in screening. More detailed personalised risk communication may be associated with a smaller increase in uptake of tests. That is, for personalised risk communication which used and presented numerical calculations of risk, the OR for test uptake was 0.82 (95\% CI 0.65 to 1.03). For risk estimates or calculations which were categorised into high, medium or low strata of risk, the OR was 1.42 (95\% CI 1.07 to 1.89 ). For risk communication that simply listed personal risk factors the OR was 1.42 (95\% CI 0.95 to 2.12).

Over half of the included studies assessed interventions in the context of mammography. These studies showed similar effects to the overall dataset. The five studies examining risk communication in high risk individuals (individuals at higher risk due to, for example, a family history of breast cancer or other conditions) showed larger odds ratios for uptake of tests than the other studies (random effects OR $1.74 ; 95 \%$ CI 1.05 to 2.88$)$.

There were insufficient data from the included studies to report odds ratios on other key outcomes such as: intention to take tests, anxiety, satisfaction with decisions, decisional conflict, knowledge and resource use.

\section{Authors' conclusions}

Personalised risk communication (as currently implemented in the included studies) may have a small effect on increasing uptake of screening tests, and there is only limited evidence that the interventions have promoted or achieved informed decision making by consumers.

\section{PLAIN LANGUAGE S UMMARY}

\section{Personalised risk information for helping people make an informed decision about taking screening tests}

Screening tests aim to identify people who may have a particular disease or condition. People considering participation in screening may receive information about the general risk of having the disease or condition, or information that is tailored to their personal risk status (personalised risk information). This updated review of trials found that people given personalised risk information may be more likely to participate in screening. However, there is not enough evidence to show whether people given personalised risk information are making more informed decisions. Providing risk information in ways that better inform people may sometimes lead to lower participation rates in screening.

\section{B A C K G R O U N D}

A variety of tests and procedures can be used to identify individuals and groups at 'high risk' of various diseases or conditions. Many of these tests and procedures form part of screening programs -

programs with the objective of sorting out apparently well persons who probably have a disease from those who probably do not. They may only highlight a risk of disease, and are not intended to 
definitely diagnose a disease or condition.

Understanding is still limited of how best to present and discuss risks and benefits of health care in general, and screening in particular, for an individual. Some screening programs provide information about population or 'average' risks of contracting a disease as a basis for discussion or decision-making about undergoing screening, or perhaps more simply to try to motivate people to attend for tests which are perceived by authorities to be in their or the population's best interests (Slaytor 1998). Others aim to provide information which is more personally relevant to the consumer in question. The latter is what we describe as 'personalised risk communication', sometimes also described as 'individualised risk communication'. This may be based on the individual's own risk factors for a condition (such as age or family history). In some cases it is calculated from an individual's risk factors using formulae derived from epidemiological data, with the information presented as an absolute risk or as a risk score, or categorised into, for example, high, medium or low risk groups. It may be less detailed, involving a listing, for example, of a consumer's risk factors as a focus for discussion and intervention. In these scenarios, it is generally anticipated that because the information is thought to be more pertinent to the individual, personalised risk communication is more likely to be useful in decision-making about whether or not to participate in screening.

Personalised risk communication has been incorporated into several healthcare interventions, including the areas of treatment, prevention and screening (Edwards 2000a). In view of the increase in screening programs in health care, and the growing awareness that consumer decisions can be influenced by the way risk information is presented (Sarfati 1998; Edwards 2001), this review focuses on the effects of personalised risk communication on consumers making decisions about taking screening tests. The effects may be varied. They include influences on 'cognitive' outcomes such as consumer knowledge or risk perception, 'affective' outcomes such as anxiety, and behavioural outcomes such as uptake of screening tests (Llewelyn-Thomas 1995; Edwards 1999).

Concern about reaching set participation targets can lead to overzealousness on the part of healthcare providers, and a disregard of ethics of good medical practice. Foster and Anderson (Foster 1998) criticise the implementers of the UK's National Cervical Screening Programme, including general practitioners, for their persuasive tactics in getting patients to comply. They stress that women should be made aware of the risks (discomfort, over-treatment of abnormal smears) and limitations (false positives; false negatives), as well as the benefits of the test. They also point out that people have different risks of contracting the disease, based on factors such as age, sexual activity, social class and smoking. In contrast, some of the harms relating to screening tests are equitably distributed among the population being screened - the risk of direct harm from having a screening test for example. Other harms, such as failure to detect disease, only apply to those with the condition. In either scenario of harm, however, Raffle (Raffle 2001) warns that 'harm to uninformed participants leads to anger, bitterness, and potentially to litigation'. Thus, the social and psychological costs of screening need to be assessed (Stewart-Brown 1997). There is increasing attention to the issue of achieving and demonstrating informed decision making about whether or not to undergo screening. The UK has recently introduced the 'Prostate Cancer Risk Management Programme' which makes the Prostate Specific Antigen (PSA) test available to all men who have received information about the test and make an informed decision to take the test. There is also a measure available for assessing informed choice in Down's Syndrome screening or testing (Marteau 2001), but more work is required to produce measures for other conditions if this type of outcome is to be widely reported in the literature.

Increasingly, the outcomes described in the literature also include such 'affective' measures as satisfaction with the decision made, and 'decisional conflict'. This includes whether an individual feels a decision is consistent with their personal values, and certainty about making the right decision (Llewelyn-Thomas 1995; O'Connor 1995; Holmes-Rovner 1996; Edwards 1999). There is also recognition that uptake of tests per se is not necessarily desirable (for example, prostate specific antigen screening and antenatal cystic fibrosis screening are contentious areas). Making an informed choice about entering screening, and adherence to the consumer's chosen option, are widely regarded as more desirable goals for risk communication (Liao 1996; Sarfati 1998; Edwards 1999).

Risk communication itself may be subdivided by the dyad involved (for example between agencies and the public, or from individual communicators), as well as according to the nature of the risk, which may be familiar or non-familiar (Vlek 1987). Reviews of 'mass' risk communication, primarily from the environmental health discipline (Fischhoff 1979; Covello 1986; Keeney 1986), and from narrow clinical fields such as familial cancer (Bottorff 1996), are available. Briss 2004 also reviewed interventions that sought to promote informed decisions about cancer screening, but not through 'personalising' risk information. In addressing the effects of personalised methods of risk communication this review focuses on risk communication which is provided, used and evaluated in healthcare encounters with individuals, couples, or immediate families (for example, parents of young children). As such, the review is broader than previous clinical risk communication reviews (Bottorff 1996) but still aims to be relevant to the community and the clinical needs of healthcare professionals across a range of disciplines. It focuses on the domain of healthcare screening.

This review updates the 2003 version, which identified thirteen relevant studies (Edwards 2003c). 


\section{O B J E C T I V E S}

To compare the effects of personalised and general risk communication in deciding whether to participate in health screening, on people's cognitive, affective and behavioural outcomes. These include their knowledge, risk perception, satisfaction with decision-making and decisional conflict, emotional wellbeing and behaviour (ie. taking screening tests).

\section{METHODS}

\section{Criteria for considering studies for this review}

\section{Types of studies}

Randomised controlled trials (RCTs). Studies which were not undertaken on the basis of 'intention to treat' were not excluded, but with weaker methodological quality less weight is attached to their findings (Edwards 2000b).

\section{Types of participants}

People facing real life decisions (not hypothetical exercises) about whether to undergo screening. They may be individuals making decisions alone or on another's behalf (for example, for a young child), or couples making decisions together.

The screening activities must involve an investigation performed by a health professional. Examples of these are (not an exhaustive list):

- mammography;

- cervical 'Papanicolaou' smears;

- colorectal cancer screening;

- prostatic cancer screening (PSA test);

- antenatal screening (including Down's syndrome, neural tube defects and other fetal anomalies);

- genetic screening (including breast cancer gene testing);

- high cholesterol / cardiovascular risk screening;

- neonatal screening (including cystic fibrosis and Duchenne testing).

Studies to be excluded if they describe only:

- mass communication;

- military or school or prison-based interventions (where consumers are less free to choose than in other healthcare settings).

\section{Types of interventions}

The interventions are personalised risk information: individualised risk score or individual actual risk information (absolute or relative risk information); or categorisations of risk status based on these estimates (for example, high, medium or low risk status); or discussion of personal risk factors relevant to the screening decision (that is, the individual's own characteristics are taken into account in assessing their actual risk or elevated risk status relative to others).

The interventions also address decision-making about screening tests; that is, testing whose objective is the presumptive identification of unrecognised disease or defect (including genetic markers for disease) by the application of tests or other procedures, which can be applied rapidly. These tests are intended to sort out apparently well persons who may have a disease from those who probably do not, and they are not intended to be diagnostic (Wilson 1968; Rose 1978).

The risk communication intervention could come before screening, at the time of the screening intervention, or at the time of counselling or promotion of screening. Personalised risk communication could be delivered via oral, written, video, or electronic (internet or CD-ROM) media.

Personalised risk information is compared to generalised risk communication interventions, including: population risk estimates, general information on risk factors, or general encouragement to acknowledge risks or change risk behaviour.

Studies were rejected if they simply evaluated health education/ promotion to reduce risk factors or increase adherence to screening, without discussion of risks and benefits of undergoing or not undergoing screening; or if general rather than personalised risk communication was the main basis of the intervention.

\section{Types of outcome measures}

The outcome measures focused on identifying changes in any of the following key areas (Llewelyn-Thomas 1995; Edwards 1999), if appropriate data were available:

- 'cognitive' outcomes: knowledge of risk, accurate risk perception;

- 'affective' outcomes: anxiety/emotional wellbeing, satisfaction with decisions made, decisional conflict, anxiety, intention to take up screening;

- behavioural outcomes: uptake of tests, adherence to choice regarding screening test, 'appropriate' uptake;

- health status outcomes: specific status measures or quality of life measures such as SF-36;

- economic outcomes: cost of intervention.

\section{Search methods for identification of studies}

Two authors searched the Cochrane Central Register of Controlled Trials (CENTRAL), MEDLINE, EMBASE, CINAHL and PsycINFO. The search strategies were developed from earlier work by Matthews et al (Matthews 1999) and the first (2003) publication of this review (Edwards 2003b; Edwards 2003c), as well as that used by Jepson et al (Jepson 2000) in their systematic review. 
It comprised three layers of search terms - keywords and medical subject headings $(\mathrm{MeSH})$ - aimed at identifying articles about screening involving counselling/education or risk specifically. The goal was for high recall (sensitivity) of literature in the field of risk communication in screening (which may therefore be at the expense of precision (specificity). We searched databases in OVID from 1985 onwards, as extensive pilot searching indicated preceding years to have extremely low yields of literature in this field (Matthews 1999).

Search strategies were tailored to the relevant databases, and as appropriate used mainly subject headings (for example, MEDLINE, CINAHL) or the equivalent translated textwords (for example, EMBASE). 'Explode' functions were used on all subject headings. All search strategies are presented in Appendices.

For the first publication of this review (Edwards 2003b; Edwards 2003c) we also searched CancerLit (1985 to 2001) and Science Citation Index Expanded (searched March 2002). Strategies are available from the lead author upon request.

The electronic searches for the 2003 review and the 2006 review update produced a combined total of 9643 titles and abstracts for assessment. We also undertook a manual follow-up of references from key publications and journals, and of key authors. This was informed by the output of the electronic searches, targeting the publications or authors encountered most frequently. Seven authors were selected on the basis of frequent publications in the initial search outputs: BK Rimer (141 references), C Lerman (117 references), MD Schwartz (89 references), V Champion (60 references), MW Kreuter (52 references), CS Skinner (30 references) and R Bastani (28 references). These yielded no more included studies, but provided a wealth of background information. Other prominent reviews or review protocols in the field were accessed to see if they had any further relevant work (published or unpublished) (Jepson 2000; O'Connor 2003). One article was identified which represents the closest this field has to a prospective trials register (Oncology 1994), documenting 11 relevant USA research programs. We also undertook citation index searches for these authors.

\section{Data collection and analysis}

Two authors (AE and JD) independently made an initial selection of publications from search outputs (titles and abstracts). Disagreements were resolved by discussion. In cases of doubt about relevance to this review, we retrieved papers in full for final decision making. Papers rejected at this stage were circulated to other members of the study group to review the decision.

\section{Data extraction}

We extracted and collated on a template key information from all selected publications. Two authors (AE and $\mathrm{SH}$ or $\mathrm{AE}$ and
JD) analysed all papers. Extracted data included country of origin, health professional group involved, screening program and patient group involved, setting, sample size, and key outcomes. We extracted further data on differences in baseline risk for assessment of effect modifiers. Consistency of assessment was checked (quality control) by weighted kappa agreement scores. Specifically, we extracted data on the nature/design of the intervention. This included the type of personalised risk communication in the main intervention: estimate or calculation of numerical risk or risk score; estimated or calculated risk categorised as, for example, high, medium or low level of risk to consumer; or listing of personal risk factors without estimate or calculation of risk level. The nature of the intervention also covered whether specific counselling or behavioural change strategies, or both, were included in the risk communication intervention.

Outcome data extracted comprised the absolute changes in numbers between groups (for dichotomous variables), and the mean change and standard deviation of the mean change (for continuous variables). From these, we calculated odd ratios (ORs) for dichotomous variables, and weighted mean differences (WMDs) for continuous outcomes. We also recorded the statistical significance of results.

We examined important effect modifiers on the changes in outcome demonstrated, examining in particular, if the data were available, for the influence of: screening program or condition, setting, professional group involved, type of intervention, differences in baseline risk, age, gender, and educational level.

We also extracted data to assess the quality of the study. Two members of the study team (AE and $\mathrm{SH}$ or $\mathrm{AE}$ and JD) assessed all studies against checklists, derived from those by Jadad 1996 and the 'Method Score' used in a wider review of the risk communication literature (Edwards 2000a). The principal elements used for this review were allocation concealment, blinding of assessors, and intention-to-treat analyses. We resolved differences in assessment of publications by discussion. Relevant data on the quality and results of studies are summarised in the table 'Characteristics of Included Studies' and the Analyses. Allocation concealment is rated as follows:

- A: Adequate concealment;

- B: Unclear;

- C: Clearly inadequate concealment;

- D: Not used (no attempt at concealment).

\section{Data Combination}

Studies in this review derive from a heterogeneous group of screening programmes. Nevertheless the essential characteristic of the risk communication interventions (personalised elements) rendered data combination appropriate. We first examined studies for qualitative synthesis. We then used standard statistical methods of the Consumers and Communication Review Group to combine data using MetaView. Tests for heterogeneity were included. Sensi- 
tivity analyses involved analysing different sections of the data, for example according to different condition for screening or studies based only on high risk participants rather than people at 'average' risk. The categorisation of personalised risk communication into three levels of detail given to consumers was also used to examine for evidence of different effect from heterogeneous groups of interventions.

Insufficient data were provided in many studies to enable (raw) data entry into MetaView. As there was some heterogeneity of the studies in terms of the screening tests addressed, participants and design of intervention, results from a random effects model (which gives a more conservative confidence interval on the estimate of effect size) were examined and are presented in cases of borderline significance - in addition to analysis using a fixed effects model.

\section{Consumer participation}

For the original publication of this review (Edwards 2003c) the lead author participated in email discussion of drafts of the protocol by a four-member consumer advisory group, including members from three countries (see Acknowledgements). The advisory group was also consulted on the content of the full review. An anonymous referee from a fourth country was involved by the Cochrane Consumers and Communication Review Group during the editorial process for the protocol.

\section{R E S U L T S}

\section{Description of studies}

See: Characteristics of included studies; Characteristics of excluded studies.

Twenty-two studies met the inclusion criteria. Nine of these studies were added during the 2006 update of this review (Bowen 2002; Campbell 1997; Champion 2000a; Champion 2002; Champion 2003; Jibaja-Weiss 2003; Lipkus 2005; Rimer 2002; Skinner 2002).

Thirteen of the 22 studies described a personalised risk communication intervention for mammography screening programmes and a further four addressed breast cancer risk and gene testing. Three addressed cervical screening, two (high) cholesterol screening, two addressed colorectal cancer screening, and one addressed prostate cancer screening (some covered more than one topic). As in the wider literature on one-to-one risk communication in health care (Edwards 2000a), most studies derived from the USA. The interventions were delivered by a range of healthcare professionals, ranging from physicians and nurses to staff specifically recruited and trained for the intervention studies.

Four interventions included a calculated risk estimate, such as from the Gail model for breast cancer risk (Gail 1989). Three interventions included a categorisation of risk level, such as into 'high', 'medium' or 'low' strata. Fifteen interventions included the most basic level of 'personalised risk', such as the listing of risk factors pertinent to an individual.

Five of the studies overall were based on samples of people thought or known to be at higher risk than average for the population. Regarding outcomes reported, most studies (13) measured uptake of screening as an outcome. Five measured changes in risk perception (or perceived susceptibility). Five also measured intention to take tests. Beyond this there were only a few outcomes with relevant or reliable data for extraction. Three studies measured knowledge (different measures), two studies measured anxiety, and there was a range of outcomes for which only one study provided data such as for comprehension, and stages of change.

A range of studies were considered closely for inclusion but were eventually excluded. Broadly these fell into two groups. Some examined personalised risk communication, but had either no control data or inadequate control data from which to draw data for comparison. Others did not specifically examine personalised risk communication. (See Characteristics of excluded studies).

The included studies described various types of interventions. We present a brief description of the interventions and outcomes below. (See also Characteristics of included studies).

Bastani 1999 described a tailored risk notification programme for women aged over 30 with a family history of breast cancer, identified via their first degree relatives diagnosed with the disease. Women from the same family were randomised as a unit into either a control group, or an intervention group in which each person received:

- a letter listing personal risk factors and classifying one as being at either slightly, moderately or substantially higher risk compared to women of the same age; and

- a generic booklet titled 'Taking Action', giving information on risk factors, as well as addressing the importance and process of mammography. Importantly, it highlighted the benefits while minimising the risks of the process, and provided counterarguments to common barriers to screening; and

- a notepad and bookmark with reminder messages.

This intervention was compared to a control group receiving a general information booklet on breast cancer. Rates of mammography based on self-report one year after the intervention were $65.2 \%$ in the intervention group compared to $57.7 \%$ in the control group, both of which had baseline compliance rates of about $55 \%$. The intervention effect was greatest in those aged over 50 years.

Bowen 2002 evaluated the effects of risk counselling about breast cancer (BRCA) genetic testing among women with a family history of breast cancer. During the counselling, each participant was provided with a calculated estimate of her risk, based on both the Gail and Claus model scores (Gail 1989). Among those receiving the intervention individually (as opposed to groups) there was a reduction in the numbers perceiving themselves as 'appropriate 
candidates' for the test $(72 / 105$ (68.6\%) versus $84 / 109$ (77.0\%) in the control group). However, this did not lead to differences in expressed interest in having the test itself $(37 / 105(35.2 \%)$ in the intervention group versus 36/109 (33.0\%) in the control group). Campbell 1997 evaluated a computer based strategy aimed at increasing uptake of cervical screening among women registered with Australian general practices. Risk factors, including if a woman had not had a smear within the previous two years, were summarised in printed format for study participants. Smear uptake was $52 / 148(35 \%)$ in the intervention group, and 33/124 (27\%) in the control group.

Champion 1994 studied women aged 35 years and older, with no history of breast cancer. They were randomised into four groups:

1. control group;

2. belief intervention - involving counselling based on the Health Belief Model variables;

3. information intervention - information about mammography and correct screening intervals;

4. belief + information interventions.

Women in groups 2 and 4 received counselling from graduate nursing research assistants that involved a discussion of individual risk factors if baseline data showed they had low susceptibility scores, ie. low perceived risks. For the purposes of this review, results for groups 2 and 4 (which contained the risk communication component) were combined and compared against those of groups 1 and 3. One year after the intervention, 117/147 (79.6\%) of people receiving the belief interventions were 'compliant' with recommendations for screening compared to $103 / 153$ (67.3\%) in the other groups. (NB: women under 41 were regarded as compliant even if they had not had mammography). Perceived susceptibility to breast cancer was the only belief variable not to undergo a significant change post-intervention, despite this being the focus of the risk communication intervention.

Champion 1995 reported a similar study, but on women aged 40 years and over. In addition, they examined movement across 'stages of change' (Prochaska 1992). Again, no statistically significant differences in susceptibility scores were identified. The belief interventions increased mammography compliance one year after intervention (OR 1.96 for the belief-only group; OR 2.26 for the belief/information group) [raw data not reported]. There was also a net movement from lower to higher stages of change which was greatest in the belief and belief/information groups.

Champion 2000a evaluated a tailored intervention to increase compliance regarding mammography in low income AfricanAmerican aged 45 to 64 years. The 'tailoring' comprised listing of personal risk factors for those women for whom 'perceived susceptibility' was identified as a way of progressing their 'stage of adoption' (others focused on perceived benefits or removing barriers). Uptake of mammography after one year was 105/139 (75.7\%) in the intervention group, compared with $99 / 139(71.1 \%)$ in the control group.

Champion 2002 also evaluated a tailored intervention based on the Health Belief Model and Transtheoretical (stages of change) model, this time with clinic or Health Maintenance Organisation (HMO) members. The interventions included both telephone counselling and mailed elements, with elements listing susceptibility factors for breast cancer risk, and these were assessed in factorial design. Each element appeared to increase uptake of mammography (tailored telephone counselling: odds ratio (OR) 1.66 (95\% confidence interval (CI) 1.12 to 2.46 ); tailored mailing OR $1.72 ; 95 \%$ CI 1.18 to 2.52 ). However absolute data on uptake are not reported in the published version, and no response was received to our attempt to contact study authors.

Champion 2003 evaluated a tailored intervention aimed at increasing mammography uptake in older women. As in the previous study (Champion 2002) it included elements listing susceptibility factors for breast cancer risk, and also used a multiple group design which was used to evaluate in-person, telephone and mailed elements of the intervention. The telephone and in-person groups were combined for data about the personalised risk communication effects for this review. The intervention group had a higher uptake of mammography at 6 months (111/242 (45.9\%)) than the control group (34/134 (25.4\%)).

Curry 1993 also used a four group design to examine the effect on mammography uptake of a risk factor questionnaire and personal risk invitation on women aged 50 years and over who were enrolled at an HMO. For the purposes of this review, we compared the results of the two groups that received the questionnaire, one followed by a general risk invitation, giving a generic list of risk factors - the 'control' - and the other by the personal risk invitation (including a list of personal risk factors). Uptake of mammography at one year after the intervention in the personal risk group was $162 / 413(39.2 \%)$, compared to $161 / 428(37.6 \%)$ in the general risk group. There were significantly higher participation rates in the personalised group among women with a family history of breast cancer (66.7\% versus $42.9 \%$ in the control group).

Hutchison 1998 investigated the effect on cholesterol screening uptake of a postal questionnaire appraising the risk of coronary heart disease (CHD). People (aged 20 to 69) in the intervention group were advised to go for a cholesterol test if their answer scores were above a certain level. The control group received a health questionnaire that determined whether they were at risk without identifying the risk factors as related to CHD. Rate of cholesterol screening during three months of follow up was 75/1544 (4.9\%) in the intervention group compared to $27 / 1603(1.7 \%)$ in the control. Specifically, screening uptake for those who met the criteria, and were thus advised to have the tests, was 45/421 (10.7\%; intervention) versus $9 / 504$ ( $1.8 \%$; control).

Jibaja-Weiss 2003 used information from medical records data to tailor messages for low income and minority women regarding both breast and cervical screening uptake. Scheduling and actual uptake of screening tests was lower among women receiving the personalised risk intervention (for example, for mammography: 120/239 (50.2\%) scheduled, 31/239 (13.0\%) uptake) compared 
to the group receiving a standard letter appropriately formatted ('personalised form' letter: 157/239 (65.7\%) scheduled, $\mathrm{P}=0.001$; $73 / 239$ (30.5\%) uptake, $\mathrm{P}<0.001)$.

Kreuter 1996 used a three-group design to investigate the effectiveness of Health Risk Assessments (HRAs) on facilitating a range of behaviour changes including uptake of mammography, pap smears and cholesterol tests. The 'typical HRA' intervention consisted of feedback of personal risk information, graphically and numerically. People in an 'Enhanced HRA' group also received individually tailored behaviour change information. For the purposes of this review, we used the data from the 'typical HRA' versus control, to assess the influence of the personalised risk communication, but the data from 'enhanced HRA' are valuable for further interpretation. Analysis only involved people (aged 18 to 75) who were non-compliant at baseline but were at least contemplating behaviour change. In the typical HRA group, 10/36 (27.8\%), 24/46 (52.2\%) and $19 / 33$ (57.6\%) were compliant after intervention for cholesterol, cervical and breast cancer screening respectively. This compares to $16 / 40$ (40\%), 21/32 (65.6\%) and $17 / 31$ (54.8\%) in the control group (non-statistically significant changes). However, there were some indications that enhanced HRA may have had a greater effect (compared to control) with, for example, cholesterol screening increasing to $16 / 30$ (53.3\%) after this intervention.

Lee 1991 conducted a study with American federal employees aged 40 and above as subjects. The intervention group received a colorectal cancer risk appraisal that included a statement of the individual's risk (categorised as high, moderate or normal) compared to their peer group, as well as general facts about colorectal cancer and the importance and availability of the Faecal Occult Blood (FOB) test. The control group received a simple information letter on the availability of the FOB test at the work site clinic. Outcomes were measured three months after the intervention. No statistically significant differences were observed between groups in terms of knowledge and beliefs regarding colorectal cancer and the FOB test [data not given]. A small rise in the proportion of people in the intervention group taking the test was observed (12/139 $(8.6 \%)$ versus $6 / 139$ (4.3\%) in the control group). Additionally, $62.6 \%(87 / 139)$ in the intervention group compared to $36.2 \%$ $(50 / 139)$ in the control group $(\mathrm{OR}=3.18)$ described an intention to get an FOB test within the next year.

Lerman 1995 investigated the effects of individualised breast cancer counselling, involving a discussion of personal risk factors and presentation of individualised risk estimates in women aged 35 and older with a family history of the disease. The control group received general health counselling. Three months after the intervention, the subjects were assessed for an improvement in risk comprehension. Those in the intervention group were more likely to improve: $26 \%(23 / 90)$ versus $17 \%$ (19/110) (OR 3.5 (95\% CI 1.3 to 9.5)); and this was more marked among African American women. However, in both groups, about two thirds of women continued to substantially overestimate their lifetime risks. In an accompanying paper (Lerman 1996), the authors also report on the impact of the risk counselling on breast-cancer-specific distress and general distress. Risk counselling succeeded in significantly reducing the former $(\mathrm{P}<0.01)$, especially in women with less formal education. The counselling did not affect general mood distress. Schwartz 1999 determined mammography uptake in the risk counselling group compared to the general counselling group one year after intervention. The groups did not differ significantly at baseline or follow up. Among the less educated women, those receiving risk counselling showed reduced mammography use (OR 0.44 (95\% CI 0.23 to 0.83$)$ ).

Lerman 1997 also evaluated the impact of education and counselling (more specifically addressing knowledge and decision-making regarding BRCA1 testing) among women with a family history of breast and/or ovarian cancer. In addition to information on the benefits, limitations and risks of testing, the educational intervention involved a qualitative discussion of individual risk factors. Women on the waiting list served as control subjects. Perceived risk and testing intentions were measured at a one-month followup. Education succeeded in reducing risk perceptions from an average score of 2.12 to 1.88 (range 1 to 4 ) compared to controls ( $\mathrm{P}$ $<0.05)$. There was no significant effect of education on intent to undergo testing, with $57 \%(66 / 116)$ versus $53 \%(87 / 164)$ in the control group stating that they would definitely or probably take the test.

Lipkus 2005 examined a personalised (tailored) intervention for carpentry workers, who have occupational risk factors for colorectal cancer. Risk factors identified from a baseline survey were fed back as part of an intervention seeking to modify people's attribution of colorectal cancer risk, as a means of modifying perceptions of risk and subsequent uptake of faecal occult blood (FOB) tests for colorectal cancer screening. No significant changes in attributions or perceptions of risk were identified, suggesting that participants did not integrate colorectal cancer risk factor information into their conceptualisations of colorectal cancer risk. However, uptake of FOB tests was higher in the intervention group (270/ $432 ; 62.5 \%)$ compared with the control group (238/428; 55.6\%), suggesting that the intervention was effective at increasing the overall screening rate, but that this had not been achieved by the intended means of modifying CRC risk perceptions and worry. Myers 1999 compared the effects of two interventions on Prostate Specific Antigen (PSA) 'adherence' in a sample of African American men aged 40 to 70 years. The minimal intervention group (ie. 'control' for the purposes of this review) received a letter of invitation for free screening, as well as reminder calls and letters. The enhanced intervention group received, in addition, a culturally sensitive educational booklet and a tailored (personal) risk factors and symptoms form based on information given by the men in a baseline survey. Fifty-one per cent (98/192) of the risk intervention group were defined as 'adherers' after one year follow-up, compared to $29 \%(64 / 221)$ in the control group.

Rimer 2002 investigated the effects of tailored print (TP) and counselling compared to usual care on mammography uptake as 
well as perceptions of breast cancer risk, with female members of an HMO aged in their 40s and 50s. The tailored print intervention included a section on personal risk of developing breast cancer in the next ten years presented graphically and numerically. Screening uptake one year after the intervention (Rimer 2001) in the TP group was 52\% (204/392) compared to 56\% (231/412) in the control, and $28 \%$ in the TP group had an accurate risk perception (defined as not overestimating risk) compared to $25 \%$ in the control. The group that received tailored print reinforced with tailored counselling fared better in terms of accurate risk perception (42\%) and were also found to have higher mammography rates of $61 \%$ (197/323). The personalised (tailored) intervention effects of greater knowledge, more accurate risk perception and lower screening test uptake were also sustained through to two years of follow up (Rimer 2002).

Saywell 1999 compared the cost effectiveness of five interventions to increase mammography screening. For the purposes of this review, the combined results of the telephone and in-person counselling groups (in which personal susceptibility was addressed depending on a woman's initial response) were compared to the control 'no counselling' group. One month after the intervention, the mammography 'compliance' rates were $29 \%(68 / 237)$ in the combined intervention group, counselled either by telephone or in person, compared to $18.2 \%(20 / 110)$ in the control group.

Schwartz 1999 evaluated breast cancer risk counselling that included elements of discussing risk factors, presenting individualised risk estimates, and recommendations for mammography use. Uptake of mammography was lower in the intervention group $(148 / 215 ; 69 \%)$ than in the control group $(161 / 215 ; 75 \%)$ whose intervention included assessment of current health practices, agespecific screening recommendations and other general health recommendations (for example, for diet, exercise, smoking).

Skinner 1994 examined the effects of tailored letters (addressing personal risk status, as well as beliefs and barriers, and taking into account people's stage of change) compared to standardised letters, on recall and readership of information, and mammography stage movement. The tailored letters were framed to sound as if they were meant for general audiences, ie. not specifically for the individual concerned, but were still based on risk calculation for the individual woman. Women (aged 40 to 65 ) who received tailored letters were more likely to remember them $(\mathrm{P}<0.05)$. However, there were no significant main effects for stage movement by letter type. Forty-four per cent (33/76) of the tailored letter recipients who were due for screening at baseline had a mammogram, compared to $31 \%$ (24/76) in the standard letter group. The intervention was most effective for African American and low income (< US $\$ 26,000$ per annum income) women.

Skinner 2002 also examined tailoring of pre-counselling materials for breast cancer gene (BRCA) testing among women with a personal or family history of breast and/or ovarian cancer. Risk information was converted into quartiles for level of risk. The personalised (tailored) intervention led to greater knowledge levels (24\% increase versus $16 \%$ for controls; $\mathrm{P}<0.0001$ ), and less over-estimation of risk ( $40 \%$ versus $70 \%$ in controls; $\mathrm{P}<0.0001)$. Anxiety levels showed no differences between groups. Fewer participants in the intervention group expressed intentions to take tests (87\%) than in the control group $(97 \% ; \mathrm{P}<0.05)$. Thus this study provides some evidence of the required elements for informed decision making (knowledge and accurately perceived risk), and without potential harms (anxiety). There is some evidence that this may diminish people's intention to take tests, but the study has not followed this through to evaluate effects on actual decision making.

\section{Risk of bias in included studies}

The studies were of variable quality, but generally good, especially in comparison to many other studies in the field of risk communication in health care (Edwards 2000a). However, few reports in the literature showed evidence of adequate concealment of allocation to randomisation groups in the trial concerned (adequate in 2 studies (Champion 2003; Jibaja-Weiss 2003), inadequate in 1 study (Kreuter 1996) and unclear in 19 studies). Seven studies analysed on an intention-to-treat basis, and $15 \mathrm{did}$ not. Most studies were also unclear about the blinding of assessors in outcome measures although many used patient-reported or objective measures for key outcomes such as assessing test uptake from computerised registers.

\section{Effects of interventions}

Overall, there is weak evidence, consistent with a small effect, that personalised risk communication (whether written, spoken, or visually presented) increases uptake of screening tests (fixed effects OR 1.13 (95\% CI 1.02 to 1.24$)$; random effects OR 1.31 (95\% CI 0.98 to 1.77), see Analysis 1.9). In three studies the interventions showed a trend towards more accurate risk perception (fixed effects OR 1.46 (95\% CI 1.13 to 1.88); random effects OR 1.65 (95\% CI 0.96 to 2.81), see Analysis 1.4), and three other trials with heterogenous outcome measures showed improvements in knowledge with personalised risk interventions. There was little other evidence from these studies that the interventions promoted or achieved informed decision making by consumers about participation in screening. One study assessed 'appropriate uptake' of tests (externally defined appropriateness: that is, uptake for people at higher risk, and non-uptake for people at lower risk) and found more appropriate uptake after the personalised risk intervention (Hutchison 1998). Another study examined whether people perceived themselves as appropriate for the tests after the intervention, with a trend towards fewer people perceiving appropriateness of tests after the intervention (but not statistically significant; Bowen 2002). Skinner 2002 also showed that people were more knowledgeable, and had more accurate perceptions of risk, but 
fewer people intended to take tests after the personalised risk intervention.

Within this overall increase in uptake, more detailed personalised risk communication may be associated with a smaller increase in uptake of tests. That is, for personalised risk communication which used and presented numerical calculations of risk, the OR for test uptake was 0.82 (95\% CI 0.65 to 1.03 ), (see Analysis 1.9 Subcategory 01). For risk estimates or calculations which were categorised into high, medium or low strata of risk, the OR was 1.42 (95\% CI 1.07 to 1.89), (see Analysis 1.9 Subcategory 02). For risk communication that simply listed personal risk factors the OR was 1.17 (95\% CI 1.04 to 1.32 ) by fixed effects model and 1.42 (95\% CI 0.95 to 2.12) by random effects model (see Analysis 1.9 Subcategory 03$)$.

The results for the studies addressing mammography showed similar effects to the overall dataset. The overall OR for an effect on uptake of screening test was 1.11 (95\% CI 0.98 to 1.24 ) by fixed effects and 1.15 (95\% CI 0.85 to 1.54 ) by random effects, but with evidence of significant heterogeneity $(\mathrm{P}<0.01)$. The numerical calculated risk estimates were associated with lower ORs for uptake of tests (OR 0.82 (95\% CI 0.66 to 1.02$)$ ) compared to the categorised risk estimates (OR 1.37 (95\% CI 1.02 to 1.84$)$ ) or lists of personal risk factors (fixed effects OR 1.22 (95\% CI 1.04 to 1.43 ); random effects OR 1.30 (95\% CI 0.81 to 2.07$)$ ). (See Analysis 3.8 and subcategories).

The five studies examining risk communication in high risk individuals showed trends towards larger odds ratios for uptake of tests than the other studies, though with heterogeneity $(\mathrm{P}<0.01)$ between the three levels of personalisation of risk communication. The OR for numerical calculated risk estimates was 1.48 by fixed effects (95\% CI 1.06 to 2.07 ) and 2.16 by random effects ( $95 \%$ CI 0.25 to 18.86$)$. The OR for categorised estimates of risk was 1.37 (95\% CI 1.02 to 1.84$)$. The OR for listed personal risk factors was 1.49 by fixed effects (95\% CI 1.16 to 1.91 ) and 1.77 by random effects (95\% CI 0.91 to 3.42). (See Analysis 5.8 and subcategories).

There were insufficient data from the included studies to report odds ratios on other key outcomes such as: intention to take tests (5 studies but with significant heterogeneity, $\mathrm{P}<0.01$ ), anxiety, satisfaction with decisions, decisional conflict, and knowledge. These other outcomes generally had one or no studies with extractable data (and so it is inappropriate to report confidence intervals). No extractable data on costs, 'appropriate' uptake, or health status (other than anxiety) were identified.

\section{ISCUSSION}

This review updates the first (2003) publication of this review (Edwards 2003b; Edwards 2003c). There are still relatively few studies in the field of screening that have examined the effects of personalised risk communication. However, nine further studies have been included in this revision and the results remain largely consistent with the findings of the first review (Edwards 2003b; Edwards 2003c). The studies that are available provide weak evidence, consistent with a small effect, that personalised risk communication (whether written, spoken or visually presented) increases uptake of screening tests, but there is little evidence that these interventions promote or achieve their effects by enhancing informed decision making by consumers. However, in the same way that screening recommendations have developed in recent years from simply seeking to maximise uptake, to promotion of informed choice about participation in screening programmes (Holland 2005), so the literature shows variation and some development towards this also. Thus some more recent studies have sought to address knowledge, perceived risk, and other elements of informed decision making that are not evident in earlier studies which sought rather simply to enhance consumers' adherence to screening recommendations. Some data suggest that when there is greater detail of disclosed information in the personalised risk communication with consumers, the uptake of tests is lower than when the risk communication is less detailed or numerically specific.

The weaknesses of these data lie in the small number of studies. Evidently this is still an emerging field and findings or hypotheses that may emerge from these data require further evaluation when more primary studies are available. The results are dominated by findings from the topic area of mammography. Caution is therefore required in generalising from these results in toto, and particularly for clinical topics other than mammography. Against this, the strength of these data lies in the fact that the studies have been gleaned from systematic searches of several key databases and contact with key authors in the field, and represent a synthesis of the existing literature base.

The relative paucity of data in the screening area reflects the difficulties for researchers or clinicians in providing personalised risk communication for consumers. The range of clinical topics covered here is narrow. Calculation or estimation of risk is dependent on adequate epidemiological background data, and feasible means of converting this into information for individual consumers based on their own risk factors. Examples include the Gail model (Gail 1989) and methods for calculating cardiovascular risk (Heart 1999), but only the latter has permeated into routine clinical practice. There is a need for equivalent epidemiological research into an extended range of clinical topics. This could provide a basis for models that allow calculation of personalised risk estimates for individuals about other conditions, such as cervical, prostate or colorectal cancer. Then further evaluation of the effects of providing such personalised risk information to consumers would be possible.

In the meantime, the pattern of the effects across the different categories of personalised risk communication is challenging. It suggests that the greater details offered by the interventions pro- 
viding calculated numerical risk estimates may lead to reduced test uptake. These results can be placed in a context of other findings from the field of risk communication, particularly those that relate to the effects of framing and other manipulations of data presentation (Edwards 2001). Those data suggest that whilst many persuasive effects of information presentation formats are evident, when more data are provided to consumers, and in particular data that are most relevant or pertinent to the decision in question, then consumers become more wary of the treatments or tests on offer. As above, this is not evidence of informed decision making per se, but when the direction of effects is contrary to the apparent trend in service provision then it suggests that the information may be having a significant impact. With reference to the studies included in this review, it may be that the most detailed levels of personalised risk information are more likely to contribute to informed decision making - but this also is associated with lower uptake of screening tests. The greater effects shown in the less specific levels of personalised risk communication may suggest that these effects reflect more the influence of the healthcare encounter - and the conventional leaning towards promoting use of services (ie. tests in this case) (Raffle 2001) - and are not necessarily evidence of informed decision making by consumers.

\section{High risk status an effect modifier}

The effects of interventions on screening uptake appeared greater among consumers or patients deemed to be at higher risk than average. In this group of studies there was no evidence or trend in the data to suggest differences in uptake between the interventions using detailed calculations of risk estimates or more general types of listing risk factors. This suggests that the 'high risk status' of the consumer is an important effect modifier for personalised risk communication. There appears to be potential for substantial modification of choices made among this group of consumers. It may be appropriate that the scope for interventions to influence decisions is large in this group of consumers. But, equally, interventions could be potentially harmful if they are not introduced carefully. Healthcare professionals must take steps to ensure that they are achieving informed decision making by consumers.

\section{Demonstrating informed choices}

There may also be an onus on professionals to demonstrate this informed decision making with evidence. Further research is required into how such informed decision making by consumers can be demonstrated validly. There are some outcome measures in this field such as the multi-dimensional measure of informed choice in Down's syndrome screening (Marteau 2001). This is based on assessing the consistency between knowledge, attitudes to tests and choices of uptake of tests. This measure is specific to Down's screening at present. Further research should explore the development of measures for other screening choices, or whether a generic measure of informed choice for screening decisions is feasible. This would require more general cognitive measures than the condition-specific knowledge items. Other scales currently available offer the scope to derive such a cognitive component for a generic measure (O'Connor 1995; Barry 1997; Edwards 2003a) but at the present time, there is no validated measure of informed choice in cancer screening (Jepson 2005).

\section{Tensions between public health and individual health policy}

Focusing on the achievement and demonstration of informed choices, in isolation, would, nonetheless, fail to address the wider context. This context concerns an apparent tension between public health and individual health policy. Policies of greater patient involvement in decisions are being pursued, and this is justified from both ethical perspectives and some (though perhaps more limited) evidence of improved health outcomes (Guadagnoli 1998). There is a need to evaluate whether such policies mean that those people invited for screening are genuinely making informed choices, and how comprehensive information affects other variables such as uptake, cost effectiveness, and satisfaction (Jepson 2005). Appropriate risk communication has an integral role in this (Elwyn 2000). But as this is followed through, it is likely that public health objectives might be compromised. An example may be seen in the case of cervical (Papanicolaou smear) screening. The absolute benefits of Papanicolaou screening may be small for most women. Most women are at very low risk of developing cervical cancer, but they may perceive their risk to be higher as a result of the level of screening activity, publicity and public health messages about the importance of screening for the population. Some women may choose not to have regular screening when informed of the absolute levels of risk and benefit from the screening programme. But the public health message, aided sometimes by financial incentives for clinicians to achieve high uptake figures, means that informed decision making by patients is still a major challenge (Thomson 2005).

The same tension exists in relation to cardiovascular screening (Marteau 2002). These tensions between public health goals and individual choices must be recognised (Rogers 2002). An informed debate should be conducted among the relevant interest groups - government, public health, clinicians, and particularly patients and patient representative groups. There are some signs that this debate is now taking place (Marteau 2002). Policy developments could explore whether individually appropriate choices, which vary from those recommended by standards and guidelines, can be accommodated in assessments of achieving best practice (ie. meeting standards) at population level. One solution may be for care to be viewed as 'adherent to guidelines' or 'satisfactory' if adequate steps have been made to achieve and demonstrate informed decision making by patients - even if it deviates from the conventional (bio-medical) recommendations of those guidelines. Taking the example of cervical cancer screening, a full discussion 
of the pros and cons of screening for cervical cancer may be viewed as a satisfactory goal for the healthcare provider, even if an individual woman chooses not to undergo screening, thus against public health advice. Counting such scenarios as satisfactory or adherent to guidelines (for example for purposes of audit) may allow healthcare professionals to enhance their communication with patients. If this is incorporated into the goals of health care then improvements in care can be achieved without also falling foul of requirements for governance, audit, and payment targets. An example was evident in the criteria for Fellowship by Assessment (FBA) of the Royal College of General Practitioners (UK). In the case of vaccination targets, the criteria stated that'candidates who are unable to demonstrate these standards must exceed the average level of vaccination and show how patients/parents/carers are enabled to make an informed choice about vaccination'. The FBA scheme has now been halted for wider revision (2006), but the issue of informed decision making in preventive activities could equally apply to screening choices. The need for measures to demonstrate informed choice across a number of healthcare decisions is further reiterated.

\section{Broader research in this field}

It is not only 'informed choice' that is yet to be fully addressed in this field. The data available are conspicuously loaded towards assessment of screening uptake. Few studies have addressed and have extractable data on other outcomes. These include the cognitive measures, such as knowledge and risk perception, which have been addressed more commonly in risk communication literature to date (Edwards 1999) and in studies of informed decision making in cancer screening (Briss 2004). They also include the affective measures that are increasingly advocated as a focus of research (Llewelyn-Thomas 1995). These are the measures that are likely to be more specific and perhaps more responsive to change (Edwards 1999), but in particular come closest to addressing the core constructs that build towards informed decision making by consumers. Such measures include decisional conflict (O'Connor 1995), satisfaction with decision making (Holmes-Rovner 1996), anxiety measures (Marteau 1992), and making decisions that are consistent with individuals' values and preferences. The use of such outcome measures is sparse in the currently available literature on personalised risk communication interventions and screening studies more generally (Briss 2004). It is important that further intervention studies in this field incorporate such measures into their evaluations (Irwig 2006).

When such evaluations are available it would enable a clearer picture about the effects of personalised risk communication interventions to be drawn. A more rounded interpretation would be possible, compared to the present in which data are only really interpretable in relation to screening uptake. This should shed light on how personalised risk information, which is often advocated for or by consumers, is influencing decision making about screen- ing choices in health care.

\section{A U THORS' CONCLUSIONS}

\section{Implications for practice}

There is weak evidence that personalised risk communication leads to small increases in uptake of screening programmes. Even in studies where increased uptake was demonstrated, and thus which may meet professionally or policy driven agendas in health care, it is not yet clear that the increased uptake is associated with informed decision making by consumers. Until such evidence of informed decision making is available it seems to be difficult to support such interventions (as currently implemented). The tension between the public health policy and individual health policy agendas should be recognised and debated by the relevant stakeholders (consumers, professionals, policy makers and purchasers). This debate should explore how to accommodate the tensions of addressing both policy agendas, which may each be justifiable but may have contrary effects on health care and health.

\section{Implications for research}

Research has been narrowly focused on assessing changes in screening test uptake after certain risk communication interventions. The research needs to be broader, more consistently assessing affective measures such as decisional conflict, satisfaction with decision or anxiety. There would also be value in developing a generic measure of informed decision making for screening choices by consumers. Using such a measure widely would also be important in assessing the true effect of personalised risk communication on people's use of screening tests.

\section{ACKNOWLEDGEMENTS}

The review authors thank the many people who commented on the project protocol and Cochrane protocol and review at various stages, helping to make it feasible. In particular this includes the 1998 consumer advisory group established for this review by the Cochrane Consumers and Communication Review Group (comprising Hilda Bastian and Genny Nolan (Australia), Teenah Handiside (New Zealand), and Christine Brunswick (USA)); Professors Theresa Marteau (University of London) and Alex Barratt (University of Sydney) for discussions about screening programmes; Silvana Unigwe (medical student) for work on the previous version of the review; the Contact Editor Dominique Broclain, the editors of the Cochrane Consumers and Communication Review Group, Review Group Coordinator Megan Prictor, Coordinating Editor Sophie Hill, former Trials Search Coordinator Judy Stoelwinder, and external peer reviewers. We gratefully acknowledge 
the financial support from the Cochrane Health Promotion and Public Health Field which enabled completion of the first published version of this review in 2003 (Edwards 2003c) and the UK Department of Health for its support (via the Review Group) to speed up completion of the updated review in 2006.

\section{R E F E R E N C E S}

\section{References to studies included in this review}

\section{Bastani 1999 \{published data only\}}

Bastani R, Maxwell AE, Bradford C, Das IP, Yan KX.

Tailored risk notification for women with a family history of breast cancer. Preventive Medicine 1999;29(5):355-64.

Bowen 2002 \{published data only\}

Bowen D, Burke W, Yasui Y, McTiernan A, McLeran D. Effects of risk counseling on interest in breast cancer genetic testing for lower risk women. Genetics in Medicine 2002;4 (5):359-65.

Campbell 1997 \{published data only\}

Campbell E, Peterkin D, Abbott R, Rogers J. Encouraging underscreened women to have cervical cancer screening: the effectiveness of a computer strategy. Preventive Medicine 1997;26(6):801-7.

\section{Champion 1994 \{published data only\}}

Champion V. Strategies to increase mammography utilization. Medical Care 1994;32(2):118-29.

\section{Champion 1995 \{published data only\}} Champion V, Huster G. Effect of interventions on stage of mammography adoption. Journal of Behavioral Medicine 1995;18(2):169-87.

\section{Champion 2000a \{published data only\}} Champion VL, Ray DW, Heilman DK, Springston J. A tailored intervention for mammography among low-income African-American women. Journal of Psychosocial Oncology 2000;18(4):1-13.

Champion 2002 \{published data only (unpublished sought but not used)\}

Champion V, Skinner C, Menon U, Seshadri R, Anzalone D, Rawl S. Comparisons of tailored mammography interventions at two months postintervention. Annals of Behavioral Medicine 2002;24(3):211-8.

\section{Champion 2003 \{published data only\}}

Champion V, Maraj M, Hui S, Perkins AJ, Tierney W, Menon U, Skinner CS. Comparison of tailored interventions to increase mammography screening in nonadherent older women. Preventive Medicine 2003;36 (2): $150-8$.

Curry 1993 \{published data only\}

Curry SJ, Taplin SH, Anderman C, Barlow WE, McBride C. A randomized trial of the impact of risk assessment and feedback on participation in mammography screening. Preventive Medicine 1993;22(3):350-60.
Hutchison 1998 \{published data only\}

Hutchison B, Birch S, Evans C, Goldsmith L, Markham B, Frank J, Paterson M. Screening for hypercholesterolaemia in primary care: randomised controlled trial of postal questionnaire appraising risk of coronary heart disease. $B M J$ 1998;316(7139):1208-13.

Jibaja-Weiss 2003 \{published data only\}

* Jibaja-Weiss M, Volk R, Kingery P, Smith Q, Holcomb J. Tailored messages for breast and cervical cancer screening of low-income and minority women using medical records data. Patient Education \& Counseling 2003;50(2):123-32. Jibaja-Weiss M, Volk R, Smith Q, Holcomb J, Kingery P. Differential effects of messages for breast and cervical cancer screening. Journal of Health Care for the Poor and Underserved 2005;16(1):42-52.

\section{Kreuter 1996 \{published data only\}}

Kreuter MW, Strecher VJ. Do tailored behaviour change messages enhance the effectiveness of health risk appraisal? Results from a randomized trial. Health Education Research 1996;11(1):97-105.

\section{Lee 1991 \{published data only\}}

Lee CY. A randomized controlled trial to motivate worksite fecal occult blood testing. Yonsei Medical Journal 1991;32 (2):131-8.

\section{Lerman 1995 \{published data only\}}

* Lerman C, Lustbader E, Rimer B, Daly M, Miller S, Sands C, Balshem A. Effects of individualized breast cancer risk counseling: a randomised trial. Journal of the National Cancer Institute 1995;87(4):286-92.

Lerman C, Schwartz MD, Miller SM, Daly M, Sands C, Rimer BK. A randomized trial of breast cancer risk counseling: interacting effects of counseling, educational level, and coping style. Health Psychology 1996;15(2): $75-83$.

Lerman 1997 \{published data only\}

Lerman C, Biesecker B, Bekendorf JL, Kerner J, GomezCaminero A, Hughes C, Reed MM. Controlled trial of pretest education approaches to enhance informed decisionmaking for BRCA1 gene testing. Journal of the National Cancer Institute 1997;89(2):148-57.

Lipkus 2005 \{published data only\}

* Lipkus I, Skinner C, Dement J, Pompeii L, Moser B, Samsa G, Ransohoff D. Increasing colorectal cancer screening among individuals in the carpentry trade: test 
of risk communication interventions. Preventive Medicine 2005;40(5):489-501.

Lipkus I, Skinner C, Green L, Dement J, Samsa G, Ransohoff D. Modifying attributions of colorectal cancer risk. Cancer Epidemiology Biomarkers and Prevention 2004; 13(4):560-6

Myers 1999 \{published data only\}

Myers R, Chodak G, Wolf T, Burgh D, McGrory G, Marcus $\mathrm{S}$, et al.Adherence by African American men to prostate cancer education and early detection. Cancer 1999;86(1): 88-104.

Rimer 2002 \{published data only\}

* Rimer B, Halabi S, Skinner C, Lipkus I, Strigo T, Kaplan E, Samsa G. Effects of a mammography decision-making intervention at 12 and 24 months. American Journal of Preventive Medicine 2002;22(4):247-57.

Rimer B, Halabi S, Sugg Skinner C, Kaplan E, Crawford Y, Samsa G, et al.The short-term impact of tailored mammography decision-making interventions. Patient Education \& Counseling 2001;43(3):269-85.

Saywell 1999 \{published data only\}

Saywell RM Jr, Champion VL, Skinner CS, McQuillen D, Martin D, Maraj M. Cost-effectiveness comparison of five interventions to increase mammography screening. Preventive Medicine 1999;29(5):374-82.

Schwartz 1999 \{published data only\} Schwartz M, Rimer B, Daly M, Sands C, Lerman C. A randomized trial of breast cancer risk counseling: the impact on self-reported mammography use. American Journal of Public Health 1999;89(6):924-6.

Skinner 1994 \{published data only (unpublished sought but not used)\} Skinner CS, Strecher VJ, Hospers H. Physicians' recommendations for mammography: do tailored messages make a difference?. American Journal of Public Health 1994; 84(1):43-9.

Skinner 2002 \{published data only\} Skinner C, Schildkraut J, Berry D, Calingaert B, Marcom P, Sugarman J, et al.Pre-counseling education materials for BRCA testing: does tailoring make a difference?. Genetic Testing 2002;6(2):93-105.

\section{References to studies excluded from this review}

Alexander 1996 \{published data only\} Alexander NE, Ross J, Sumner W, Nease RF Jr, Littenberg $B$. The effect of an educational intervention on the perceived risk of breast cancer. Journal of General Internal Medicine 1996;11(2):92-7.

Champion 2000b \{published data only\} Champion V, Skinner C, Foster J. The effects of standard care counseling or telephone/in-person counseling on beliefs, knowledge, and behavior related to mammography screening. Oncology Nursing Forum 2000;27(10):1565-71.

Dignan 1996 \{published data only\}

Dignan M, Michielutte R, Blinson K, Wells HB, Case LD, Sharp $\mathrm{P}$, et al.Effectiveness of health education to increase screening for cervical cancer among eastern band Cherokee Indian women in North Carolina. Journal of the National Cancer Institute 1996;88(22):1670-6.

Engelstad 2005 \{published data only\}

Engelstad L, Stewart S, Otero-Sabogal R, Leung M, Davis P, Pasick R. The effectiveness of a community outreach intervention to improve follow-up among underserved women at highest risk for cervical cancer. Preventive Medicine 2005;41(3):741-8.

Gagnon 1996 \{published data only\}

Gagnon P, Massie MJ, Gronert M, Heerdt AS, Brown K, et al.Perception of breast cancer risk and psychological distress in women attending a surveillance program. Psycho-oncology 1996;5:259-69.

Giles 2001 \{published data only\}

Giles JT, Kennedy DT, Dunn EC, Wallace WL, Meadows SL, Cafiero AC. Results of a community pharmacy-based breast cancer risk-assessment and education program. Pharmacotherapy 2001;21(2):243-53.

Kadison 1998 \{published data only\} Kadison P, Pelletier EM, Mounib EL, Oppedisano P, Harry T. Improved screening for breast cancer associated with a telephone-based risk assessment. Preventive Medicine 1998; 27(3):493-501.

Kreuter 2005 \{published data only\} Kreuter M, Sugg-Skinner C, Holt C, Clark E, Haire-Joshu $\mathrm{D}, \mathrm{Fu} \mathrm{Q}$, et al.Cultural tailoring for mammography and fruit and vegetable intake among low-income AfricanAmerican women in urban public health centers. Preventive Medicine 2005;41(1):53-62.

Leigh 1991 \{published data only\}

Leigh J, Harrison J. Reduction of ischaemic heart disease risk factors following direct probabilistic risk communication in the workplace. Journal of Occupational Health \& Safety 1991;7:467-72.

Lipkus 2000 \{published data only\}

Lipkus IM, Rimer BK, Halabi S, Strigo TS. Can tailored interventions increase mammography use among HMO women?. American Journal of Preventive Medicine 2000;18 (1):1-10.

Miller 2005 \{published data only\}

Miller S, Fleisher L, Roussi P, Buzaglo J, Schnoll R, Slater $\mathrm{E}$, et al.Facilitating informed decision making about breast cancer risk and genetic counseling among women calling the NCI's Cancer Information Service. Journal of Health Communication 2005;10(Suppl 1):119-36.

Pye 1988 \{published data only\}

Pye G, Christie M, Chamberlain JO, Moss SM, Hardcastle JD. A comparison of methods for increasing compliance within a general practitioner based screening project for colorectal cancer and the effect on practitioner workload. Journal of Epidemiology \& Community Health 1988;42(1): 66-71.

Rakowski 1998 \{published data only\} Rakowski W, Ehrich B, Goldstein MG, Rimer BK, Pearlman DN, Clark MA, et al.Increasing mammography among 
women aged $40-74$ by use of a stage-matched, tailored intervention. Preventive Medicine 1998;27(5 pt 1):748-56.

Rhodes 2001 \{published data only\}

Rhodes K, Lauderdale D, Stocking C, Howes D, Roizen M, Levinson W. Better health while you wait: a controlled trial of a computer-based intervention for screening and health promotion in the emergency department. Annals of Emergency Medicine 2001;37(3):284-91.

Rimer 1999 \{published data only\}

Rimer BK, Conaway M, Lyna P, Glassman B, Yarnall KSH, Lipkus I, Barber T. The impact of tailored interventions on a community health center population. Patient Education \& Counseling 1999;37(2):125-40.

Weber 1997 \{published data only\}

Weber B, Reilly B. Enhancing mammography use in the inner city: a randomized trial of intensive case management. Archives of Internal Medicine 1997;157:2345-9.

\section{Additional references}

\section{Barry 1997}

Barry MJ, Cherkin D, Chang Y, Fowler C, Skates S. A randomized trial of a multimedia shared decision-making program for men facing a treatment decision for benign prostatic hyperplasia. Disease Management and Clinical Outcomes 1997;1:5-14.

\section{Bottorff 1996}

Bottorff JD, Ratner PA, Johnson JL, Lovato CY, Joab SA. Uncertainties and challenges: communicating risk in the context of familial cancer. Report to the National Cancer Institute of Canada. Vancouver: School of Nursing and Institute of Health Promotion Research, University of British Columbia, 1996.

\section{Briss 2004}

Briss P, Rimer B, Reilley B, Coates R, Lee N, Mullen P, et al.Promoting informed decisions about cancer screening in communities and healthcare systems. American Journal of Preventive Medicine 2004;26(1):67-80.

Covello 1986

Covello VT, von Winterfeldt D, Slovic P. Risk communication: a review of the literature. Risk Abstracts 1986;3(4):171-81.

\section{Edwards 1999}

Edwards AGK, Elwyn GJ. How should 'effectiveness' of risk communication to aid patients' decisions be judged? A review of the literature. Medical Decision Making 1999;19 (4):428-34.

Edwards 2000a

Edwards A, Hood K, Matthews E, Barker J, Bloor M, Burnard P, et al.The effectiveness of one-to-one risk communication interventions in health care: a systematic review. Medical Decision Making 2000;20(3):290-7.

\section{Edwards 2000b}

Edwards AGK, Elwyn GJ, Hood K, Rollnick S. Judging the 'weight of evidence' in systematic reviews: introducing rigour into the qualitative overview stage by assessing signal and noise. Journal of Evaluation in Clinical Practice 2000;6 (2):177-84.

\section{Edwards 2001}

Edwards A, Elwyn G, Covey J, Mathews E, Pill R. Presenting risk information - a review of the effects of 'framing' and other manipulations on patient outcomes. Journal of Health Communication 2001;6(1):61-82.

\section{Edwards 2003a}

Edwards A, Elwyn G, Hood K, Robling M, Atwell C, Holmes-Rovner M, et al.The development of COMRADE - a patient-based outcome measure to evaluate the effectiveness of risk communication and treatment decision making in consultations. Patient Education \& Counseling 2003;50(3):311-22.

\section{Elwyn 2000}

Elwyn G, Edwards A, Kinnersley P, Grol R. Shared decision-making and the concept of equipoise: defining the 'competences' of involving patients in health care choices. British Journal of General Practice 2000;50(460):892-9.

\section{Fischhoff 1979}

Fischhoff B, Slovic P, Lichtenstein S. Which risks are acceptable?. Environment 1979;21:17-38.

\section{Foster 1998}

Foster P, Anderson CM. Reaching targets in the national cervical screening programme: are current practices unethical?. Journal of Medical Ethics 1998;24(3):151-7.

\section{Gail 1989}

Gail MH, Brinton LA, Byar DP, Corle DK, Green SB, Schairer C, et al.Projecting individualized probabilities of developing breast cancer for white females who are being examined annually. Journal of the National Cancer Institute 1989;81(24):1879-86.

Guadagnoli 1998 Guadagnoli E, Ward P. Patient participation in decisionmaking. Social Science \& Medicine 1998;47(3):329-39.

Heart 1999

British Cardiac Society, British Hyperlipidaemia Association, British Hypertension Society. Joint British recommendations on prevention of coronary heart disease in clinical practice. Heart 1999;80 (Supplement 2):S1-S29.

\section{Holland 2005}

Holland W, Stewart S. Key issues in screening: genetics, information and economics. In: Holland W, Stewart $S$ editor(s). Screening in disease prevention: what works? First Edition. Oxford: Radcliffe, 2005:17-32.

Holmes-Rovner 1996 Holmes-Rovner M, Kroll J, Schmitt N, Rovner DR, Breer ML, Rothert ML, et al.Patient satisfaction with health care decisions: the satisfaction with decision scale. Medical Decision Making 1996;16(1):58-64.

Irwig 2006

Irwig L, McCaffery K, Salkeld G, Bossuyt P. Screening and choice: informed choice for screening: implications for evaluation. BMJ 2006;332:1148-1150. 
Jadad 1996

Jadad A, Moore M, Carrol D, Jenkinson C, Reynolds DJM, Gavaghan DJ, et al.Assessing the quality of reports of randomised clinical trials; is blinding necessary?. Controlled Clinical Trials 1996;17(1):1-12.

Jepson 2000

Jepson R, Clegg A, Forbes C, Lewis R, Sowden A, Kleijnen J. The determinants of screening uptake and interventions for increasing uptake: a systematic review. Health Technology Assessment Programme, UK National Health Service 2000; Vol. 4, issue 14.

Jepson 2005

Jepson R, Hewison J, Thompson A, Weller D. How should we measure informed choice? The case of cancer screening. Journal of Medical Ethics 2005;31:192-6.

\section{Keeney 1986}

Keeney RL, von Winterfeldt D. Improving risk communication. Risk Analysis 1986;6(4):417-24

Liao 1996

Liao L, Jollis JG, DeLong ER, Peterson ED, Morris KG, Mark DB. Impact of an interactive video on decision making of patients with ischemic heart disease. Journal of General Internal Medicine 1996;11(6):373-6.

Llewelyn-Thomas 1995

Llewellyn-Thomas HA. Patients' health care decisionmaking: a framework for descriptive and experimental investigations. Medical Decision Making 1995;15:101-6.

Marteau 1992

Marteau TM, Bekker H. The development of a six-item short form of the state scale of the Spielberger state-trait anxiety inventory. British Journal of Clinical Psychology 1992;31(Pt 3):301-6.

\section{Marteau 2001}

Marteau TM, Dormandy E, Michie S. A multi-dimensional measure of informed choice. Health Expectations 2001;4: 99-108.

\section{Marteau 2002}

Marteau TM, Kinmonth AL. Screening for cardiovascular risk: public health imperative or matter for individual informed choice?. BMJ 2002;325(7355):78-80.

Matthews 1999

Matthews E, Edwards A, Barker J, Bloor M, Covey J, Hood $\mathrm{K}$, et al.Efficient literature searching in diffuse topics: lessons from a systematic review of research on communicating risk to patients in primary care. Health Libraries Review 1999;16(2):112-20.

\section{O'Connor 1995}

O'Connor AM. Validation of a decisional conflict scale. Medical Decision Making 1995;15(1):25-30.

\section{O'Connor 2003}

O'Connor AM, Stacey D, Entwistle V, Llewellyn-Thomas $\mathrm{H}$, Rovner D, Holmes-Rovner M, et al.Decision aids for people facing health treatment or screening decisions. Cochrane Database of Systematic Reviews 2003, Issue 1. [DOI: 10.1002/14651858.CD001431]

\section{Oncology 1994}

Oncology (Anonymous). Genetic testing for cancer risk: research projects being funded. Oncology 1994;8(12):16-8.

\section{Prochaska 1992}

Prochaska JO, DiClemente CC. Stages of change in the modification of problem behaviors. Progress in Behavior Modification 1992;28:183-218.

Raffle 2001

Raffle A. Information about screening - is it to achieve high uptake or to ensure informed choice?. Health Expectations 2001;4:92-8.

\section{Rogers 2002}

Rogers W. Are guidelines ethical? Some considerations for general practice. British Journal of General Practice 2002;52 (481):663-8.

Rose 1978

Rose G, Barker DJ. Epidemiology for the uninitiated: screening. British Medical Journal 1978;2(6149):1417-8.

Sarfati 1998

Sarfati D, Howden-Chapman P, Woodward, Salmond C. Does the frame affect the picture? A study into how attitudes to screening for cancer are affected by the way benefits are expressed. Journal of Medical Screening 1998;5: $137-40$.

\section{Slaytor 1998}

Slaytor E, Ward JE. How risks of breast cancer and benefits of screening are communicated to women: analysis of 58 pamphlets. BMJ 1998;317:263-4.

\section{Stewart-Brown 1997}

Stewart-Brown S, Farmer A. Screening could seriously damage your health [Editorial]. BMJ 1997;314:533.

Thomson 2005

Thomson R, Murtagh M, Khaw F. Tensions in public health policy: patient engagement, evidence-based public health and health inequalities. Quality \& Safety in Health Care 2005;14(6):398-400.

Vlek 1987

Vlek C. Risk assessment, risk perception and decision making about courses of action involving genetic risk: an overview of concepts and methods. Birth Defects: Original Article Series 1987;23(2):171-207.

\section{Wilson 1968}

Wilson JMG, Jungner G. Principles and Practice of Screening for Disease (Public Health Paper Number 34). Geneva: WHO, 1968.

\section{References to other published versions of this review}

\section{Edwards 2003b}

Edwards A, Unigwe S, Elwyn G, Hood K. Effects of communicating individual risks in screening programmes: Cochrane systematic review. BMJ 2003;327(7417):703-9.

Edwards 2003c

Edwards A, Unigwe S, Elwyn G, Hood K. Personalised risk communication for informed decision making 
about entering screening programs. Cochrane Database

of Systematic Reviews 2003, Issue 1. [DOI: 10.1002/

14651858.CD001865]

* Indicates the major publication for the study 


\section{CHARACTERISTICS OF STUDIES}

\section{Characteristics of included studies [ordered by study ID]}

\section{Bastani 1999}

\begin{tabular}{|c|c|c|}
\hline Methods & \multicolumn{2}{|l|}{ RCT } \\
\hline Participants & \multicolumn{2}{|c|}{ Women over 30; breast cancer in first degree relative; resident in USA or Canada } \\
\hline Interventions & \multicolumn{2}{|c|}{$\begin{array}{l}\text { Mailed personalised risk assessment notification and other theoretically driven } \\
\text { (Adherence Model) materials tailored for high risk women. }\end{array}$} \\
\hline Outcomes & \multicolumn{2}{|c|}{ Uptake of mammography one year after baseline survey. } \\
\hline \multicolumn{3}{|l|}{ Notes } \\
\hline \multicolumn{3}{|l|}{ Risk of bias } \\
\hline Bias & Authors' judgement & Support for judgement \\
\hline Allocation concealment (selection bias) & Unclear risk & B - Unclear \\
\hline
\end{tabular}

Bowen 2002

\begin{tabular}{|c|c|c|}
\hline Methods & \multicolumn{2}{|l|}{ RCT } \\
\hline Participants & \multicolumn{2}{|c|}{ Women with first degree relative with breast cancer; Seattle, USA } \\
\hline Interventions & \multicolumn{2}{|c|}{ Individual or group-based genetic counselling, including Gail and Claus scores } \\
\hline Outcomes & \multicolumn{2}{|c|}{ Interest in having BRCA tests; perception of self as appropriate candidate for tests } \\
\hline \multicolumn{3}{|l|}{ Notes } \\
\hline \multicolumn{3}{|l|}{ Risk of bias } \\
\hline Bias & Authors' judgement & Support for judgement \\
\hline Allocation concealment (selection bias) & Unclear risk & B - Unclear \\
\hline
\end{tabular}

Campbell 1997

\begin{tabular}{ll}
\hline Methods & RCT \\
\hline Participants & $\begin{array}{l}\text { Women who had not had a cervical (Pap) smear in previous } 30 \text { months; New South Wales, } \\
\text { Australia }\end{array}$
\end{tabular}


Campbell 1997 (Continued)

\begin{tabular}{|c|c|c|}
\hline Interventions & \multicolumn{2}{|c|}{$\begin{array}{l}\text { Computer generated printed feedback, listing 'risk factor' of not having a smear within past } \\
2 \text { years }\end{array}$} \\
\hline Outcomes & \multicolumn{2}{|c|}{ Uptake of cervical (Pap) smear. } \\
\hline \multicolumn{3}{|l|}{ Notes } \\
\hline \multicolumn{3}{|l|}{ Risk of bias } \\
\hline Bias & Authors' judgement & Support for judgement \\
\hline Allocation concealment (selection bias) & Unclear risk & B - Unclear \\
\hline
\end{tabular}

\section{Champion 1994}

\begin{tabular}{|c|c|c|}
\hline Methods & \multicolumn{2}{|l|}{ RCT } \\
\hline Participants & \multicolumn{2}{|c|}{ Women aged $>=35$; never having had breast cancer. USA. } \\
\hline Interventions & \multicolumn{2}{|c|}{$\begin{array}{l}\text { In-home interviews conducted by graduate nursing research assistants. Discussion about } \\
\text { individual risk factors - susceptibility intervention- as part of a belief modifying intervention }\end{array}$} \\
\hline Outcomes & \multicolumn{2}{|c|}{$\begin{array}{l}\text { Change in beliefs and knowledge (including susceptibility scores) post-intervention; mam- } \\
\text { mography compliance } 1 \text { year post-intervention }\end{array}$} \\
\hline \multicolumn{3}{|l|}{ Notes } \\
\hline \multicolumn{3}{|l|}{ Risk of bias } \\
\hline Bias & Authors' judgement & Support for judgement \\
\hline Allocation concealment (selection bias) & Unclear risk & B - Unclear \\
\hline
\end{tabular}

\section{Champion 1995}

\begin{tabular}{ll}
\hline Methods & RCT \\
\hline Participants & $\begin{array}{l}\text { Women aged }>=35 \text {; not diagnosed with breast cancer. } \\
\text { USA. (Analysis of intervention effect only on those } 40 \text { years and over) }\end{array}$ \\
\hline Interventions & $\begin{array}{l}\text { In-home interviews conducted by graduate nursing students.Discussion about individual } \\
\text { risk factors - susceptibility intervention - as part of a belief modifying intervention }\end{array}$ \\
\hline Outcomes & $\begin{array}{l}\text { Change in beliefs and knowledge (including susceptibility (scores); mammography com- } \\
\text { pliance; movement across stages of change }\end{array}$
\end{tabular}




\section{Risk of bias}

\begin{tabular}{lll}
\hline Bias & Authors' judgement & Support for judgement \\
\hline Allocation concealment (selection bias) & Unclear risk & B - Unclear \\
\hline
\end{tabular}

\section{Champion 2000a}

\begin{tabular}{|c|c|c|}
\hline Methods & \multicolumn{2}{|l|}{ RCT } \\
\hline Participants & \multicolumn{2}{|c|}{ Low-income African American women aged 45-64; Indiana, USA. } \\
\hline Interventions & \multicolumn{2}{|c|}{$\begin{array}{l}\text { In-person tailored interventions based on Health Belief and Transtheoretical Models, in- } \\
\text { cluding listing of susceptibility factors }\end{array}$} \\
\hline Outcomes & \multicolumn{2}{|c|}{ Screening mammography uptake at 12 months. } \\
\hline \multicolumn{3}{|l|}{ Notes } \\
\hline \multicolumn{3}{|l|}{ Risk of bias } \\
\hline Bias & Authors' judgement & Support for judgement \\
\hline Allocation concealment (selection bias) & Unclear risk & B - Unclear \\
\hline
\end{tabular}

\section{Champion 2002}

\begin{tabular}{|c|c|c|}
\hline Methods & \multicolumn{2}{|l|}{ RCT } \\
\hline Participants & \multicolumn{2}{|c|}{$\begin{array}{l}\text { Women aged over } 50 \text { not adherent to mammography recommendations; medical clinic at } \\
\text { St Louis and HMO in Indianapolis, USA }\end{array}$} \\
\hline Interventions & \multicolumn{2}{|c|}{$\begin{array}{l}\text { Tailored interventions based on Health Belief and Transtheoretical Models, including per- } \\
\text { ceived risk and risk factors (eg. age, family history) }\end{array}$} \\
\hline Outcomes & \multicolumn{2}{|c|}{ Self-reported mammography uptake at 2 months. } \\
\hline \multicolumn{3}{|l|}{ Notes } \\
\hline \multicolumn{3}{|l|}{ Risk of bias } \\
\hline Bias & Authors' judgement & Support for judgement \\
\hline Allocation concealment (selection bias) & Unclear risk & B - Unclear \\
\hline
\end{tabular}


Champion 2003

\begin{tabular}{|c|c|c|}
\hline Methods & \multicolumn{2}{|l|}{ RCT } \\
\hline Participants & \multicolumn{2}{|c|}{$\begin{array}{l}\text { Women in the } 51-84 \text { years age range who have not received a mammogram in the last } 15 \\
\text { months; from an HMO and general medicine clinic, USA }\end{array}$} \\
\hline Interventions & \multicolumn{2}{|c|}{$\begin{array}{l}\text { Tailored interventions based on Health Belief and Transtheoretical Models, including listing } \\
\text { of susceptibility factors }\end{array}$} \\
\hline Outcomes & \multicolumn{2}{|c|}{ Screening mammography uptake at 6 months. } \\
\hline \multicolumn{3}{|l|}{ Notes } \\
\hline \multicolumn{3}{|l|}{ Risk of bias } \\
\hline Bias & Authors' judgement & Support for judgement \\
\hline Allocation concealment (selection bias) & Low risk & A - Adequate \\
\hline
\end{tabular}

Curry 1993

\begin{tabular}{ll}
\hline Methods & RCT \\
\hline Participants & $\begin{array}{l}\text { Women aged }>=50 \text {; newly enrolled in an HMO, without prior history of breast cancer or } \\
\text { of mammography use in the previous } 12 \text { months. USA, }\end{array}$ \\
\hline Interventions & Mailed risk factor questionnaire plus personal risk invitation detailing personal risk factors \\
\hline Outcomes & Mammography use within 1 year of invitation. \\
\hline Notes & \\
\hline
\end{tabular}

\section{Risk of bias}

\begin{tabular}{lll}
\hline Bias & Authors' judgement & Support for judgement \\
\hline Allocation concealment (selection bias) & Unclear risk & B - Unclear \\
\hline
\end{tabular}

Hutchison 1998

\begin{tabular}{ll}
\hline Methods & RCT \\
\hline Participants & Patients aged 20-69 years, from 2 Canadian primary care group practices \\
\hline Interventions & $\begin{array}{l}\text { Risk appraisal questionnaire (yielding risk score). Those with scores above 2 advised to go } \\
\text { for screening }\end{array}$ \\
\hline Outcomes & Rate of cholesterol testing during the three months of follow up
\end{tabular}


Hutchison 1998 (Continued)

\section{Notes}

\section{Risk of bias}

\begin{tabular}{lll}
\hline Bias & Authors' judgement & Support for judgement \\
\hline Allocation concealment (selection bias) & Unclear risk & B - Unclear \\
\hline
\end{tabular}

\section{Jibaja-Weiss 2003}

\begin{tabular}{|c|c|c|}
\hline Methods & \multicolumn{2}{|l|}{ RCT } \\
\hline Participants & \multicolumn{2}{|c|}{ Women registered at 2 urban community health centres; Houston, USA } \\
\hline Interventions & \multicolumn{2}{|c|}{ Personalised letter, tailored for risk factor data and giving screening recommendations } \\
\hline Outcomes & \multicolumn{2}{|c|}{ Scheduling and uptake of cervical (Pap) smear test and mammogram } \\
\hline \multicolumn{3}{|l|}{ Notes } \\
\hline \multicolumn{3}{|l|}{ Risk of bias } \\
\hline Bias & Authors' judgement & Support for judgement \\
\hline Allocation concealment (selection bias) & Low risk & A - Adequate \\
\hline
\end{tabular}

\section{Kreuter 1996}

\begin{tabular}{|c|c|c|}
\hline Methods & \multicolumn{2}{|l|}{ RCT } \\
\hline Participants & \multicolumn{2}{|c|}{ Patients aged $18-75$ from 8 family medical practices, N. Carolina, USA } \\
\hline Interventions & \multicolumn{2}{|c|}{$\begin{array}{l}\text { Mailed HRA (Health Risk Appraisal) - risk information tailored to information given at } \\
\text { baseline questionnaire }\end{array}$} \\
\hline Outcomes & \multicolumn{2}{|c|}{$\begin{array}{l}\text { Rate of pap smear, mammography and cholesterol uptake after } 6 \text { months in those contem- } \\
\text { plating these behaviours at baseline }\end{array}$} \\
\hline \multicolumn{3}{|l|}{ Notes } \\
\hline \multicolumn{3}{|l|}{ Risk of bias } \\
\hline Bias & Authors' judgement & Support for judgement \\
\hline Allocation concealment (selection bias) & High risk & $\mathrm{C}$ - Inadequate \\
\hline
\end{tabular}


Lee 1991

\begin{tabular}{|c|c|c|}
\hline Methods & \multicolumn{2}{|c|}{ RCT, stratified for previous screening history and risk status } \\
\hline Participants & \multicolumn{2}{|c|}{ Federal employees aged $>=40$ years. USA. } \\
\hline Interventions & \multicolumn{2}{|c|}{ Colorectal cancer risk appraisal - categorised as high medium or low personal risk } \\
\hline Outcomes & \multicolumn{2}{|c|}{ Knowledge, intention to take test, and uptake. } \\
\hline \multicolumn{3}{|l|}{ Notes } \\
\hline \multicolumn{3}{|l|}{ Risk of bias } \\
\hline Bias & Authors' judgement & Support for judgement \\
\hline Allocation concealment (selection bias) & Unclear risk & B - Unclear \\
\hline
\end{tabular}

Lerman 1995

\begin{tabular}{|c|c|c|}
\hline Methods & \multicolumn{2}{|l|}{ RCT } \\
\hline Participants & \multicolumn{2}{|c|}{$\begin{array}{l}\text { Women aged } 35 \text { years and older with a family history of breast cancer in a first degree } \\
\text { relative. USA }\end{array}$} \\
\hline Interventions & \multicolumn{2}{|c|}{$\begin{array}{l}\text { Breast cancer risk counselling including discussion of factors contributing to elevated risk } \\
\text { and presentation of individualized risk data }\end{array}$} \\
\hline Outcomes & \multicolumn{2}{|c|}{ Changes/improvement in risk comprehension. } \\
\hline Notes & \multicolumn{2}{|c|}{$\begin{array}{l}\text { Additional paper (Lerman et al, 1996) addresses effects on general and breast cancer-specific } \\
\text { distress }\end{array}$} \\
\hline \multicolumn{3}{|l|}{ Risk of bias } \\
\hline Bias & Authors' judgement & Support for judgement \\
\hline Allocation concealment (selection bias) & Unclear risk & B - Unclear \\
\hline
\end{tabular}

Lerman 1997

\begin{tabular}{ll}
\hline Methods & RCT \\
\hline Participants & $\begin{array}{l}\text { Women aged 18-75 who had at least one first degree relative with breast and/or ovarian } \\
\text { cancer. USA }\end{array}$ \\
\hline Interventions & $\begin{array}{l}\text { Educational session including a review of individual risk factors for breast and ovarian } \\
\text { cancers }\end{array}$ \\
\hline Outcomes & Changes in risk perception; testing intentions. \\
\hline
\end{tabular}


Lerman 1997 (Continued)

\begin{tabular}{lll}
\hline Notes & No data on taking test in control group. \\
\hline Risk of bias & \\
\hline Bias & Authors' judgement & Support for judgement \\
\hline Allocation concealment (selection bias) & Unclear risk & B - Unclear \\
\hline
\end{tabular}

Lipkus 2005

\begin{tabular}{|c|c|c|}
\hline Methods & \multicolumn{2}{|c|}{$\begin{array}{l}\text { RCT ( } 2 \times 2 \text { factorial with basic versus more comprehensive information as well as person- } \\
\text { alised (tailored) versus non-personalised }\end{array}$} \\
\hline Participants & \multicolumn{2}{|c|}{ 99\% male, New Jersey Carpenters Fund members; aged over 50 years } \\
\hline Interventions & \multicolumn{2}{|c|}{$\begin{array}{l}\text { Tailored risk information with information about risk factors for colorectal cancer derived } \\
\text { from baseline questionnaire }\end{array}$} \\
\hline Outcomes & \multicolumn{2}{|c|}{ Faecal Occult Blood test uptake at 1, 2 and 3 years. } \\
\hline Notes & \multicolumn{2}{|c|}{$\begin{array}{l}\text { Also assessed 'attributions of colorectal cancer risk' but not as risk perceptions directly } \\
\text { affected by interventions }\end{array}$} \\
\hline \multicolumn{3}{|l|}{ Risk of bias } \\
\hline Bias & Authors' judgement & Support for judgement \\
\hline Allocation concealment (selection bias) & Unclear risk & B - Unclear \\
\hline
\end{tabular}

Myers 1999

\begin{tabular}{ll}
\hline Methods & RCT \\
\hline Participants & African American men, aged 40-70 years. Patients at the University of Chicago, USA \\
\hline Interventions & A personalised 'ProRecord' which included a tailored risk factors and symptoms form \\
\hline Outcomes & $\begin{array}{l}\text { 'Adherence', ie. men who made an office visit for prostate cancer education and early } \\
\text { detection within a year }\end{array}$ \\
\hline Notes & \\
\hline
\end{tabular}

\section{Risk of bias}




\section{Myers 1999 (Continued)}

Allocation concealment (selection bias) $\quad$ Unclear risk $\quad$ B - Unclear

\begin{tabular}{|c|c|c|}
\hline Methods & \multicolumn{2}{|l|}{ RCT } \\
\hline Participants & \multicolumn{2}{|c|}{$\begin{array}{l}\text { Women in their } 40 \text { s and } 50 \text { s, and members of Blue Cross and Blue Shield, N. Carolina, } \\
\text { USA }\end{array}$} \\
\hline Interventions & \multicolumn{2}{|c|}{$\begin{array}{l}\text { Tailored print materials detailing a woman's personal risk (numerical and graphical) of } \\
\text { breast cancer based on Gail score }\end{array}$} \\
\hline Outcomes & \multicolumn{2}{|c|}{ Knowledge, accuracy of risk perceptions; mammography uptake. } \\
\hline Notes & \multicolumn{2}{|c|}{ Tailored print + telephone counselling arm excluded as different and extra content } \\
\hline \multicolumn{3}{|l|}{ Risk of bias } \\
\hline Bias & Authors' judgement & Support for judgement \\
\hline Allocation concealment (selection bias) & Unclear risk & B - Unclear \\
\hline
\end{tabular}

Saywell 1999

\begin{tabular}{|c|c|c|}
\hline Methods & \multicolumn{2}{|l|}{ RCT } \\
\hline Participants & \multicolumn{2}{|c|}{$\begin{array}{l}\text { Women } 50-85 \text { years; non-compliant with mammography guidelines; no history of breast } \\
\text { cancer. USA, }\end{array}$} \\
\hline Interventions & \multicolumn{2}{|c|}{ Telephone and in-person counselling including discussion of personal risk factors } \\
\hline Outcomes & \multicolumn{2}{|c|}{ Mammography compliance 4-6 weeks after counselling. } \\
\hline \multicolumn{3}{|l|}{ Notes } \\
\hline \multicolumn{3}{|l|}{ Risk of bias } \\
\hline Bias & Authors' judgement & Support for judgement \\
\hline Allocation concealment (selection bias) & Unclear risk & B - Unclear \\
\hline
\end{tabular}


Schwartz 1999

\begin{tabular}{|c|c|c|}
\hline Methods & \multicolumn{2}{|l|}{ RCT } \\
\hline Participants & \multicolumn{2}{|c|}{$\begin{array}{l}\text { Women with family history of breast cancer (first degree relative of sufferer) aged } 40 \text { years } \\
\text { and older. USA }\end{array}$} \\
\hline Interventions & \multicolumn{2}{|c|}{ Risk counselling including individualised risk figures. } \\
\hline Outcomes & \multicolumn{2}{|c|}{ Self reported mammography use 1 year after (compared to baseline) } \\
\hline Notes & \multicolumn{2}{|c|}{ This is a follow-up to the Lerman et al, 1995 trial. } \\
\hline \multicolumn{3}{|l|}{ Risk of bias } \\
\hline Bias & Authors' judgement & Support for judgement \\
\hline Allocation concealment (selection bias) & Unclear risk & B - Unclear \\
\hline
\end{tabular}

Skinner 1994

\begin{tabular}{|c|c|c|}
\hline Methods & \multicolumn{2}{|c|}{ RCT, stratified between clinics. } \\
\hline Participants & \multicolumn{2}{|c|}{ Female family practice attenders aged $40-65$ years. USA. } \\
\hline Interventions & \multicolumn{2}{|c|}{ Tailored text about beliefs, mammography stages, risk factors and barriers } \\
\hline Outcomes & \multicolumn{2}{|c|}{ Mammography stage and uptake. } \\
\hline \multicolumn{3}{|l|}{ Notes } \\
\hline \multicolumn{3}{|l|}{ Risk of bias } \\
\hline Bias & Authors' judgement & Support for judgement \\
\hline Allocation concealment (selection bias) & Unclear risk & B - Unclear \\
\hline
\end{tabular}

Skinner 2002

\begin{tabular}{|c|c|}
\hline Methods & RCT \\
\hline Participants & $\begin{array}{l}\text { Women with personal and family history of breast and/or ovarian cancer; N. Carolina, } \\
\text { USA }\end{array}$ \\
\hline Interventions & $\begin{array}{l}\text { Tailored print materials about cancer, risk factors, genes and genetic testing and risk quartile } \\
\text { in verbal or verbal and numerical format according to woman's preference }\end{array}$ \\
\hline Outcomes & Knowledge, anxiety, accuracy of perceived risk and intention to take genetic test \\
\hline Notes & \\
\hline
\end{tabular}

Copyright $\odot 201$ I The Cochrane Collaboration. Published by John Wiley \& Sons, Ltd. 
Skinner 2002 (Continued)

\begin{tabular}{lll} 
Risk of bias & & \\
\hline Bias & Authors' judgement & Support for judgement \\
\hline Allocation concealment (selection bias) & Unclear risk & B - Unclear \\
\hline
\end{tabular}

RCT $=$ randomised controlled trial.

Characteristics of excluded studies [ordered by study ID]

\begin{tabular}{|c|c|}
\hline Study & Reason for exclusion \\
\hline Alexander 1996 & A one group pre-test and post-test design. No control group. \\
\hline Champion 2000b & $\begin{array}{l}\text { Not personalised risk elements despite some attention to susceptibility; personalisation is for transtheoretical } \\
\text { stage }\end{array}$ \\
\hline Dignan 1996 & $\begin{array}{l}\text { Individualised counselling based on each woman's barriers to obtaining cervical screening, but not estimating } \\
\text { her personal level of risk or risk factors }\end{array}$ \\
\hline Engelstad 2005 & Intervention for follow-up of abnormal Pap smears, not screening \\
\hline Gagnon 1996 & $\begin{array}{l}\text { Intervention involved counselling in which an estimate of a woman's risk of developing breast cancer was given, } \\
\text { but no control group present; and main behavioural outcome was not mammography but breast self-examination }\end{array}$ \\
\hline Giles 2001 & Personalised risks given, but no control group for this pre-post study \\
\hline Kadison 1998 & No control group. \\
\hline Kreuter 2005 & Tailoring for beliefs and cultural adaptation but not of risk information itself \\
\hline Leigh 1991 & A longitudinal study, with risk calculated after cardiovascular screening \\
\hline Lipkus 2000 & Tailored print and counselling, but no clear evidence that personalised risk information was given \\
\hline Miller 2005 & Patient initiated call for information, consideration of testing; not screening \\
\hline Pye 1988 & $\begin{array}{l}\text { Identified from the Jepson review as being a 'risk factor assessment study'; but questionnaire assessed symptoms } \\
\text { and not risk factors as such }\end{array}$ \\
\hline Rakowski 1998 & Stage (of change) matched intervention but not explicitly dealing with individually calculated risk estimates \\
\hline Rhodes 2001 & Personal health recommendations but not risk communication in screening. Process measures and no outcomes \\
\hline
\end{tabular}




\section{(Continued)}

Rimer 1999 A tailored intervention, but not with regards to personal risks

Weber 1997 Structured outreach, with identification and removal of barriers to care, but not estimating her personal level of risk or risk factors 
DATA AND ANALYSES

Comparison 1. personalised risk communication versus general risk information

\begin{tabular}{|c|c|c|c|c|}
\hline Outcome or subgroup title & $\begin{array}{l}\text { No. of } \\
\text { studies }\end{array}$ & $\begin{array}{c}\text { No. of } \\
\text { participants }\end{array}$ & Statistical method & Effect size \\
\hline $\begin{array}{l}1 \text { knowledge regarding screening } \\
\text { test / condition concerned }\end{array}$ & 2 & 568 & Mean Difference (IV, Fixed, 95\% CI) & $2.45[1.94,2.96]$ \\
\hline $\begin{array}{l}1.1 \text { calculated risk score } \\
\text { (numerical) v general } \\
\text { information }\end{array}$ & 0 & 0 & Mean Difference (IV, Fixed, 95\% CI) & $0.0[0.0,0.0]$ \\
\hline $\begin{array}{l}1.2 \text { calculated risk score } \\
\text { (categorised) } \mathrm{v} \text { general } \\
\text { information }\end{array}$ & 1 & 260 & Mean Difference (IV, Fixed, 95\% CI) & $12.0[6.89,17.11]$ \\
\hline $\begin{array}{l}1.3 \text { personal risk factor list } \mathrm{v} \\
\text { general information }\end{array}$ & 1 & 308 & Mean Difference (IV, Fixed, 95\% CI) & $2.35[1.84,2.86]$ \\
\hline $\begin{array}{l}2 \text { knowledge regarding screening } \\
\text { test / condition concerned }\end{array}$ & 1 & 804 & Odds Ratio (M-H, Fixed, 95\% CI) & $1.44[0.95,2.19]$ \\
\hline $\begin{array}{l}2.1 \text { calculated risk score } \\
\text { (numerical) } \mathrm{v} \text { general } \\
\text { information }\end{array}$ & 1 & 804 & Odds Ratio (M-H, Fixed, 95\% CI) & $1.44[0.95,2.19]$ \\
\hline $\begin{array}{l}2.2 \text { calculated risk score } \\
\text { (categorised) v general } \\
\text { information }\end{array}$ & 0 & 0 & Odds Ratio (M-H, Fixed, 95\% CI) & $0.0[0.0,0.0]$ \\
\hline $\begin{array}{l}2.3 \text { personal risk factor list } \mathrm{v} \\
\text { general information }\end{array}$ & 0 & 0 & Odds Ratio (M-H, Fixed, 95\% CI) & $0.0[0.0,0.0]$ \\
\hline $\begin{array}{l}3 \text { perceived risk - perceiving self as } \\
\text { appropriate candidate for test }\end{array}$ & 1 & 214 & Odds Ratio (M-H, Fixed, 95\% CI) & $0.65[0.35,1.19]$ \\
\hline $\begin{array}{l}3.1 \text { calculated risk score } \\
\text { (numerical) v general } \\
\text { information }\end{array}$ & 1 & 214 & Odds Ratio (M-H, Fixed, 95\% CI) & $0.65[0.35,1.19]$ \\
\hline $\begin{array}{l}3.2 \text { calculated risk score } \\
\text { (categorised) v general } \\
\text { information }\end{array}$ & 0 & 0 & Odds Ratio (M-H, Fixed, 95\% CI) & $0.0[0.0,0.0]$ \\
\hline $\begin{array}{l}3.3 \text { personal risk factor list } \mathrm{v} \\
\text { general information }\end{array}$ & 0 & 0 & Odds Ratio (M-H, Fixed, 95\% CI) & $0.0[0.0,0.0]$ \\
\hline 4 accurately perceived risk & 3 & 1264 & Odds Ratio (M-H, Fixed, 95\% CI) & $1.46[1.13,1.88]$ \\
\hline $\begin{array}{l}4.1 \text { calculated risk score } \\
\text { (numerical) v general } \\
\text { information }\end{array}$ & 2 & 1004 & Odds Ratio (M-H, Fixed, 95\% CI) & $1.22[0.91,1.64]$ \\
\hline $\begin{array}{l}4.2 \text { calculated risk score } \\
\text { (categorised) } \mathrm{v} \text { general } \\
\text { information }\end{array}$ & 1 & 260 & Odds Ratio (M-H, Fixed, 95\% CI) & $2.50[1.48,4.20]$ \\
\hline $\begin{array}{l}4.3 \text { personal risk factor list } \mathrm{v} \\
\text { general information }\end{array}$ & 0 & 0 & Odds Ratio (M-H, Fixed, 95\% CI) & $0.0[0.0,0.0]$ \\
\hline $\begin{array}{l}5 \text { anxiety (Cancer related anxiety } \\
\text { and helplessness scale; IES } \\
\text { breast cancer distress) }\end{array}$ & 2 & 499 & Mean Difference (IV, Fixed, 95\% CI) & $-0.03[-0.30,0.25]$ \\
\hline
\end{tabular}

Personalised risk communication for informed decision making about taking screening tests (Review)

Copyright (C) 201 I The Cochrane Collaboration. Published by John Wiley \& Sons, Ltd. 


\begin{tabular}{|c|c|c|c|c|}
\hline $\begin{array}{l}5.1 \text { calculated risk score } \\
\text { (numerical) } \mathrm{v} \text { general } \\
\text { information }\end{array}$ & 1 & 239 & Mean Difference (IV, Fixed, 95\% CI) & $-4.1[-7.54,-0.66]$ \\
\hline $\begin{array}{l}5.2 \text { calculated risk score } \\
\text { (categorised) v general } \\
\text { information }\end{array}$ & 1 & 260 & Mean Difference (IV, Fixed, 95\% CI) & $0.0[-0.28,0.28]$ \\
\hline $\begin{array}{l}5.3 \text { personal risk factor list v } \\
\text { general information }\end{array}$ & 0 & 0 & Mean Difference (IV, Fixed, 95\% CI) & $0.0[0.0,0.0]$ \\
\hline satisfaction with decision & 0 & 0 & Mean Difference (IV, Fixed, 95\% CI) & $0.0[0.0,0.0]$ \\
\hline $\begin{array}{l}6.1 \text { calculated risk score } \\
\text { (numerical) } \mathrm{v} \text { general } \\
\text { information }\end{array}$ & 0 & 0 & Mean Difference (IV, Fixed, 95\% CI) & $0.0[0.0,0.0]$ \\
\hline $\begin{array}{l}6.2 \text { calculated risk score } \\
\text { (categorised) v general } \\
\text { information }\end{array}$ & 0 & 0 & Mean Difference (IV, Fixed, 95\% CI) & $0.0[0.0,0.0]$ \\
\hline $\begin{array}{l}6.3 \text { personal risk factor list } \mathrm{v} \\
\text { general information }\end{array}$ & 0 & 0 & Mean Difference (IV, Fixed, 95\% CI) & $0.0[0.0,0.0]$ \\
\hline decision conflict & 0 & 0 & Mean Difference (IV, Fixed, 95\% CI) & $0.0[0.0,0.0]$ \\
\hline $\begin{array}{l}7.1 \text { calculated risk score } \\
\text { (numerical) } \mathrm{v} \text { general } \\
\text { information }\end{array}$ & 0 & 0 & Mean Difference (IV, Fixed, 95\% CI) & $0.0[0.0,0.0]$ \\
\hline $\begin{array}{l}7.2 \text { calculated risk score } \\
\text { (categorised) v general } \\
\text { information }\end{array}$ & 0 & 0 & Mean Difference (IV, Fixed, 95\% CI) & $0.0[0.0,0.0]$ \\
\hline $\begin{array}{l}7.3 \text { personal risk factor list } \mathrm{v} \\
\text { general information }\end{array}$ & 0 & 0 & Mean Difference (IV, Fixed, 95\% CI) & $0.0[0.0,0.0]$ \\
\hline intention to take screening test & 5 & 2016 & Odds Ratio (M-H, Fixed, 95\% CI) & $0.86[0.71,1.03]$ \\
\hline $\begin{array}{l}8.1 \text { calculated risk score } \\
\text { (numerical) } \mathrm{v} \text { general } \\
\text { information }\end{array}$ & 1 & 214 & Odds Ratio (M-H, Fixed, 95\% CI) & $1.10[0.63,1.94]$ \\
\hline $\begin{array}{l}8.2 \text { calculated risk score } \\
\text { (categorised) v general } \\
\text { information }\end{array}$ & 2 & 538 & Odds Ratio (M-H, Fixed, 95\% CI) & $1.68[1.12,2.53]$ \\
\hline $\begin{array}{l}8.3 \text { personal risk factor list } \mathrm{v} \\
\text { general information }\end{array}$ & 2 & 1264 & Odds Ratio (M-H, Fixed, 95\% CI) & $0.68[0.54,0.84]$ \\
\hline uptake of screening test & 14 & 7341 & Odds Ratio (M-H, Fixed, 95\% CI) & $1.13[1.02,1.24]$ \\
\hline $\begin{array}{l}9.1 \text { calculated risk score } \\
\text { (numerical) v general } \\
\text { information }\end{array}$ & 2 & 1234 & Odds Ratio (M-H, Fixed, 95\% CI) & $0.82[0.65,1.03]$ \\
\hline $\begin{array}{l}9.2 \text { calculated risk score } \\
\text { (categorised) v general } \\
\text { information }\end{array}$ & 2 & 1031 & Odds Ratio (M-H, Fixed, 95\% CI) & $1.42[1.07,1.89]$ \\
\hline $\begin{array}{l}9.3 \text { personal risk factor list } \mathrm{v} \\
\text { general information }\end{array}$ & 10 & 5076 & Odds Ratio (M-H, Fixed, 95\% CI) & $1.17[1.04,1.32]$ \\
\hline $\begin{array}{l}\text { appropriate use of cholesterol } \\
\text { test }\end{array}$ & 1 & 3152 & Odds Ratio (M-H, Fixed, 95\% CI) & $1.32[1.14,1.55]$ \\
\hline $\begin{array}{l}10.1 \text { calculated risk score } \\
\text { (numerical) v general } \\
\text { information }\end{array}$ & 0 & 0 & Odds Ratio (M-H, Fixed, 95\% CI) & $0.0[0.0,0.0]$ \\
\hline
\end{tabular}


10.2 calculated risk score

(categorised) v genera

information

10.3 personal risk factor list $\mathrm{v}$

11 smoking

11.1 calculated risk score

Odds Ratio (M-H, Fixed, 95\% CI)

Odds Ratio (M-H, Fixed, 95\% CI)

$1.04[0.60,1.82]$

$1.04[0.60,1.82]$

information

11.2 calculated risk score

(categorised) $\mathrm{v}$ general

information

11.3 personal risk factor list $\mathrm{v}$ general information

12 stages of change

12.1 personal risk factor list $\mathrm{v}$ general information

13 improvement in risk comprehension/perception

13.1 calculated risk score

(numerical) v general

information

13.2 calculated risk score

0

(categorised) v general

information

13.3 personal risk factor list $\mathrm{v}$ general information

14 making a recommended

behaviour change

14.1 personal risk factor list $\mathrm{v}$ general information

14.2 calculated risk score

(categorised) v general

information

14.3 personal risk factor list $\mathrm{v}$

general information
Other data

Other data

Peto Odds Ratio (Peto, Fixed, 95\% CI)

$1.64[0.83,3.25]$

1

Peto Odds Ratio (Peto, Fixed, 95\% CI)

$1.64[0.83,3.25]$

$0.0[0.0,0.0]$

Peto Odds Ratio (Peto, Fixed, 95\% CI)

$0.0[0.0,0.0]$

$0.98[0.76,1.28]$

$0.98[0.76,1.28]$

Odds Ratio (M-H, Fixed, 95\% CI)

$0.0[0.0,0.0]$

Odds Ratio (M-H, Fixed, 95\% CI)

$0.0[0.0,0.0]$

\section{Comparison 2. personalised risk communication versus general risk information for PAP SMEARS}

\begin{tabular}{lcccc} 
Outcome or subgroup title & $\begin{array}{c}\text { No. of } \\
\text { studies }\end{array}$ & $\begin{array}{c}\text { No. of } \\
\text { participants }\end{array}$ & Statistical method & Effect size \\
\hline $\begin{array}{c}1 \text { intention to take screening test } \\
\quad 1\end{array}$ & 084 & Odds Ratio (M-H, Fixed, 95\% CI) & $0.58[0.45,0.74]$ \\
$\begin{array}{c}1.1 \text { calculated risk score } \\
\text { (numerical) v general }\end{array}$ & 0 & 0 & Odds Ratio (M-H, Fixed, 95\% CI) & $0.0[0.0,0.0]$ \\
$\begin{array}{l}\text { information } \\
1.2 \text { calculated risk score }\end{array}$ & 0 & 0 & Odds Ratio (M-H, Fixed, 95\% CI) & $0.0[0.0,0.0]$ \\
$\quad \begin{array}{l}\text { (categorised) v general } \\
\text { information }\end{array}$ & & & & \\
\hline
\end{tabular}

Personalised risk communication for informed decision making about taking screening tests (Review) 


\begin{tabular}{|c|c|c|c|c|}
\hline $\begin{array}{l}1.3 \text { personal risk factor list } \mathrm{v} \\
\text { general information }\end{array}$ & 1 & 984 & Odds Ratio (M-H, Fixed, 95\% CI) & $0.58[0.45,0.74]$ \\
\hline 2 uptake of screening test & 3 & 1552 & Odds Ratio (M-H, Fixed, 95\% CI) & $0.62[0.50,0.77]$ \\
\hline $\begin{array}{l}2.1 \text { calculated risk score } \\
\text { (numerical) v general } \\
\text { information }\end{array}$ & 1 & 296 & Odds Ratio (M-H, Fixed, 95\% CI) & $1.26[0.75,2.13]$ \\
\hline $\begin{array}{l}2.2 \text { calculated risk score } \\
\text { (categorised) v general } \\
\text { information }\end{array}$ & 0 & 0 & Odds Ratio (M-H, Fixed, 95\% CI) & $0.0[0.0,0.0]$ \\
\hline $\begin{array}{l}2.3 \text { personal risk factor list } \mathrm{v} \\
\text { general information }\end{array}$ & 2 & 1256 & Odds Ratio (M-H, Fixed, 95\% CI) & $0.53[0.42,0.67]$ \\
\hline
\end{tabular}

Comparison 3. personalised risk communication versus general risk information for MAMMOGRAPHY

\begin{tabular}{|c|c|c|c|c|}
\hline Outcome or subgroup title & $\begin{array}{l}\text { No. of } \\
\text { studies }\end{array}$ & $\begin{array}{c}\text { No. of } \\
\text { participants }\end{array}$ & Statistical method & Effect size \\
\hline $\begin{array}{l}1 \text { knowledge regarding screening } \\
\text { test / condition concerned }\end{array}$ & 0 & 0 & Mean Difference (IV, Fixed, 95\% CI) & $0.0[0.0,0.0]$ \\
\hline $\begin{array}{l}1.1 \text { calculated risk score } \\
\text { (numerical) } \mathrm{v} \text { general } \\
\text { information }\end{array}$ & 0 & 0 & Mean Difference (IV, Fixed, 95\% CI) & $0.0[0.0,0.0]$ \\
\hline $\begin{array}{l}1.2 \text { calculated risk score } \\
\text { (categorised) } \mathrm{v} \text { general } \\
\text { information }\end{array}$ & 0 & 0 & Mean Difference (IV, Fixed, 95\% CI) & $0.0[0.0,0.0]$ \\
\hline $\begin{array}{l}1.3 \text { personal risk factor list } \mathrm{v} \\
\text { general information }\end{array}$ & 0 & 0 & Mean Difference (IV, Fixed, 95\% CI) & $0.0[0.0,0.0]$ \\
\hline $\begin{array}{l}2 \text { knowledge regarding screening } \\
\text { test / condition concerned }\end{array}$ & 1 & 804 & Odds Ratio (M-H, Fixed, 95\% CI) & $1.44[0.95,2.19]$ \\
\hline $\begin{array}{l}2.1 \text { calculated risk score } \\
\text { (numerical) v general } \\
\text { information }\end{array}$ & 1 & 804 & Odds Ratio (M-H, Fixed, 95\% CI) & $1.44[0.95,2.19]$ \\
\hline $\begin{array}{l}2.2 \text { calculated risk score } \\
\text { (categorised) } \mathrm{v} \text { general } \\
\text { information }\end{array}$ & 0 & 0 & Odds Ratio (M-H, Fixed, 95\% CI) & $0.0[0.0,0.0]$ \\
\hline $\begin{array}{l}2.3 \text { personal risk factor list } \mathrm{v} \\
\text { general information }\end{array}$ & 0 & 0 & Odds Ratio (M-H, Fixed, 95\% CI) & $0.0[0.0,0.0]$ \\
\hline 3 accuracy of perceived risk & 1 & 804 & Odds Ratio (M-H, Fixed, 95\% CI) & $1.17[0.86,1.60]$ \\
\hline $\begin{array}{l}3.1 \text { calculated risk score } \\
\text { (numerical) v general } \\
\text { information }\end{array}$ & 1 & 804 & Odds Ratio (M-H, Fixed, 95\% CI) & $1.17[0.86,1.60]$ \\
\hline $\begin{array}{l}3.2 \text { calculated risk score } \\
\text { (categorised) v general } \\
\text { information }\end{array}$ & 0 & 0 & Odds Ratio (M-H, Fixed, 95\% CI) & $0.0[0.0,0.0]$ \\
\hline $\begin{array}{l}3.3 \text { personal risk factor list } \mathrm{v} \\
\text { general information }\end{array}$ & 0 & 0 & Odds Ratio (M-H, Fixed, 95\% CI) & $0.0[0.0,0.0]$ \\
\hline 4 decision conflict & 0 & 0 & Mean Difference (IV, Fixed, 95\% CI) & $0.0[0.0,0.0]$ \\
\hline
\end{tabular}




\begin{tabular}{|c|c|c|c|c|}
\hline $\begin{array}{l}4.1 \text { calculated risk score } \\
\text { (numerical) } \mathrm{v} \text { general } \\
\text { information }\end{array}$ & 0 & 0 & Mean Difference (IV, Fixed, 95\% CI) & $0.0[0.0,0.0]$ \\
\hline $\begin{array}{l}4.2 \text { calculated risk score } \\
\text { (categorised) v general } \\
\text { information }\end{array}$ & 0 & 0 & Mean Difference (IV, Fixed, 95\% CI) & $0.0[0.0,0.0]$ \\
\hline $\begin{array}{l}4.3 \text { personal risk factor list } \mathrm{v} \\
\text { general information }\end{array}$ & 0 & 0 & Mean Difference (IV, Fixed, 95\% CI) & $0.0[0.0,0.0]$ \\
\hline 5 anxiety & 0 & 0 & Mean Difference (IV, Fixed, 95\% CI) & $0.0[0.0,0.0]$ \\
\hline $\begin{array}{l}5.1 \text { calculated risk score } \\
\text { (numerical) v general } \\
\text { information }\end{array}$ & 0 & 0 & Mean Difference (IV, Fixed, 95\% CI) & $0.0[0.0,0.0]$ \\
\hline $\begin{array}{l}5.2 \text { calculated risk score } \\
\text { (categorised) v general } \\
\text { information }\end{array}$ & 0 & 0 & Mean Difference (IV, Fixed, 95\% CI) & $0.0[0.0,0.0]$ \\
\hline $\begin{array}{l}5.3 \text { personal risk factor list } \mathrm{v} \\
\text { general information }\end{array}$ & 0 & 0 & Mean Difference (IV, Fixed, 95\% CI) & $0.0[0.0,0.0]$ \\
\hline 6 satisfaction with decision & 0 & 0 & Mean Difference (IV, Fixed, 95\% CI) & $0.0[0.0,0.0]$ \\
\hline $\begin{array}{l}6.1 \text { calculated risk score } \\
\text { (numerical) v general } \\
\text { information }\end{array}$ & 0 & 0 & Mean Difference (IV, Fixed, 95\% CI) & $0.0[0.0,0.0]$ \\
\hline $\begin{array}{l}6.2 \text { calculated risk score } \\
\text { (categorised) v general } \\
\text { information }\end{array}$ & 0 & 0 & Mean Difference (IV, Fixed, 95\% CI) & $0.0[0.0,0.0]$ \\
\hline $\begin{array}{l}6.3 \text { personal risk factor list } \mathrm{v} \\
\text { general information }\end{array}$ & 0 & 0 & Mean Difference (IV, Fixed, 95\% CI) & $0.0[0.0,0.0]$ \\
\hline 7 intention to take screening test & 1 & 478 & Odds Ratio (M-H, Fixed, 95\% CI) & $0.53[0.36,0.76]$ \\
\hline $\begin{array}{l}7.1 \text { calculated risk score } \\
\text { (numerical) v general } \\
\text { information }\end{array}$ & 0 & 0 & Odds Ratio (M-H, Fixed, 95\% CI) & $0.0[0.0,0.0]$ \\
\hline $\begin{array}{l}7.2 \text { calculated risk score } \\
\text { (categorised) v general } \\
\text { information }\end{array}$ & 0 & 0 & Odds Ratio (M-H, Fixed, 95\% CI) & $0.0[0.0,0.0]$ \\
\hline $\begin{array}{l}7.3 \text { personal risk factor list } \mathrm{v} \\
\text { general information }\end{array}$ & 1 & 478 & Odds Ratio (M-H, Fixed, 95\% CI) & $0.53[0.36,0.76]$ \\
\hline 8 uptake of screening test & 11 & 5234 & Odds Ratio (M-H, Fixed, 95\% CI) & $1.11[0.98,1.24]$ \\
\hline $\begin{array}{l}8.1 \text { calculated risk score } \\
\text { (numerical) v general } \\
\text { information }\end{array}$ & 3 & 1456 & Odds Ratio (M-H, Fixed, 95\% CI) & $0.82[0.66,1.02]$ \\
\hline $\begin{array}{l}8.2 \text { calculated risk score } \\
\text { (categorised) } \mathrm{v} \text { general } \\
\text { information }\end{array}$ & 1 & 753 & Odds Ratio (M-H, Fixed, 95\% CI) & $1.37[1.02,1.84]$ \\
\hline $\begin{array}{l}8.3 \text { personal risk factor list } \mathrm{v} \\
\text { general information }\end{array}$ & 7 & 3025 & Odds Ratio (M-H, Fixed, 95\% CI) & $1.22[1.04,1.43]$ \\
\hline 9 stages of change & & & Other data & No numeric data \\
\hline $\begin{array}{l}9.1 \text { personal risk factor list } \mathrm{v} \\
\text { general information }\end{array}$ & & & Other data & No numeric data \\
\hline $\begin{array}{l}10 \text { anxiety (Cancer related anxiety } \\
\text { and helplessness scale) }\end{array}$ & 0 & 0 & Mean Difference (IV, Fixed, 95\% CI) & $0.0[0.0,0.0]$ \\
\hline
\end{tabular}


10.1 calculated risk score

(numerical) $\mathrm{v}$ general

information

10.2 calculated risk score

(categorised) $\mathrm{v}$ general

information

10.3 personal risk factor list $\mathrm{v}$ general information

11 improvement in risk comprehension/perception

11.1 calculated risk score (numerical) v general information

11.2 calculated risk score (categorised) $\mathrm{v}$ general information

11.3 personal risk factor list $\mathrm{v}$ general information

Comparison 4. personalised risk communication versus general risk information for CHOLESTEROL TESTS

\begin{tabular}{|c|c|c|c|c|}
\hline Outcome or subgroup title & $\begin{array}{l}\text { No. of } \\
\text { studies }\end{array}$ & $\begin{array}{c}\text { No. of } \\
\text { participants }\end{array}$ & Statistical method & Effect size \\
\hline 1 uptake of screening test & 1 & 276 & Odds Ratio (M-H, Fixed, 95\% CI) & $0.98[0.57,1.65]$ \\
\hline $\begin{array}{l}1.1 \text { calculated risk score } \\
\text { (numerical) v general } \\
\text { information }\end{array}$ & 1 & 276 & Odds Ratio (M-H, Fixed, 95\% CI) & $0.98[0.57,1.65]$ \\
\hline $\begin{array}{l}1.2 \text { calculated risk score } \\
\text { (categorised) v general } \\
\text { information }\end{array}$ & 0 & 0 & Odds Ratio (M-H, Fixed, 95\% CI) & $0.0[0.0,0.0]$ \\
\hline $\begin{array}{l}1.3 \text { personal risk factor list } \mathrm{v} \\
\text { general information }\end{array}$ & 0 & 0 & Odds Ratio (M-H, Fixed, 95\% CI) & $0.0[0.0,0.0]$ \\
\hline $\begin{array}{l}2 \text { appropriate use of cholesterol } \\
\text { test }\end{array}$ & 1 & 3152 & Odds Ratio (M-H, Fixed, 95\% CI) & $1.32[1.14,1.55]$ \\
\hline $\begin{array}{l}2.1 \text { calculated risk score } \\
\text { (numerical) v general } \\
\text { information }\end{array}$ & 0 & 0 & Odds Ratio (M-H, Fixed, 95\% CI) & $0.0[0.0,0.0]$ \\
\hline $\begin{array}{l}2.2 \text { calculated risk score } \\
\text { (categorised) v general } \\
\text { information }\end{array}$ & 0 & 0 & Odds Ratio (M-H, Fixed, 95\% CI) & $0.0[0.0,0.0]$ \\
\hline $\begin{array}{l}2.3 \text { personal risk factor list } \mathrm{v} \\
\text { general information }\end{array}$ & 1 & 3152 & Odds Ratio (M-H, Fixed, 95\% CI) & $1.32[1.14,1.55$ \\
\hline
\end{tabular}




\begin{tabular}{|c|c|c|c|c|}
\hline Outcome or subgroup title & $\begin{array}{l}\text { No. of } \\
\text { studies }\end{array}$ & $\begin{array}{c}\text { No. of } \\
\text { participants }\end{array}$ & Statistical method & Effect size \\
\hline $\begin{array}{l}1 \text { knowledge regarding screening } \\
\text { test / condition concerned }\end{array}$ & 2 & 568 & Mean Difference (IV, Fixed, 95\% CI) & $2.45[1.94,2.96]$ \\
\hline $\begin{array}{l}1.1 \text { calculated risk score } \\
\text { (numerical) v general } \\
\text { information }\end{array}$ & 0 & 0 & Mean Difference (IV, Fixed, 95\% CI) & $0.0[0.0,0.0]$ \\
\hline $\begin{array}{l}1.2 \text { calculated risk score } \\
\text { (categorised) v general } \\
\text { information }\end{array}$ & 1 & 260 & Mean Difference (IV, Fixed, 95\% CI) & $12.0[6.89,17.11]$ \\
\hline $\begin{array}{l}1.3 \text { personal risk factor list } \mathrm{v} \\
\text { general information }\end{array}$ & 1 & 308 & Mean Difference (IV, Fixed, 95\% CI) & $2.35[1.84,2.86]$ \\
\hline $\begin{array}{l}2 \text { perceived risk - perceiving self as } \\
\text { appropriate candidate for test }\end{array}$ & 1 & 214 & Odds Ratio (M-H, Fixed, 95\% CI) & $0.65[0.35,1.19]$ \\
\hline $\begin{array}{l}2.1 \text { calculated risk score } \\
\text { (numerical) v general } \\
\text { information }\end{array}$ & 1 & 214 & Odds Ratio (M-H, Fixed, 95\% CI) & $0.65[0.35,1.19]$ \\
\hline $\begin{array}{l}2.2 \text { calculated risk score } \\
\text { (categorised) v general } \\
\text { information }\end{array}$ & 0 & 0 & Odds Ratio (M-H, Fixed, 95\% CI) & $0.0[0.0,0.0]$ \\
\hline $\begin{array}{l}2.3 \text { personal risk factor list } \mathrm{v} \\
\text { general information }\end{array}$ & 0 & 0 & Odds Ratio (M-H, Fixed, 95\% CI) & $0.0[0.0,0.0]$ \\
\hline 3 accurately perceived risk & 2 & 460 & Odds Ratio (M-H, Fixed, 95\% CI) & $2.25[1.44,3.53]$ \\
\hline $\begin{array}{l}3.1 \text { calculated risk score } \\
\text { (numerical) v general } \\
\text { information }\end{array}$ & 1 & 200 & Odds Ratio (M-H, Fixed, 95\% CI) & $1.69[0.70,4.06]$ \\
\hline $\begin{array}{l}3.2 \text { calculated risk score } \\
\text { (categorised) v general } \\
\text { information }\end{array}$ & 1 & 260 & Odds Ratio (M-H, Fixed, 95\% CI) & $2.50[1.48,4.20]$ \\
\hline $\begin{array}{l}3.3 \text { personal risk factor list } \mathrm{v} \\
\text { general information }\end{array}$ & 0 & 0 & Odds Ratio (M-H, Fixed, 95\% CI) & $0.0[0.0,0.0]$ \\
\hline 4 anxiety & 2 & 499 & Mean Difference (IV, Fixed, 95\% CI) & $-0.03[-0.30,0.25]$ \\
\hline $\begin{array}{l}4.1 \text { calculated risk score } \\
\text { (numerical) v general } \\
\text { information }\end{array}$ & 1 & 239 & Mean Difference (IV, Fixed, 95\% CI) & $-4.1[-7.54,-0.66]$ \\
\hline $\begin{array}{l}4.2 \text { calculated risk score } \\
\text { (categorised) v general } \\
\text { information }\end{array}$ & 1 & 260 & Mean Difference (IV, Fixed, 95\% CI) & $0.0[-0.28,0.28]$ \\
\hline $\begin{array}{l}4.3 \text { personal risk factor list } \mathrm{v} \\
\text { general information }\end{array}$ & 0 & 0 & Mean Difference (IV, Fixed, 95\% CI) & $0.0[0.0,0.0]$ \\
\hline 5 satisfaction with decision & 0 & 0 & Mean Difference (IV, Fixed, 95\% CI) & $0.0[0.0,0.0]$ \\
\hline $\begin{array}{l}5.1 \text { calculated risk score } \\
\text { (numerical) v general } \\
\text { information }\end{array}$ & 0 & 0 & Mean Difference (IV, Fixed, 95\% CI) & $0.0[0.0,0.0]$ \\
\hline $\begin{array}{l}5.2 \text { calculated risk score } \\
\text { (categorised) v general } \\
\text { information }\end{array}$ & 0 & 0 & Mean Difference (IV, Fixed, 95\% CI) & $0.0[0.0,0.0]$ \\
\hline
\end{tabular}

Personalised risk communication for informed decision making about taking screening tests (Review) 


\begin{tabular}{|c|c|c|c|c|}
\hline $\begin{array}{l}5.3 \text { personal risk factor list } \mathrm{v} \\
\text { general information }\end{array}$ & 0 & 0 & Mean Difference (IV, Fixed, 95\% CI) & $0.0[0.0,0.0]$ \\
\hline 6 decision conflict & 0 & 0 & Mean Difference (IV, Fixed, 95\% CI) & $0.0[0.0,0.0]$ \\
\hline $\begin{array}{l}6.1 \text { calculated risk score } \\
\text { (numerical) v general } \\
\text { information }\end{array}$ & 0 & 0 & Mean Difference (IV, Fixed, 95\% CI) & $0.0[0.0,0.0]$ \\
\hline $\begin{array}{l}6.2 \text { calculated risk score } \\
\text { (categorised) v general } \\
\text { information }\end{array}$ & 0 & 0 & Mean Difference (IV, Fixed, 95\% CI) & $0.0[0.0,0.0]$ \\
\hline $\begin{array}{l}6.3 \text { personal risk factor list } \mathrm{v} \\
\text { general information }\end{array}$ & 0 & 0 & Mean Difference (IV, Fixed, 95\% CI) & $0.0[0.0,0.0]$ \\
\hline 7 intention to take screening test & 2 & 540 & Odds Ratio (M-H, Fixed, 95\% CI) & $0.84[0.55,1.27]$ \\
\hline $\begin{array}{l}7.1 \text { calculated risk score } \\
\text { (numerical) v general } \\
\text { information }\end{array}$ & 0 & 0 & Odds Ratio (M-H, Fixed, 95\% CI) & $0.0[0.0,0.0]$ \\
\hline $\begin{array}{l}7.2 \text { calculated risk score } \\
\text { (categorised) v general } \\
\text { information }\end{array}$ & 1 & 260 & Odds Ratio (M-H, Fixed, 95\% CI) & $0.21[0.07,0.65]$ \\
\hline $\begin{array}{l}7.3 \text { personal risk factor list } \mathrm{v} \\
\text { general information }\end{array}$ & 1 & 280 & Odds Ratio (M-H, Fixed, 95\% CI) & $1.17[0.72,1.89]$ \\
\hline 8 uptake of screening test & 5 & 3145 & Odds Ratio (M-H, Fixed, 95\% CI) & $1.45[1.23,1.71]$ \\
\hline $\begin{array}{l}8.1 \text { calculated risk score } \\
\text { (numerical) v general } \\
\text { information }\end{array}$ & 2 & 1355 & Odds Ratio (M-H, Fixed, 95\% CI) & $1.48[1.06,2.07]$ \\
\hline $\begin{array}{l}8.2 \text { calculated risk score } \\
\text { (categorised) v general } \\
\text { information }\end{array}$ & 1 & 753 & Odds Ratio (M-H, Fixed, 95\% CI) & $1.37[1.02,1.84]$ \\
\hline $\begin{array}{l}8.3 \text { personal risk factor list } \mathrm{v} \\
\text { general information }\end{array}$ & 2 & 1037 & Odds Ratio (M-H, Fixed, 95\% CI) & $1.49[1.16,1.91]$ \\
\hline $\begin{array}{l}9 \text { improvement in risk } \\
\text { comprehension/perception }\end{array}$ & 0 & 0 & Peto Odds Ratio (Peto, Fixed, 95\% CI) & $0.0[0.0,0.0]$ \\
\hline $\begin{array}{l}9.1 \text { calculated risk score } \\
\text { (numerical) v general } \\
\text { information }\end{array}$ & 0 & 0 & Peto Odds Ratio (Peto, Fixed, 95\% CI) & $0.0[0.0,0.0]$ \\
\hline $\begin{array}{l}9.2 \text { calculated risk score } \\
\text { (categorised) v general } \\
\text { information }\end{array}$ & 0 & 0 & Peto Odds Ratio (Peto, Fixed, 95\% CI) & $0.0[0.0,0.0]$ \\
\hline $\begin{array}{l}9.3 \text { personal risk factor list } \mathrm{v} \\
\text { general information }\end{array}$ & 0 & 0 & Peto Odds Ratio (Peto, Fixed, 95\% CI) & $0.0[0.0,0.0]$ \\
\hline $\begin{array}{l}10 \text { anxiety (Cancer related anxiety } \\
\text { and helplessness scale) }\end{array}$ & 0 & 0 & Mean Difference (IV, Fixed, 95\% CI) & $0.0[0.0,0.0]$ \\
\hline $\begin{array}{l}10.1 \text { calculated risk score } \\
\text { (numerical) v general } \\
\text { information }\end{array}$ & 0 & 0 & Mean Difference (IV, Fixed, 95\% CI) & $0.0[0.0,0.0]$ \\
\hline $\begin{array}{l}10.2 \text { calculated risk score } \\
\text { (categorised) v general } \\
\text { information }\end{array}$ & 0 & 0 & Mean Difference (IV, Fixed, 95\% CI) & $0.0[0.0,0.0]$ \\
\hline $\begin{array}{l}10.3 \text { personal risk factor list } \mathrm{v} \\
\text { general information }\end{array}$ & 0 & 0 & Mean Difference (IV, Fixed, 95\% CI) & $0.0[0.0,0.0]$ \\
\hline
\end{tabular}


Comparison 6. personalised risk communication versus general risk information for COLORECTAL SCREENING

\begin{tabular}{|c|c|c|c|c|}
\hline Outcome or subgroup title & $\begin{array}{l}\text { No. of } \\
\text { studies }\end{array}$ & $\begin{array}{c}\text { No. of } \\
\text { participants }\end{array}$ & Statistical method & Effect size \\
\hline 1 uptake of screening test & 1 & 278 & Odds Ratio (M-H, Fixed, 95\% CI) & $2.09[0.76,5.75]$ \\
\hline $\begin{array}{l}1.1 \text { calculated risk score } \\
\text { (numerical) } \mathrm{v} \text { general } \\
\text { information }\end{array}$ & 0 & 0 & Odds Ratio (M-H, Fixed, 95\% CI) & $0.0[0.0,0.0]$ \\
\hline $\begin{array}{l}1.2 \text { calculated risk score } \\
\text { (categorised) v general } \\
\text { information }\end{array}$ & 1 & 278 & Odds Ratio (M-H, Fixed, 95\% CI) & $2.09[0.76,5.75]$ \\
\hline $\begin{array}{l}1.3 \text { personal risk factor list } \mathrm{v} \\
\text { general information }\end{array}$ & 0 & 0 & Odds Ratio (M-H, Fixed, 95\% CI) & $0.0[0.0,0.0]$ \\
\hline
\end{tabular}

Comparison 7. personalised risk communication versus general risk information for PROSTATE CANCER SCREENING

\begin{tabular}{lcccc} 
Outcome or subgroup title & $\begin{array}{c}\text { No. of } \\
\text { studies }\end{array}$ & $\begin{array}{c}\text { No. of } \\
\text { participants }\end{array}$ & Statistical method & Effect size \\
\hline $\begin{array}{l}1 \text { uptake of screening test } \\
\quad 1.1 \text { calculated risk score }\end{array}$ & 1 & 413 & Odds Ratio (M-H, Fixed, 95\% CI) & $2.56[1.70,3.84]$ \\
$\quad \begin{array}{l}\text { (numerical) v general } \\
\text { information }\end{array}$ & 0 & 0 & Odds Ratio (M-H, Fixed, 95\% CI) & $0.0[0.0,0.0]$ \\
$\quad \begin{array}{l}1.2 \text { calculated risk score } \\
\text { (categorised) v general }\end{array}$ & 0 & 0 & Odds Ratio (M-H, Fixed, 95\% CI) & $0.0[0.0,0.0]$ \\
$\quad \begin{array}{l}\text { information } \\
\quad 1.3 \text { personal risk factor list v }\end{array}$ & 1 & 413 & Odds Ratio (M-H, Fixed, 95\% CI) & $2.56[1.70,3.84]$ \\
$\quad$ general information & & & & \\
\hline
\end{tabular}


Analysis I.I. Comparison I personalised risk communication versus general risk information, Outcome I knowledge regarding screening test / condition concerned.

Review: Personalised risk communication for informed decision making about taking screening tests

Comparison: I personalised risk communication versus general risk information

Outcome: I knowledge regarding screening test / condition concerned

Study or subgroup personalised risk $\quad$ general risk info Mean Difference Weight

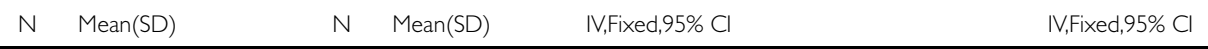

I calculated risk score (numerical) $\vee$ general information

Subtotal (95\% CI)

$\mathbf{0}$

$\mathbf{0}$

Heterogeneity: not applicable

Test for overall effect: not applicable

2 calculated risk score (categorised) $\vee$ general information
Skinner 2002
$130 \quad 78(21)$

130

130

130

Subtotal (95\% CI)

Heterogeneity: not applicable

Test for overall effect: $Z=4.61$ ( $P<0.0000$ I)

3 personal risk factor list $v$ general information
Lerman 1997
$1287.74(2.16)$
180
$5.39(2.39)$

128

180

Subtotal (95\% CI)

Heterogeneity: not applicable

Test for overall effect: $Z=9.00(P<0.0000$ I $)$

Total (95\% CI)

258

Heterogeneity: Chi $^{2}=13.59, \mathrm{df}=1(\mathrm{P}=0.00023) ;\left.\right|^{2}=93 \%$

Test for overall effect: $Z=9.4 \mathrm{I}(\mathrm{P}<0.0000 \mathrm{I})$

Test for subgroup differences: $\mathrm{Chi}^{2}=13.59, \mathrm{df}=\mathrm{I}(\mathrm{P}=0.00), \mathrm{I}^{2}=93 \%$

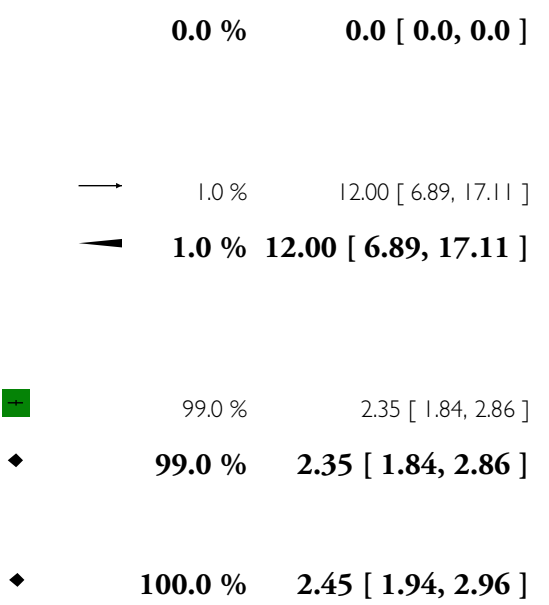

$0.0 \% \quad 0.0[0.0,0.0]$

$0.0 \% \quad 0.0[0.0,0.0]$

$\longrightarrow \quad 1.0 \% \quad 12.00[6.89,17.11]$

$-1.0 \% 12.00[6.89,17.11]$

$99.0 \% \quad 2.35[1.84,2.86]$

$99.0 \% \quad 2.35[1.84,2.86]$

$-\quad 100.0 \% \quad 2.45[1.94,2.96]$

$\bullet$ 
Analysis I.2. Comparison I personalised risk communication versus general risk information, Outcome 2 knowledge regarding screening test / condition concerned.

Review: Personalised risk communication for informed decision making about taking screening tests

Comparison: I personalised risk communication versus general risk information

Outcome: 2 knowledge regarding screening test / condition concerned

\begin{tabular}{|c|c|c|c|c|c|}
\hline \multirow[t]{2}{*}{ Study or subgroup } & personalised risk & general risk info & Odds Ratio & \multirow[t]{2}{*}{ Weight } & \multirow{2}{*}{$\begin{array}{r}\text { Odds Ratio } \\
\text { M-H,Fixed,95\% Cl }\end{array}$} \\
\hline & $\mathrm{n} / \mathrm{N}$ & $\mathrm{n} / \mathrm{N}$ & M-H,Fixed,95\% Cl & & \\
\hline \multicolumn{6}{|c|}{ I calculated risk score (numerical) v general information } \\
\hline Rimer 2002 & $59 / 392$ & $45 / 412$ & & $100.0 \%$ & $1.44[0.95,2.19]$ \\
\hline Subtotal (95\% CI) & 392 & 412 & & $100.0 \%$ & $1.44[0.95,2.19]$ \\
\hline \multicolumn{6}{|c|}{ Total events: 59 (personalised risk), 45 (general risk info) } \\
\hline \multicolumn{6}{|c|}{ Heterogeneity: not applicable } \\
\hline \multicolumn{6}{|c|}{ Test for overall effect: $Z=1.74(P=0.082)$} \\
\hline \multicolumn{6}{|c|}{2 calculated risk score (categorised) $\vee$ general information } \\
\hline Subtotal (95\% CI) & $\mathbf{0}$ & $\mathbf{0}$ & & $0.0 \%$ & $0.0[0.0,0.0]$ \\
\hline \multicolumn{6}{|c|}{ Total events: 0 (personalised risk), 0 (general risk info) } \\
\hline \multicolumn{6}{|l|}{ Heterogeneity: not applicable } \\
\hline \multicolumn{6}{|c|}{ Test for overall effect: not applicable } \\
\hline \multicolumn{6}{|c|}{3 personal risk factor list $v$ general information } \\
\hline Subtotal (95\% CI) & $\mathbf{0}$ & $\mathbf{0}$ & & $0.0 \%$ & $0.0[0.0,0.0]$ \\
\hline \multicolumn{6}{|c|}{ Total events: 0 (personalised risk), 0 (general risk info) } \\
\hline \multicolumn{6}{|c|}{ Heterogeneity: not applicable } \\
\hline \multicolumn{6}{|c|}{ Test for overall effect: not applicable } \\
\hline Total (95\% CI) & 392 & 412 & & $100.0 \%$ & $1.44[0.95,2.19]$ \\
\hline \multicolumn{6}{|c|}{ Total events: 59 (personalised risk), 45 (general risk info) } \\
\hline \multicolumn{6}{|c|}{ Heterogeneity: not applicable } \\
\hline \multicolumn{6}{|c|}{ Test for overall effect: $Z=1.74(P=0.082)$} \\
\hline Test for subgroup differenc & Jot applicable & & & & \\
\hline
\end{tabular}

$\begin{array}{lllllll}0.1 & 0.2 & 0.5 & 1 & 2 & 5 & 10\end{array}$

Favours general Favours personalised 
Analysis I.3. Comparison I personalised risk communication versus general risk information, Outcome 3 perceived risk - perceiving self as appropriate candidate for test.

Review: Personalised risk communication for informed decision making about taking screening tests

Comparison: I personalised risk communication versus general risk information

Outcome: 3 perceived risk - perceiving self as appropriate candidate for test

\begin{tabular}{|c|c|c|c|c|c|}
\hline \multirow[t]{2}{*}{ Study or subgroup } & personalised risk & general risk info & Odds Ratio & \multirow[t]{2}{*}{ Weight } & \multirow{2}{*}{$\begin{array}{r}\text { Odds Ratio } \\
\mathrm{M}-\mathrm{H}, \text { Fixed,95\% Cl }\end{array}$} \\
\hline & $n / N$ & $n / N$ & M-H,Fixed,95\% Cl & & \\
\hline \multicolumn{6}{|c|}{ I calculated risk score (numerical) $\vee$ general information } \\
\hline Bowen 2002 & $72 / 105$ & $84 / 109$ & & $100.0 \%$ & $0.65[0.35,1.19]$ \\
\hline Subtotal (95\% CI) & 105 & 109 & & $100.0 \%$ & $0.65[0.35,1.19]$ \\
\hline \multicolumn{6}{|c|}{ Total events: 72 (personalised risk), 84 (general risk info) } \\
\hline \multicolumn{6}{|c|}{ Heterogeneity: not applicable } \\
\hline \multicolumn{6}{|c|}{ Test for overall effect: $Z=1.39(P=0.16)$} \\
\hline \multicolumn{6}{|c|}{2 calculated risk score (categorised) $\vee$ general information } \\
\hline Subtotal (95\% CI) & $\mathbf{0}$ & $\mathbf{0}$ & & $0.0 \%$ & $0.0[0.0,0.0]$ \\
\hline \multicolumn{6}{|c|}{ Total events: 0 (personalised risk), 0 (general risk info) } \\
\hline \multicolumn{6}{|c|}{ Heterogeneity: not applicable } \\
\hline \multicolumn{6}{|c|}{ Test for overall effect: not applicable } \\
\hline \multicolumn{6}{|c|}{3 personal risk factor list $v$ general information } \\
\hline Subtotal (95\% CI) & $\mathbf{0}$ & $\mathbf{0}$ & & $0.0 \%$ & $0.0[0.0,0.0]$ \\
\hline \multicolumn{6}{|c|}{ Total events: 0 (personalised risk), 0 (general risk info) } \\
\hline \multicolumn{6}{|c|}{ Heterogeneity: not applicable } \\
\hline \multicolumn{6}{|c|}{ Test for overall effect: not applicable } \\
\hline Total (95\% CI) & 105 & 109 & & $100.0 \%$ & $0.65[0.35,1.19]$ \\
\hline \multicolumn{6}{|c|}{ Total events: 72 (personalised risk), 84 (general risk info) } \\
\hline \multicolumn{6}{|c|}{ Heterogeneity: not applicable } \\
\hline \multicolumn{6}{|c|}{ Test for overall effect: $Z=1.39(P=0.16)$} \\
\hline Test for subgroup differenc & lot applicable & & & & \\
\hline
\end{tabular}

$\begin{array}{lllllll}0.1 & 0.2 & 0.5 & 1 & 2 & 5 & 10\end{array}$

Lower with personal Lower with general 
Analysis I.4. Comparison I personalised risk communication versus general risk information, Outcome 4 accurately perceived risk.

Review: Personalised risk communication for informed decision making about taking screening tests

Comparison: I personalised risk communication versus general risk information

Outcome: 4 accurately perceived risk

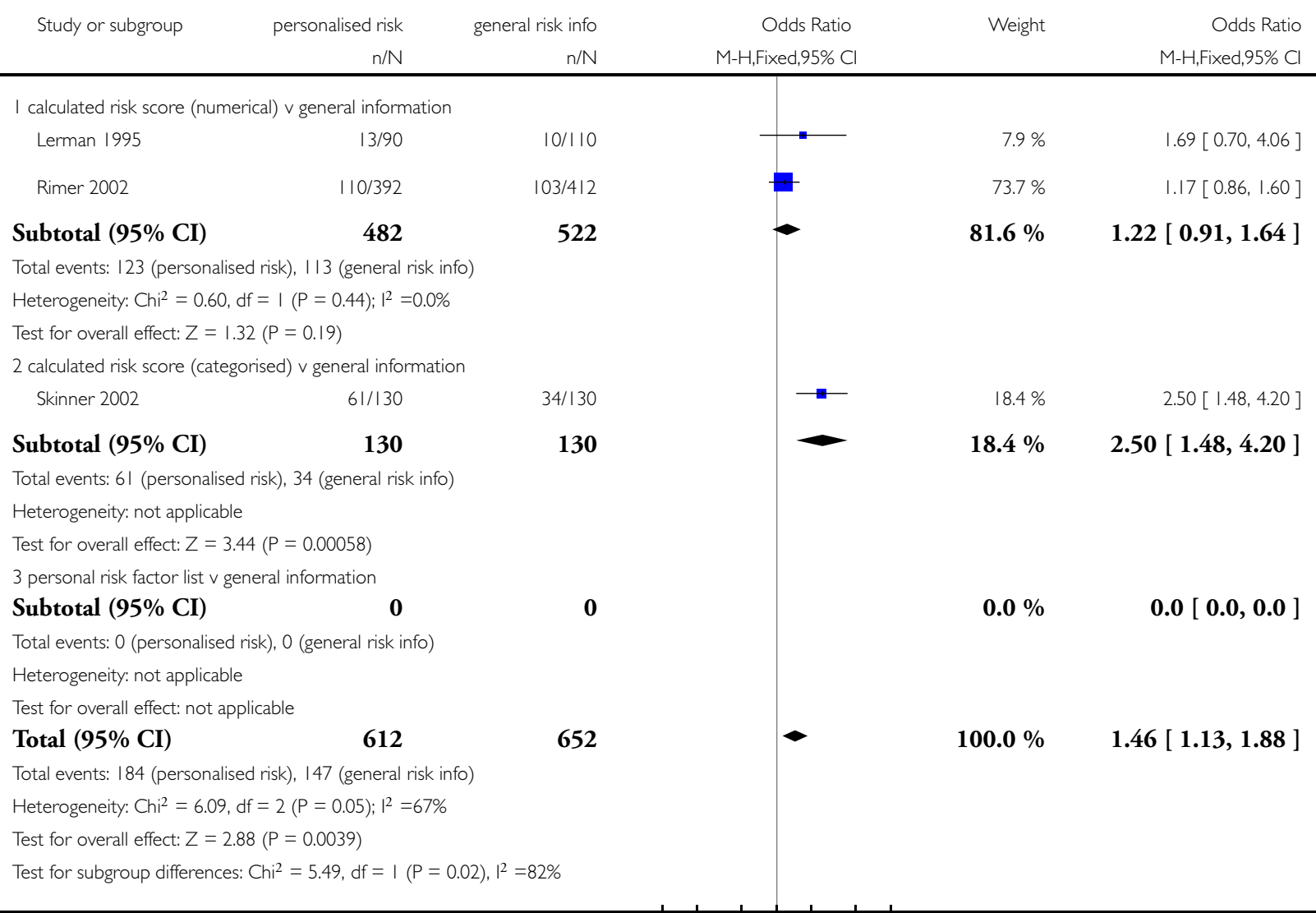

$\begin{array}{lllllll}0.1 & 0.2 & 0.5 & 1 & 2 & 5 & 10\end{array}$

Favours general Favours personalised 
Analysis I.5. Comparison I personalised risk communication versus general risk information, Outcome 5 anxiety (Cancer related anxiety and helplessness scale; IES breast cancer distress).

Review: Personalised risk communication for informed decision making about taking screening tests

Comparison: I personalised risk communication versus general risk information

Outcome: 5 anxiety (Cancer related anxiety and helplessness scale; IES breast cancer distress)

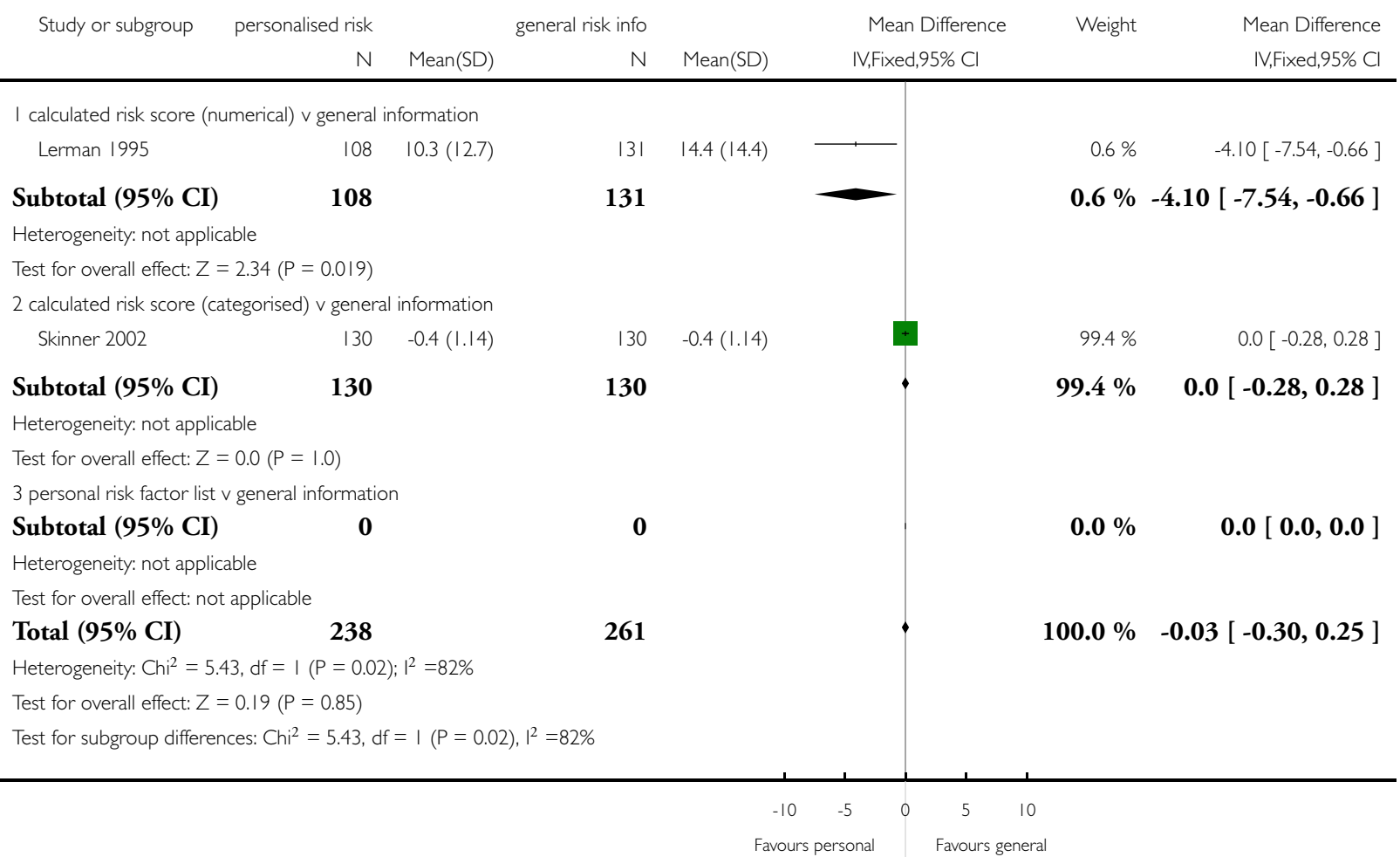


Analysis I.8. Comparison I personalised risk communication versus general risk information, Outcome 8 intention to take screening test.

Review: Personalised risk communication for informed decision making about taking screening tests

Comparison: I personalised risk communication versus general risk information

Outcome: 8 intention to take screening test

\begin{tabular}{|c|c|c|c|c|c|}
\hline \multirow[t]{2}{*}{ Study or subgroup } & personalised risk & general risk info & Odds Ratio & \multirow[t]{2}{*}{ Weight } & \multirow{2}{*}{$\begin{array}{r}\text { Odds Ratio } \\
\text { M-H,Fixed,95\% Cl }\end{array}$} \\
\hline & $n / N$ & $n / N$ & M-H,Fixed,95\% Cl & & \\
\hline \multicolumn{6}{|c|}{ I calculated risk score (numerical) $\vee$ general information } \\
\hline Bowen 2002 & $37 / 105$ & $36 / 109$ & & $9.3 \%$ & $1.10[0.63,1.94]$ \\
\hline Subtotal (95\% CI) & 105 & 109 & & $9.3 \%$ & $1.10[0.63,1.94]$ \\
\hline \multicolumn{6}{|c|}{ Total events: 37 (personalised risk), 36 (general risk info) } \\
\hline \multicolumn{6}{|c|}{ Heterogeneity: not applicable } \\
\hline \multicolumn{6}{|c|}{ Test for overall effect: $Z=0.34(P=0.73)$} \\
\hline \multicolumn{6}{|c|}{2 calculated risk score (categorised) $\vee$ general information } \\
\hline Lee 199| & $87 / 139$ & $50 / 139$ & $\longrightarrow$ & $7.6 \%$ & $2.98[1.83,4.85]$ \\
\hline Skinner 2002 & $113 / 130$ & $126 / 130$ & $\longleftrightarrow$ & $6.7 \%$ & $0.21[0.07,0.65]$ \\
\hline Subtotal (95\% CI) & 269 & 269 & $\longrightarrow$ & $14.3 \%$ & $1.68[1.12,2.53]$ \\
\hline \multicolumn{6}{|c|}{ Total events: 200 (personalised risk), 176 (general risk info) } \\
\hline \multicolumn{6}{|c|}{ Heterogeneity: Chi $^{2}=18.50, d f=|(P=0.00002) ;|^{2}=95 \%$} \\
\hline \multicolumn{6}{|c|}{ Test for overall effect: $Z=2.50(P=0.013)$} \\
\hline \multicolumn{6}{|c|}{3 personal risk factor list $v$ general information } \\
\hline Jibaja-Weiss 2003 & $208 / 524$ & $245 / 460$ & 7 & $63.8 \%$ & $0.58[0.45,0.74]$ \\
\hline Lerman 1997 & $66 / 116$ & $87 / 164$ & $\rightarrow-$ & $12.6 \%$ & $1.17[0.72,1.89]$ \\
\hline Subtotal (95\% CI) & 640 & 624 & $\bullet$ & $76.4 \%$ & $0.68[0.54,0.84]$ \\
\hline \multicolumn{6}{|c|}{ Total events: 274 (personalised risk), 332 (general risk info) } \\
\hline \multicolumn{6}{|c|}{ Heterogeneity: $\mathrm{Chi}^{2}=6.50, \mathrm{df}=\mathrm{I}(\mathrm{P}=0.0 \mathrm{I}) ; \mathrm{I}^{2}=85 \%$} \\
\hline \multicolumn{6}{|c|}{ Test for overall effect: $Z=3.46(P=0.00054)$} \\
\hline Total $(95 \%$ CI $)$ & 1014 & 1002 & $\bullet$ & $100.0 \%$ & $0.86[0.71,1.03]$ \\
\hline \multicolumn{6}{|c|}{ Total events: 51 I (personalised risk), 544 (general risk info) } \\
\hline \multicolumn{6}{|c|}{ Heterogeneity: $\mathrm{Chi}^{2}=42.77, \mathrm{df}=4(\mathrm{P}<0.0000 \mathrm{I}) ; \mathrm{I}^{2}=91 \%$} \\
\hline \multicolumn{6}{|c|}{ Test for overall effect: $Z=1.63(P=0.10)$} \\
\hline Test for subgroup differenc & $h i^{2}=15.67, d f=2$ & $0), I^{2}=87 \%$ & & & \\
\hline
\end{tabular}

$\begin{array}{lllllll}0.1 & 0.2 & 0.5 & 1 & 2 & 5 & 10\end{array}$

Favours general Favours personal 
Analysis I.9. Comparison I personalised risk communication versus general risk information, Outcome 9 uptake of screening test.

Review: Personalised risk communication for informed decision making about taking screening tests

Comparison: I personalised risk communication versus general risk information

Outcome: 9 uptake of screening test

\begin{tabular}{|c|c|c|c|c|c|}
\hline \multirow[t]{2}{*}{ Study or subgroup } & personalised risk & general risk info & \multirow{2}{*}{$\begin{array}{c}\text { Odds Ratio } \\
\text { M-H,Fixed,95\% Cl }\end{array}$} & \multirow[t]{2}{*}{ Weight } & \multirow{2}{*}{$\begin{array}{r}\text { Odds Ratio } \\
\mathrm{M}-\mathrm{H}, \text { Fixed,95\% Cl }\end{array}$} \\
\hline & $n / N$ & $n / N$ & & & \\
\hline \multicolumn{6}{|c|}{ I calculated risk score (numerical) v general information } \\
\hline Rimer 2002 & 204/392 & $231 / 412$ & - & $14.2 \%$ & $0.85[0.64,1.12]$ \\
\hline Schwartz 1999 & $148 / 2 \mid 5$ & $161 / 215$ & $\rightarrow$ & $6.6 \%$ & $0.74[0.49,1.13]$ \\
\hline Subtotal (95\% CI) & 607 & 627 & - & $20.8 \%$ & $0.82[0.65,1.03]$ \\
\hline \multicolumn{6}{|c|}{ Total events: 352 (personalised risk), 392 (general risk info) } \\
\hline \multicolumn{6}{|c|}{ Heterogeneity: $\mathrm{Ch}^{2}=0.29, \mathrm{df}=\mathrm{I}(\mathrm{P}=0.59) ; \mathrm{I}^{2}=0.0 \%$} \\
\hline \multicolumn{6}{|c|}{ Test for overall effect: $Z=1.72(P=0.085)$} \\
\hline \multicolumn{6}{|c|}{2 calculated risk score (categorised) $v$ general information } \\
\hline Bastani 1999 & $249 / 382$ & $2|4 / 37|$ & $\rightarrow$ & $9.9 \%$ & $1.37[1.02,1.84]$ \\
\hline Lee |99| & $12 / 139$ & $6 / 139$ & & $0.7 \%$ & $2.09[0.76,5.75]$ \\
\hline Subtotal (95\% CI) & 521 & 510 & $<$ & $10.7 \%$ & $1.42[1.07,1.89]$ \\
\hline \multicolumn{6}{|c|}{ Total events: 26I (personalised risk), 220 (general risk info) } \\
\hline \multicolumn{6}{|c|}{ Heterogeneity: $\mathrm{Chi}^{2}=0.62, \mathrm{df}=\mathrm{I}(\mathrm{P}=0.43) ; \mathrm{I}^{2}=0.0 \%$} \\
\hline \multicolumn{6}{|c|}{ Test for overall effect: $Z=2.45(P=0.014)$} \\
\hline \multicolumn{6}{|c|}{3 personal risk factor list $v$ general information } \\
\hline Campbell 1997 & $52 / 148$ & $33 / 124$ & & $3.1 \%$ & $1.49[0.89,2.52]$ \\
\hline Champion 1994 & $117 / 147$ & $103 / 153$ & & $2.7 \%$ & $1.89[1.12,3.20]$ \\
\hline Champion 1995 & $|46 / 19|$ & $142 / 2 \mid 4$ & 1, & $4.1 \%$ & $1.65[1.06,2.55]$ \\
\hline Champion 2000a & $105 / 139$ & $99 / 139$ & + & $3.2 \%$ & $1.25[0.73,2.13]$ \\
\hline Champion 2003 & | | |/242 & $34 / 134$ & $\longrightarrow$ & $3.1 \%$ & $2.49[1.57,3.96]$ \\
\hline Curry 1993 & $162 / 413$ & $161 / 428$ & - & $12.6 \%$ & $1.07[0.81,1.41]$ \\
\hline Jibaja-Weiss 2003 & $124 / 524$ & $202 / 460$ & - & $21.6 \%$ & $0.40[0.30,0.52]$ \\
\hline Myers 1999 & $98 / 192$ & $64 / 221$ & $\longrightarrow$ & $3.8 \%$ & $2.56[1.70,3.84]$ \\
\hline Saywell 1999 & $69 / 237$ & $20 / 110$ & $\longrightarrow$ & $2.5 \%$ & $1.85[1.06,3.23]$ \\
\hline Lipkus 2005 & $270 / 432$ & $238 / 428$ & 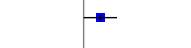 & $11.8 \%$ & $1.33[1.01,1.75]$ \\
\hline Subtotal (95\% CI) & 2665 & 2411 & $\bullet$ & $68.6 \%$ & $1.17[1.04,1.32]$ \\
\hline \multicolumn{6}{|c|}{ Total events: 1254 (personalised risk), 1096 (general risk info) } \\
\hline \multicolumn{6}{|c|}{ Heterogeneity: $\mathrm{Chi}^{2}=95.28, \mathrm{df}=9(\mathrm{P}<0.0000 \mathrm{I}) ; \mathrm{I}^{2}=91 \%$} \\
\hline Test for overall effect: $Z=$ & $(P=0.0072)$ & & & & \\
\hline
\end{tabular}

$\begin{array}{lllllll}0.1 & 0.2 & 0.5 & 1 & 2 & 5 & 10\end{array}$

favours general favours personal

(Continued...) 


\begin{tabular}{|c|c|c|c|c|c|}
\hline \multirow[t]{2}{*}{ Study or subgroup } & personalised risk & general risk info & Odds Ratio & Weight & $\begin{array}{c}\text { (... Continued) } \\
\text { Odds Ratio }\end{array}$ \\
\hline & $\mathrm{n} / \mathrm{N}$ & $n / \mathrm{N}$ & M-H,Fixed,95\% Cl & & M-H,Fixed,95\% Cl \\
\hline Total $(95 \% \mathrm{CI})$ & 3793 & 3548 & $\bullet$ & $100.0 \%$ & $1.13[1.02,1.24]$ \\
\hline \multicolumn{6}{|c|}{ Total events: 1867 (personalised risk), I 708 (general risk info) } \\
\hline \multicolumn{6}{|c|}{ Heterogeneity: Chi $^{2}=106.70, d f=13(P<0.00001) ;\left.\right|^{2}=88 \%$} \\
\hline \multicolumn{6}{|c|}{ Test for overall effect: $Z=2.38(P=0.017)$} \\
\hline \multicolumn{6}{|c|}{ Test for subgroup differences: $\mathrm{Chi}^{2}=10.55, \mathrm{df}=2(\mathrm{P}=0.0 \mathrm{I}), \mathrm{I}^{2}=8 \mathrm{I} \%$} \\
\hline
\end{tabular}

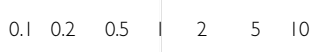

favours general favours personal

Analysis I.I0. Comparison I personalised risk communication versus general risk information, Outcome 10 appropriate use of cholesterol test.

Review: Personalised risk communication for informed decision making about taking screening tests

Comparison: I personalised risk communication versus general risk information

Outcome: 10 appropriate use of cholesterol test

Study or subgroup $\quad$ personalised risk $\quad$ general risk info Odds Ratio $\quad$ Weight

$\mathrm{n} / \mathrm{N} \quad \mathrm{n} / \mathrm{N} \quad \mathrm{M}-\mathrm{H}$, Fixed,95\% Cl M-H,Fixed,95\% Cl

I calculated risk score (numerical) $v$ general information

Subtotal (95\% CI)

0

$\mathbf{0}$

$0.0 \%$

$0.0[0.0,0.0]$

Total events: 0 (personalised risk), 0 (general risk info)

Heterogeneity: not applicable

Test for overall effect: not applicable

2 calculated risk score (categorised) $\vee$ general information

Subtotal (95\% CI)

$\mathbf{0}$

$\mathbf{0}$

$0.0 \%$

$0.0[0.0,0.0]$

Total events: 0 (personalised risk), 0 (general risk info)

Heterogeneity: not applicable

Test for overall effect: not applicable

3 personal risk factor list $v$ general information

Hutchison $1998 \quad$ I|43/1549 1090/1603

$1549 \quad 1603$

Subtotal (95\% CI)
Total events: I I 43 (personalised risk), I 090 (general risk info)

Heterogeneity: not applicable

Test for overall effect: $Z=3.57(P=0.00035)$

Total (95\% CI)

1549

1603

Total events: I I 43 (personalised risk), 1090 (general risk info)

Heterogeneity: not applicable

Test for overall effect: $Z=3.57(P=0.00035)$

Test for subgroup differences: Not applicable 
Analysis I.I I. Comparison I personalised risk communication versus general risk information, Outcome I I smoking.

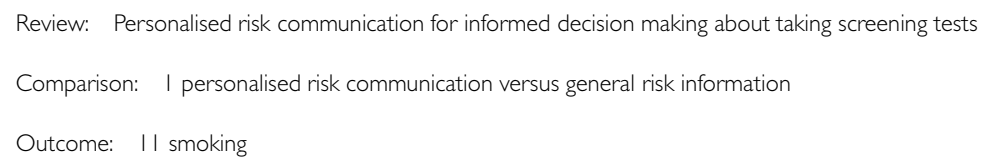

I calculated risk score (numerical) $\vee$ general information

Kreuter 1996

$61 / 102$

$60 / 102$

$100.0 \%$

$1.04[0.60,1.82]$

Subtotal (95\% CI)

102

102



Total events: 6I (personalised risk), 60 (prior levels)

Heterogeneity: not applicable

Test for overall effect: $Z=0.14(P=0.89)$

2 calculated risk score (categorised) $\vee$ general information

Subtotal (95\% CI)

$\mathbf{0}$

Total events: 0 (personalised risk), 0 (prior levels)

Heterogeneity: not applicable

Test for overall effect: not applicable

3 personal risk factor list $v$ general information

Subtotal (95\% CI)

0

Total events: 0 (personalised risk), 0 (prior levels)

Heterogeneity: not applicable

Test for overall effect: not applicable

Total (95\% CI)

102

102

Total events: 61 (personalised risk), 60 (prior levels)

Heterogeneity: not applicable

Test for overall effect: $Z=0.14(P=0.89)$

Test for subgroup differences: Not applicable

$\mathbf{0}$

$0.0 \%$

$0.0[0.0,0.0]$

$100.0 \% \quad 1.04[0.60,1.82$ ]

$0.0 \%$

$\mathbf{0 . 0}[0.0,0.0]$

$\mathbf{0}$

$100.0 \%$ $1.04[0.60,1.82]$

Analysis I.12. Comparison I personalised risk communication versus general risk information, Outcome 12 stages of change.

stages of change

Study

personal risk factor list $\mathrm{v}$ general information

Personalised risk communication for informed decision making about taking screening tests (Review)

Copyright (C) 20II The Cochrane Collaboration. Published by John Wiley \& Sons, Ltd. 
stages of change (Continued)

Skinner 1994 71\% did not change; 14\% advanced one stage; 12\% 'regressed': no significant differences between tailored message and control

Analysis I.13. Comparison I personalised risk communication versus general risk information, Outcome 13 improvement in risk comprehension/perception.

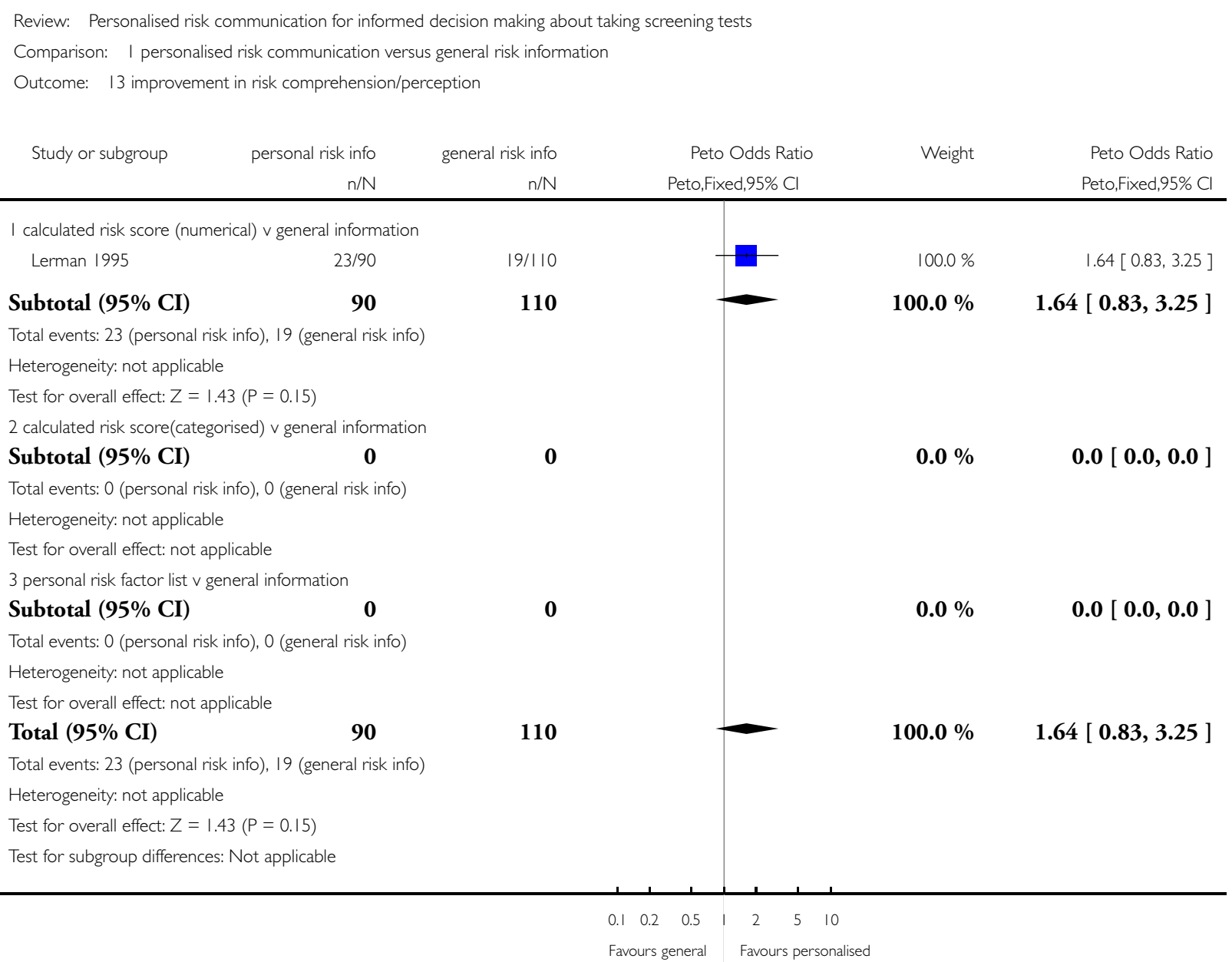


Analysis I.I4. Comparison I personalised risk communication versus general risk information, Outcome 14 making a recommended behaviour change.

Review: Personalised risk communication for informed decision making about taking screening tests

Comparison: I personalised risk communication versus general risk information

Outcome: 14 making a recommended behaviour change

$\begin{array}{llll}\text { Study or subgroup } & \text { personalised risk } & \text { general risk info } & \text { Odds Ratio }\end{array}$

$\mathrm{n} / \mathrm{N} \quad \mathrm{n} / \mathrm{N} \quad \mathrm{M}-\mathrm{H}$, Fixed,95\% Cl M-H,Fixed,95\% Cl

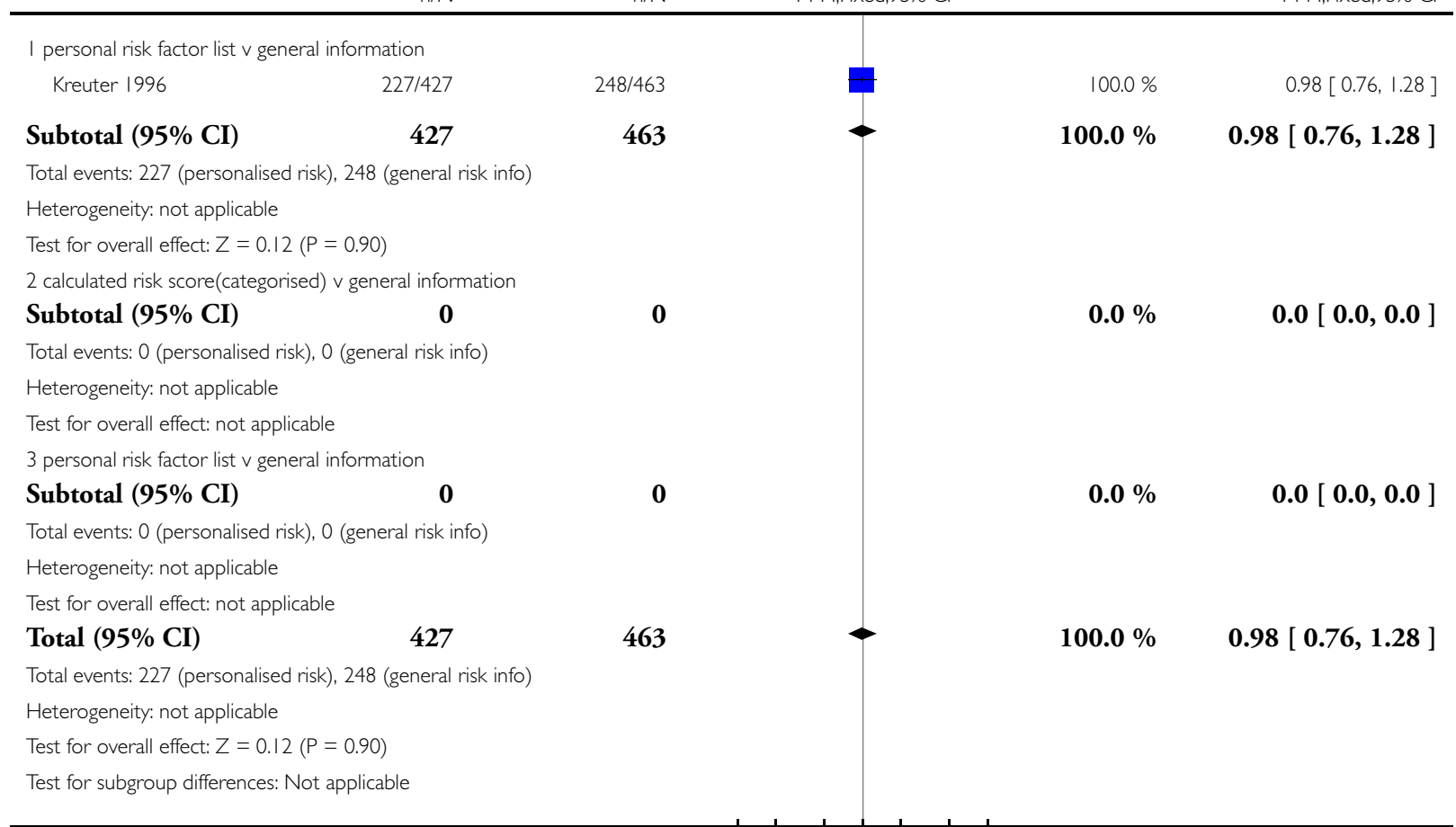

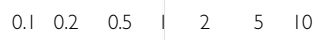

Favours general Favours personalised 
Analysis 2.I. Comparison 2 personalised risk communication versus general risk information for PAP SMEARS, Outcome I intention to take screening test.

Review: Personalised risk communication for informed decision making about taking screening tests

Comparison: 2 personalised risk communication versus general risk information for PAP SMEARS

Outcome: I intention to take screening test

Study or subgroup personalised risk $n / N$
Odds Ratio M-H,Fixed,95\% Cl
Weight $n / N$

$\mathbf{0}$

Subtotal (95\% CI)

0

Total events: 0 (personalised risk), 0 (general risk info)

Heterogeneity: not applicable

Test for overall effect: not applicable

2 calculated risk score (categorised) $\vee$ general information

Subtotal (95\% CI)

$$
\mathbf{0}
$$

Total events: 0 (personalised risk), 0 (general risk info)

Heterogeneity: not applicable

Test for overall effect: not applicable

3 personal risk factor list $v$ general information

$$
\text { Jibaja-Weiss } 2003 \quad \text { 208/524 }
$$

524

Subtotal (95\% CI)

Total events: 208 (personalised risk), 245 (general risk info)

Heterogeneity: not applicable

Test for overall effect: $Z=4.25(P=0.000022)$

Total (95\% CI)

524

Total events: 208 (personalised risk), 245 (general risk info)

Heterogeneity: not applicable

Test for overall effect: $Z=4.25$ ( $P=0.000022)$

Test for subgroup differences: Not applicable $\mathbf{0}$

$245 / 460$

460

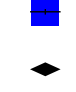

460
$0.0 \%$

$0.0[0.0,0.0]$

$0.0[0.0,0.0]$

$100.0 \%$

$0.58[0.45,0.74]$

$100.0 \%$

$0.58[0.45,0.74]$ 
Analysis 2.2. Comparison 2 personalised risk communication versus general risk information for PAP SMEARS, Outcome 2 uptake of screening test.

Review: Personalised risk communication for informed decision making about taking screening tests

Comparison: 2 personalised risk communication versus general risk information for PAP SMEARS

Outcome: 2 uptake of screening test

Study or subgroup personalised risk

I calculated risk score (numerical) $\vee$ general information

Kreuter 1996

162

Subtotal (95\% CI)

Heterogeneity: not applicable

Test for overall effect: $Z=0.88(P=0.38)$

2 calculated risk score (categorised) $\vee$ general information

Subtotal (95\% CI)

0

general risk info

Odds Ratio M-H,Fixed,95\% Cl

$n / N$

Total events: 0 (personalised risk), 0 (general risk info)

Heterogeneity: not applicable

Test for overall effect: not applicable

3 personal risk factor list $v$ general information

$\begin{array}{lr}\text { Campbell } 1997 & \text { 52/148 } \\ \text { Jibaja-Weiss } 2003 & \text { 124/524 }\end{array}$

Subtotal (95\% CI)

672

Total events: 176 (personalised risk), 235 (general risk info)

Heterogeneity: $\mathrm{Chi}^{2}=19.52, \mathrm{df}=\mid(\mathrm{P}<0.0000 \mathrm{I}) ; \mathrm{I}^{2}=95 \%$

Test for overall effect: $Z=5.22(P<0.0000 \mathrm{I})$

Total (95\% CI)

834

Total events: 222 (personalised risk), 267 (general risk info)

Heterogeneity: $\mathrm{Chi}^{2}=28.37, \mathrm{df}=2(\mathrm{P}<0.0000 \mathrm{I}) ; \mathrm{I}^{2}=93 \%$

Test for overall effect: $Z=4.40(P=0.0000 \mathrm{I} \mathrm{I})$

Test for subgroup differences: $\mathrm{Chi}^{2}=8.69, \mathrm{df}=\mathrm{I}(\mathrm{P}=0.00), \mathrm{I}^{2}=88 \%$
Total events: 46 (personalised risk), 32 (general risk info)

\begin{tabular}{|c|c|c|}
\hline $32 / 134$ & $\mp$ & $1.26[0.75,2.13]$ \\
\hline 134 & $11.8 \%$ & $1.26[0.75,2.13]$ \\
\hline $\mathbf{0}$ & $0.0 \%$ & $0.0[0.0,0.0]$ \\
\hline $33 / 124$ & $11.0 \%$ & $1.49[0.89,2.52]$ \\
\hline $202 / 460$ & $77.2 \%$ & $0.40[0.30,0.52]$ \\
\hline 584 & $88.2 \%$ & $0.53[0.42,0.67]$ \\
\hline 718 & $100.0 \%$ & $0.62[0.50,0.77]$ \\
\hline
\end{tabular}



favours general favours personal

Personalised risk communication for informed decision making about taking screening tests (Review) 
Analysis 3.2. Comparison 3 personalised risk communication versus general risk information for MAMMOGRAPHY, Outcome 2 knowledge regarding screening test / condition concerned.

Review: Personalised risk communication for informed decision making about taking screening tests

Comparison: 3 personalised risk communication versus general risk information for MAMMOGRAPHY

Outcome: 2 knowledge regarding screening test / condition concerned

Study or subgroup $\quad$ personalised risk $\quad$ general risk info $\quad$ Odds Ratio $\quad$ Weight

$$
\mathrm{n} / \mathrm{N}
$$
M-H,Fixed,95\% Cl

I calculated risk score (numerical) $\vee$ general information

$$
\text { Rimer } 2002
$$

$45 / 412$

$100.0 \%$

$1.44[0.95,2.19]$

Subtotal (95\% CI)

392

412

$+$

Total events: 59 (personalised risk), 45 (general risk info)

Heterogeneity: not applicable

Test for overall effect: $Z=1.74(P=0.082)$

2 calculated risk score (categorised) $v$ general information

Subtotal (95\% CI)

$\mathbf{0}$

$\mathbf{0}$

Total events: 0 (personalised risk), 0 (general risk info)

Heterogeneity: not applicable

Test for overall effect: not applicable

3 personal risk factor list $v$ general information

Subtotal $(95 \% \mathrm{CI})$

0

Total events: 0 (personalised risk), 0 (general risk info)

Heterogeneity: not applicable

Test for overall effect: not applicable

Total (95\% CI)

392

Total events: 59 (personalised risk), 45 (general risk info)

412

$\mathbf{0}$

$100.0 \%$

$1.44[0.95,2.19]$

Heterogeneity: not applicable

Test for overall effect: $Z=1.74(P=0.082)$

Test for subgroup differences: Not applicable 
Analysis 3.3. Comparison 3 personalised risk communication versus general risk information for MAMMOGRAPHY, Outcome 3 accuracy of perceived risk.

Review: Personalised risk communication for informed decision making about taking screening tests

Comparison: 3 personalised risk communication versus general risk information for MAMMOGRAPHY

Outcome: 3 accuracy of perceived risk

Study or subgroup_ persoanlised risk

$\mathrm{n} / \mathrm{N}$ general risk info

$\mathrm{n} / \mathrm{N}$

Odds Ratio M-H,Fixed,95\% Cl

I calculated risk score (numerical) $\vee$ general information

Rimer 2002

$110 / 392$

392

Subtotal (95\% CI)

Total events: I 10 (persoanlised risk), 103 (general risk info)

Heterogeneity: not applicable

Test for overall effect: $Z=0.98(P=0.33)$

2 calculated risk score (categorised) $\vee$ general information Subtotal (95\% CI)

Total events: 0 (persoanlised risk), 0 (general risk info)

Heterogeneity: not applicable

Test for overall effect: not applicable

3 personal risk factor list $v$ general information

Subtotal (95\% CI)

0

Total events: 0 (persoanlised risk), 0 (general risk info)

Heterogeneity: not applicable

Test for overall effect: not applicable

Total (95\% CI)

392

Total events: I I0 (persoanlised risk), I03 (general risk info)

Heterogeneity: not applicable

Test for overall effect: $Z=0.98(P=0.33)$

Test for subgroup differences: Not applicable
412

0

0

412

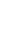

$0.0[0.0,0.0]$

$1.17[0.86,1.60]$

$0.0 \%$

$0.0[0.0,0.0]$

$100.0 \%$

$1.17[0.86,1.60]$

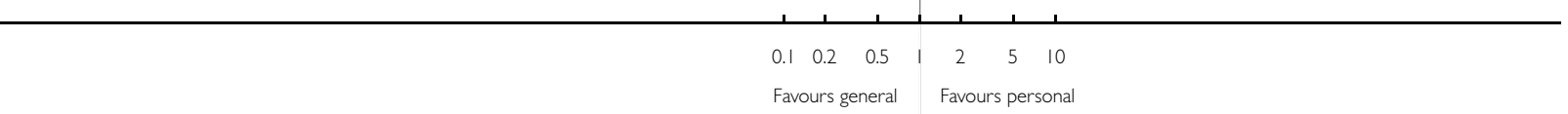




\section{Analysis 3.7. Comparison 3 personalised risk communication versus general risk information for MAMMOGRAPHY, Outcome 7 intention to take screening test.}

Review: Personalised risk communication for informed decision making about taking screening tests

Comparison: 3 personalised risk communication versus general risk information for MAMMOGRAPHY

Outcome: 7 intention to take screening test

I calculated risk score (numerical) $\vee$ general information

Subtotal (95\% CI)

Total events: 0 (personalised risk), 0 (general risk info)

Heterogeneity: not applicable

Test for overall effect: not applicable

2 calculated risk score (categorised) $\vee$ general information

Subtotal (95\% CI)

$$
\mathbf{0}
$$

$\mathbf{0}$

Total events: 0 (personalised risk), 0 (general risk info)

Heterogeneity: not applicable

Test for overall effect: not applicable

3 personal risk factor list $v$ general information

$$
\text { Jibaja-Weiss } 2003 \quad \text { 120/239 }
$$

Subtotal $(95 \% \mathrm{CI})$

general risk info)

Total events: 120 (personalised

Heterogeneity: not applicable

Test for overall effect: $Z=3.41(P=0.00064)$

Total (95\% CI)

Total events: 120 (personalised risk), I57 (general risk info)

Heterogeneity: not applicable

Test for overall effect: $Z=3.41$ ( $P=0.00064)$

Test for subgroup differences: Not applicable
157/239

239



$100.0 \%$

$0.53[0.36,0.76]$

$100.0 \%$

$0.53[0.36,0.76]$

239


$100.0 \%$
$0.0 \%$

$0.0[0.0,0.0]$ 
Analysis 3.8. Comparison 3 personalised risk communication versus general risk information for MAMMOGRAPHY, Outcome 8 uptake of screening test.

Review: Personalised risk communication for informed decision making about taking screening tests

Comparison: 3 personalised risk communication versus general risk information for MAMMOGRAPHY

Outcome: 8 uptake of screening test

Study or subgroup personalised risk $\mathrm{n} / \mathrm{N}$ general risk info

$\mathrm{n} / \mathrm{N}$
Odds Ratio M-H,Fixed,95\% Cl
Weight

Odds Ratio M-H,Fixed,95\% C

I calculated risk score (numerical) $\vee$ general information

Kreuter 1996

$31 / 102$

Rimer 2002

$204 / 392$

$148 / 215$

727

Subtotal (95\% CI)

Total events: 385 (personalised risk), 423 (general risk info)

Heterogeneity: $\mathrm{Chi}^{2}=0.32, \mathrm{df}=2(\mathrm{P}=0.85) ; \mathrm{I}^{2}=0.0 \%$

Test for overall effect: $Z=1.78(P=0.076)$

2 calculated risk score (categorised) $v$ general information Bastani 1999

$249 / 382$

382

Subtotal (95\% CI)

Total events: 249 (personalised risk), 214 (general risk info)

Heterogeneity: not applicable

Test for overall effect: $Z=2.1$ I $(P=0.035)$

3 personal risk factor list $v$ general information

Champion 1994

1 17/147

Champion 1995

|46/19|

Champion 2000a

$105 / 139$

Champion 2003

| | 1/242

Curry 1993

$162 / 413$

Jibaja-Weiss 2003

$31 / 239$

Saywell 1999

$69 / 237$

1608

Subtotal (95\% CI)

Total events: 74I (personalised risk), 632 (general risk info) Heterogeneity: $\mathrm{Chi}^{2}=45.45, \mathrm{df}=6(\mathrm{P}<0.0000 \mathrm{I}) ; \mathrm{I}^{2}=87 \%$

Test for overall effect: $Z=2.46(P=0.014)$

Total (95\% CI)

2717

Total events: 1375 (personalised risk), 1269 (general risk info)

Heterogeneity: $\mathrm{Chi}^{2}=56.72, \mathrm{df}=10(\mathrm{P}<0.0000 \mathrm{I}) ; \mathrm{I}^{2}=82 \%$

Test for overall effect: $Z=1.70(P=0.089)$

Test for subgroup differences: $\mathrm{Chi}^{2}=10.80, \mathrm{df}=2(\mathrm{P}=0.00), \mathrm{I}^{2}=8 \mathrm{l} \%$
$231 / 412$

$161 / 215$

729

$2|4 / 37|$

1417

2517

$0.85[0.64,1.12]$
$14.1 \%$

$1.37[1.02,1.84]$

$14.1 \%$

$1.37[1.02,1.84]$

$3.8 \%$

$5.9 \%$

$4.5 \%$

$4.4 \%$

$17.9 \%$

$11.8 \%$

$3.6 \%$

$52.0 \%$

$4.5 \%$

$0.87[0.49,1.55]$

$0.74[0.49,1.13]$

$0.82[0.66,1.02]$

$1.89[1.12,3.20]$

$1.65[1.06,2.55]$

$1.25[0.73,2.13]$

$2.49[1.57,3.96]$

$1.07[0.81,1.41]$

$0.34[0.21,0.54]$

$1.85[1.06,3.23]$

$1.22[1.04,1.43]$

$100.0 \%$

$1.11[0.98,1.24]$

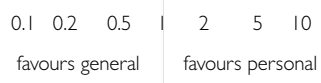


Analysis 3.9. Comparison 3 personalised risk communication versus general risk information for MAMMOGRAPHY, Outcome 9 stages of change.

stages of change

Study

personal risk factor list $\mathrm{v}$ general information

Skinner 1994 71\% did not change; 14\% advanced one stage; 12\% 'regressed': no significant differences between tailored message and control

\section{Analysis 4.I. Comparison 4 personalised risk communication versus general risk information for CHOLESTEROL TESTS, Outcome I uptake of screening test.}

Review: Personalised risk communication for informed decision making about taking screening tests

Comparison: 4 personalised risk communication versus general risk information for CHOLESTEROL TESTS

Outcome: I uptake of screening test

\begin{tabular}{|c|c|c|c|c|c|}
\hline \multirow[t]{2}{*}{ Study or subgroup } & \multirow{2}{*}{$\begin{array}{r}\text { personalised risk } \\
n / N\end{array}$} & \multirow{2}{*}{$\begin{array}{r}\text { general risk info } \\
n / N\end{array}$} & Odds Ratio & \multirow[t]{2}{*}{ Weight } & \multirow{2}{*}{$\begin{array}{r}\text { Odds Ratio } \\
\mathrm{M}-\mathrm{H}, \text { Fixed,95\% Cl}\end{array}$} \\
\hline & & & M-H,Fixed,95\% Cl & & \\
\hline \multicolumn{6}{|c|}{ I calculated risk score (numerical) v general information } \\
\hline Kreuter 1996 & $36 / 132$ & $40 / 144$ & & $100.0 \%$ & $0.98[0.57,1.65]$ \\
\hline Subtotal (95\% CI) & 132 & 144 & & $100.0 \%$ & $0.98[0.57,1.65]$ \\
\hline \multicolumn{6}{|c|}{ Total events: 36 (personalised risk), 40 (general risk info) } \\
\hline \multicolumn{6}{|c|}{ Heterogeneity: not applicable } \\
\hline \multicolumn{6}{|c|}{ Test for overall effect: $Z=0.09(P=0.93)$} \\
\hline \multicolumn{6}{|c|}{2 calculated risk score (categorised) $\vee$ general information } \\
\hline Subtotal (95\% CI) & $\mathbf{0}$ & $\mathbf{0}$ & & $0.0 \%$ & $0.0[0.0,0.0]$ \\
\hline \multicolumn{6}{|c|}{ Total events: 0 (personalised risk), 0 (general risk info) } \\
\hline \multicolumn{6}{|c|}{ Heterogeneity: not applicable } \\
\hline \multicolumn{6}{|c|}{ Test for overall effect: not applicable } \\
\hline \multicolumn{6}{|c|}{3 personal risk factor list $v$ general information } \\
\hline Subtotal (95\% CI) & $\mathbf{0}$ & $\mathbf{0}$ & & $0.0 \%$ & $0.0[0.0,0.0]$ \\
\hline \multicolumn{6}{|c|}{ Total events: 0 (personalised risk), 0 (general risk info) } \\
\hline \multicolumn{6}{|c|}{ Heterogeneity: not applicable } \\
\hline \multicolumn{6}{|c|}{ Test for overall effect: not applicable } \\
\hline Total $(95 \% \mathrm{CI})$ & 132 & 144 & & $100.0 \%$ & $0.98[0.57,1.65]$ \\
\hline \multicolumn{6}{|c|}{ Total events: 36 (personalised risk), 40 (general risk info) } \\
\hline \multicolumn{6}{|c|}{ Heterogeneity: not applicable } \\
\hline \multicolumn{6}{|c|}{ Test for overall effect: $Z=0.09(P=0.93)$} \\
\hline \multicolumn{6}{|c|}{ Test for subgroup differences: Not applicable } \\
\hline
\end{tabular}




\section{Analysis 4.2. Comparison 4 personalised risk communication versus general risk information for CHOLESTEROL TESTS, Outcome 2 appropriate use of cholesterol test.}

Review: Personalised risk communication for informed decision making about taking screening tests

Comparison: 4 personalised risk communication versus general risk information for CHOLESTEROL TESTS

Outcome: 2 appropriate use of cholesterol test

Study or subgroup $\quad$ personalised risk $n / N$ general risk info

$\mathrm{n} / \mathrm{N}$

$\mathbf{0}$

Subtotal (95\% CI)

Total events: 0 (personalised risk), 0 (general risk info)

Heterogeneity: not applicable

Test for overall effect: not applicable

2 calculated risk score (categorised) $\vee$ general information

Subtotal (95\% CI)

$$
\mathbf{0}
$$

Total events: 0 (personalised risk), 0 (general risk info)

Heterogeneity: not applicable

Test for overall effect: not applicable

3 personal risk factor list $v$ general information

$$
\text { Hutchison } 1998
$$

1549

1090/1603

$\mathbf{0}$

Subtotal (95\% CI)

1603

Total events: I I 43 (personalised risk), 1090 (general risk info)

Heterogeneity: not applicable

Test for overall effect: $Z=3.57(P=0.00035)$

Total (95\% CI)

1549

1603

Total events: II43 (personalised risk), 1090 (general risk info)

Heterogeneity: not applicable

Test for overall effect: $Z=3.57(P=0.00035)$

Test for subgroup differences: Not applicable
Odds Ratio M-H,Fixed,95\% C

Weight

Odds Ratio M-H,Fixed,95\% C

|

$0.0 \%$

$0.0[0.0,0.0]$

$0.0[0.0,0.0]$

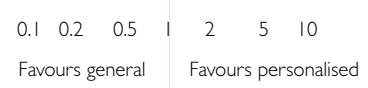

$1.32[1.14,1.55]$

$\checkmark \quad 100.0 \%$

$1.32[1.14,1.55]$

$100.0 \%$

$1.32[1.14,1.55]$ 
Analysis 5.I. Comparison 5 personalised risk communication versus general risk information for 'HIGH RISK' PEOPLE, Outcome I knowledge regarding screening test / condition concerned.

Review: Personalised risk communication for informed decision making about taking screening tests

Comparison: 5 personalised risk communication versus general risk information for 'HIGH RISK' PEOPLE

Outcome: I knowledge regarding screening test / condition concerned

N Mean(SD)

general risk info

Mean Difference Weight Mean Difference

N Mean(SD)

IV,Fixed,95\% Cl

IV,Fixed,95\% Cl

I calculated risk score (numerical) $\vee$ general information

Subtotal (95\% CI)

$\mathbf{0}$

$\mathbf{0}$

Heterogeneity: not applicable

Test for overall effect: not applicable

2 calculated risk score (categorised) $v$ general information

Skinner 2002

$130 \quad 78(21)$

Subtotal (95\% CI)

130

130

$66(21)$

Heterogeneity: not applicable

Test for overall effect: $Z=4.61$ ( $P<0.0000$ I)

3 personal risk factor list $v$ general information

Lerman 1997

$128 \quad 7.74(2.16)$

$180 \quad 5.39(2.39)$

128

180

Subtotal (95\% CI)

Heterogeneity: not applicable

Test for overall effect: $Z=9.00(P<0.0000$ I)

Total (95\% CI)

258

310

(n)

Heterogeneity: $\mathrm{Chi}^{2}=13.59, \mathrm{df}=1(\mathrm{P}=0.00023) ;\left.\right|^{2}=93 \%$

Test for overall effect: $Z=9.41(P<0.0000 I)$

Test for subgroup differences: $\mathrm{Chi}^{2}=13.59, \mathrm{df}=\mathrm{I}(\mathrm{P}=0.00), \mathrm{I}^{2}=93 \%$

$0.0 \% \quad 0.0[0.0,0.0]$

$1.0 \% \quad 12.00[6.89,17.11]$

$-\quad 1.0 \% 12.00[6.89,17.11]$

$99.0 \% \quad 2.35[1.84,2.86]$

$99.0 \% \quad 2.35[1.84,2.86]$

$100.0 \% \quad 2.45[1.94,2.96]$ 
Analysis 5.2. Comparison 5 personalised risk communication versus general risk information for 'HIGH RISK' PEOPLE, Outcome 2 perceived risk - perceiving self as appropriate candidate for test.

Review: Personalised risk communication for informed decision making about taking screening tests

Comparison: 5 personalised risk communication versus general risk information for 'HIGH RISK' PEOPLE

Outcome: 2 perceived risk - perceiving self as appropriate candidate for test

Study or subgroup $\quad$ personalised risk $\quad$ general risk info $\quad$ Odds Ratio $\quad$ Weight $\mathrm{n} / \mathrm{N}$ $\mathrm{n} / \mathrm{N}$ M-H,Fixed,95\% Cl M-H,Fixed,95\% Cl

I calculated risk score (numerical) $\vee$ general information

Bowen 2002

$84 / 109$

$100.0 \%$

$0.65[0.35,1.19]$

Subtotal (95\% CI)

105

109

$100.0 \%$

$0.65[0.35,1.19]$

Total events: 72 (personalised risk), 84 (general risk info)

Heterogeneity: not applicable

Test for overall effect: $Z=1.39(P=0.16)$

2 calculated risk score (categorised) $\vee$ general information

Subtotal (95\% CI)

$\mathbf{0}$

$\mathbf{0}$

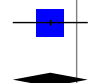

Total events: 0 (personalised risk), 0 (general risk info)

Heterogeneity: not applicable

Test for overall effect: not applicable

3 personal risk factor list $v$ general information

Subtotal (95\% CI)

$\mathbf{0}$

Total events: 0 (personalised risk), 0 (general risk info)

Heterogeneity: not applicable

Test for overall effect: not applicable

Total (95\% CI)

105

Total events: 72 (personalised risk), 84 (general risk info)

Heterogeneity: not applicable

Test for overall effect: $Z=1.39(P=0.16)$

Test for subgroup differences: Not applicable

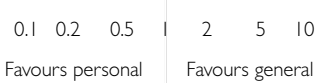


Analysis 5.3. Comparison 5 personalised risk communication versus general risk information for 'HIGH RISK' PEOPLE, Outcome 3 accurately perceived risk.

Review: Personalised risk communication for informed decision making about taking screening tests

Comparison: 5 personalised risk communication versus general risk information for 'HIGH RISK' PEOPLE

Outcome: 3 accurately perceived risk

Study or subgroup personalised risk

$n / N$

I calculated risk score (numerical) $\vee$ general information

Lerman 1995

$13 / 90$

90

Subtotal (95\% CI)

general risk info

Total events: 13 (personalised risk), 10 (general risk info)

Heterogeneity: not applicable

Test for overall effect: $Z=1.17(P=0.24)$

2 calculated risk score (categorised) $\vee$ general information Skinner 2002

$61 / 130$

$34 / 130$

$10 / 110$

Subtotal (95\% CI)

130

Total events: 6 I (personalised risk), 34 (general risk info)

Heterogeneity: not applicable

Test for overall effect: $Z=3.44(P=0.00058)$

3 personal risk factor list $v$ general information

Subtotal (95\% CI)

0

Total events: 0 (personalised risk), 0 (general risk info)

Heterogeneity: not applicable

Test for overall effect: not applicable

Total (95\% CI)

220

Total events: 74 (personalised risk), 44 (general risk info)

Heterogeneity: $\mathrm{Chi}^{2}=0.56, \mathrm{df}=\mathrm{I}(\mathrm{P}=0.45) ; \mathrm{I}^{2}=0.0 \%$

Test for overall effect: $Z=3.56(P=0.00036)$

Test for subgroup differences: $\mathrm{Chi}^{2}=0.56, \mathrm{df}=\mathrm{I}(\mathrm{P}=0.45), \mathrm{I}^{2}=0.0 \%$
Odds Ratio

$n / N$ M-H,Fixed,95\% Cl

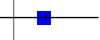

110

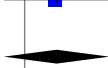

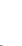

130

Weight Odds Ratio M-H,Fixed,95\% Cl

$29.9 \%$

$1.69[0.70,4.06]$

$29.9 \%$

$1.69[0.70,4.06]$

$70.1 \%$

$2.50[1.48,4.20]$

$70.1 \%$

$2.50[1.48,4.20]$

0

$0.0 \%$

$0.0[0.0,0.0]$

240

$100.0 \%$

$2.25[1.44,3.53]$

$\begin{array}{lllllll}0.1 & 0.2 & 0.5 & \mid & 2 & 5 & 10\end{array}$

Favours general Favours personalised 
Analysis 5.4. Comparison 5 personalised risk communication versus general risk information for 'HIGH RISK' PEOPLE, Outcome 4 anxiety.

Review: Personalised risk communication for informed decision making about taking screening tests

Comparison: 5 personalised risk communication versus general risk information for 'HIGH RISK' PEOPLE

Outcome: 4 anxiety

Study or subgroup personalised risk
N Mean(SD)

I calculated risk score (numerical) $\vee$ general information Lerman 1995

$108 \quad 10.3(12.7)$

Subtotal (95\% CI)

108

Heterogeneity: not applicable

Test for overall effect: $Z=2.34(P=0.019)$

2 calculated risk score (categorised) $\vee$ general information
Skinner 2002
$130-0.4(1.14)$

Subtotal (95\% CI)

130

Heterogeneity: not applicable

Test for overall effect: $Z=0.0(P=1.0)$

3 personal risk factor list $v$ general information

Subtotal (95\% CI)

$\mathbf{0}$

general risk info

Mean(SD)

Mean Difference

IV,Fixed,95\% Cl

Weight

Mean Difference

Heterogeneity: not applicable

Test for overall effect: not applicable

Total (95\% CI)

238

Heterogeneity: Chi $^{2}=5.43, \mathrm{df}=\mathrm{I}(\mathrm{P}=0.02) ; \mathrm{I}^{2}=82 \%$

Test for overall effect: $Z=0.19(P=0.85)$

Test for subgroup differences: $\mathrm{Chi}^{2}=5.43, \mathrm{df}=\mathrm{I}(\mathrm{P}=0.02), \mathrm{I}^{2}=82 \%$
131

$130-0.4(1.14)$

130

$31 \quad$ |4.4(14.4)



261

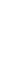

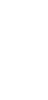

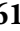

$99.4 \%$

$0.0[-0.28,0.28]$

$99.4 \% \quad 0.0[-0.28,0.28]$

$0.0 \%$

$0.0[0.0,0.0]$

$100.0 \%-0.03[-0.30,0.25]$
$0.6 \%-4.10[-7.54,-0.66]$

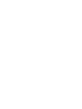


Analysis 5.7. Comparison 5 personalised risk communication versus general risk information for 'HIGH RISK' PEOPLE, Outcome 7 intention to take screening test.

Review: Personalised risk communication for informed decision making about taking screening tests

Comparison: 5 personalised risk communication versus general risk information for 'HIGH RISK' PEOPLE

Outcome: 7 intention to take screening test

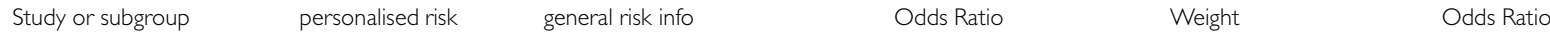

$\mathrm{n} / \mathrm{N} \quad \mathrm{n} / \mathrm{N} \quad \mathrm{M}-\mathrm{H}$, Fixed,95\% Cl
M-H,Fixed,95\% Cl

I calculated risk score (numerical) $v$ general information

Subtotal (95\% CI)

$\mathbf{0}$

$\mathbf{0}$

Total events: 0 (personalised risk), 0 (general risk info)

Heterogeneity: not applicable

Test for overall effect: not applicable

2 calculated risk score (categorised) $\vee$ general information

$$
\text { Skinner } 2002 \quad \text { | |3/130 }
$$

$126 / 130$

$34.7 \%$

$0.21[0.07,0.65]$

Subtotal (95\% CI)

130

$34.7 \%$

$0.21[0.07,0.65]$

Total events: 113 (personalised risk), 126 (general risk info)

Heterogeneity: not applicable

Test for overall effect: $Z=2.73(P=0.0064)$

3 personal risk factor list $v$ general information

$$
\text { Lerman } 1997
$$

116

Subtotal (95\% CI)

Total events: 66 (personalised risk), 87 (general risk info)

Heterogeneity: not applicable

Test for overall effect: $Z=0.64(P=0.52)$

Total (95\% CI)

246

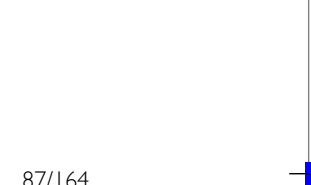

Total events: 179 (personalised risk), 213 (general risk info)

$87 / 164$

Heterogeneity: $\mathrm{Chi}^{2}=7.70, \mathrm{df}=\mathrm{I}(\mathrm{P}=0.0 \mathrm{I}) ; \mathrm{I}^{2}=87 \%$

Test for overall effect: $Z=0.83(P=0.41)$

Test for subgroup differences: $\mathrm{Chi}^{2}=7.60, \mathrm{df}=\mathrm{I}(\mathrm{P}=0.0 \mathrm{I}), \mathrm{I}^{2}=87 \%$

164

$65.3 \%$

$1.17[0.72,1.89]$

294

$100.0 \%$

$0.84[0.55,1.27]$ 
Analysis 5.8. Comparison 5 personalised risk communication versus general risk information for 'HIGH RISK' PEOPLE, Outcome 8 uptake of screening test.

Review: Personalised risk communication for informed decision making about taking screening tests

Comparison: 5 personalised risk communication versus general risk information for 'HIGH RISK' PEOPLE

Outcome: 8 uptake of screening test

Study or subgroup personalised risk $n / N$

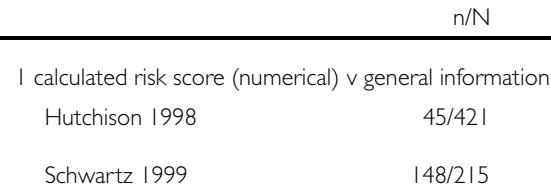

\section{Subtotal (95\% CI)}

636

Total events: 193 (personalised risk), 170 (general risk info)

Heterogeneity: $\mathrm{Chi}^{2}=26.48, \mathrm{df}=\mathrm{I}(\mathrm{P}<0.0000 \mathrm{I}) ; \mathrm{I}^{2}=96 \%$

Test for overall effect: $Z=2.32(P=0.020)$

2 calculated risk score (categorised) $\vee$ general information

$$
\text { Bastani } 1999 \quad 249 / 382
$$

382

Subtotal (95\% CI)

general risk info

Odds Ratio M-H,Fixed,95\% Cl

$\mathrm{n} / \mathrm{N}$

Weight

Odds Ratio $9 / 504$

$161 / 215$

(14/37|

Total events: 249 (personalised risk), 214 (general risk info) Heterogeneity: not applicable

Test for overall effect: $Z=2.11$ ( $P=0.035)$

3 personal risk factor list $v$ general information

$$
\begin{array}{lr}
\text { Curry } 1993 & \text { 50/75 } \\
\text { Lipkus 2005 } & \text { 270/432 }
\end{array}
$$

507

Subtotal (95\% CI)

Total events: 320 (personalised risk), 282 (general risk info)

Heterogeneity: $\mathrm{Chi}^{2}=3.92, \mathrm{df}=1(\mathrm{P}=0.05) ; \mathrm{I}^{2}=74 \%$

Test for overall effect: $Z=3.14(P=0.0017)$

Total (95\% CI)

1525

Total events: 762 (personalised risk), 666 (general risk info)

Heterogeneity: $\mathrm{Chi}^{2}=30.39, \mathrm{df}=4(\mathrm{P}<0.0000 \mathrm{I}) ; \mathrm{I}^{2}=87 \%$

Test for overall effect: $Z=4.42(P<0.0000 \mathrm{I})$

Test for subgroup differences: $C^{2} i^{2}=0.19, d f=2(P=0.91), I^{2}=0.0 \%$

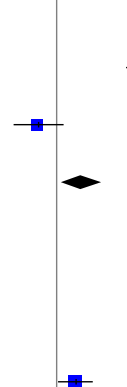

719

$2|4 / 37|$

371

$3.1 \%$

$21.3 \%$

$24.4 \%$

$32.1 \%$

$1.37[1.02,1.84]$

$32.1 \%$

$1.37[1.02,1.84]$

$5.3 \%$

$38.1 \%$

$43.4 \%$

530

1620 M-H,Fixed,95\% C

$0.19, d f=2(P=0.91), 12=0.0 \%$ 


\section{Analysis 6.I. Comparison 6 personalised risk communication versus general risk information for COLORECTAL SCREENING, Outcome I uptake of screening test.}

Review: Personalised risk communication for informed decision making about taking screening tests

Comparison: 6 personalised risk communication versus general risk information for COLORECTAL SCREENING

Outcome: I uptake of screening test

Study or subgroup $\quad$ personalised risk

$n / N$ general risk info

$\mathrm{n} / \mathrm{N}$

$\mathbf{0}$

Subtotal (95\% CI)

0

Total events: 0 (personalised risk), 0 (general risk info)

Heterogeneity: not applicable

Test for overall effect: not applicable

2 calculated risk score (categorised) $\vee$ general information
Lee 199|
$12 / 139$

139

Subtotal (95\% CI)

139

Total events: 12 (personalised risk), 6 (general risk info)

Heterogeneity: not applicable

Test for overall effect: $Z=1.44(P=0.15)$

3 personal risk factor list $v$ general information

Subtotal (95\% CI)

$\mathbf{0}$

Total events: 0 (personalised risk), 0 (general risk info)

Heterogeneity: not applicable

Test for overall effect: not applicable

Total (95\% CI)

139

Total events: 12 (personalised risk), 6 (general risk info)

Heterogeneity: not applicable

Test for overall effect: $Z=1.44(P=0.15)$

Test for subgroup differences: Not applicable
Odds Ratio M-H,Fixed,95\% C

Weight

Odds Ratio M-H,Fixed,95\% C

(n)

(n)

$0.0 \%$

$0.0[0.0,0.0]$




Analysis 7.I. Comparison 7 personalised risk communication versus general risk information for PROSTATE CANCER SCREENING, Outcome I uptake of screening test.

Review: Personalised risk communication for informed decision making about taking screening tests

Comparison: 7 personalised risk communication versus general risk information for PROSTATE CANCER SCREENING

Outcome: I uptake of screening test

Study or subgroup personalised risk

$n / N$ general risk info

$n / N$

$\mathbf{0}$

Subtotal (95\% CI)

Total events: 0 (personalised risk), 0 (general risk info)

Heterogeneity: not applicable

Test for overall effect: not applicable

2 calculated risk score (categorised) $\vee$ general information

Subtotal (95\% CI)

$\mathbf{0}$

Total events: 0 (personalised risk), 0 (general risk info)

Heterogeneity: not applicable

Test for overall effect: not applicable

3 personal risk factor list $v$ general information

$$
\text { Myers } 1999
$$

192

Subtotal (95\% CI)

eral risk info)

Total events: 98 (personalised

Heterogeneity: not applicable

Test for overall effect: $Z=4.54(P<0.0000$ I)

Total (95\% CI)

192

Total events: 98 (personalised risk), 64 (general risk info)

Heterogeneity: not applicable

Test for overall effect: $Z=4.54(P<0.0000$ I $)$

Test for subgroup differences: Not applicable
Odds Ratio M-H,Fixed,95\% C

Weight

Odds Ratio M-H,Fixed,95\% C

\begin{tabular}{|c|c|c|}
\hline $\mathbf{0}$ & $0.0 \%$ & $0.0[0.0,0.0]$ \\
\hline $\mathbf{0}$ & $0.0 \%$ & $0.0[0.0,0.0]$ \\
\hline $64 / 221$ & $100.0 \%$ & $2.56[1.70,3.84]$ \\
\hline 221 & $100.0 \%$ & $2.56[1.70,3.84]$ \\
\hline 221 & $100.0 \%$ & $2.56[1.70,3.84]$ \\
\hline
\end{tabular}

favours general favours personal 


\section{A P P E N D I C E S}

\section{Appendix I. Search Strategy: CENTRAL}

The Cochrane Central Register of Controlled Trials (CENTRAL (The Cochrane Library Issue 4, 2004))

1. risk ${ }^{*}$ or (patient near tailor $\left.{ }^{*}\right)$ or (patient near personal $\left.{ }^{*}\right)$ or $\left(\right.$ patients near tailor $\left.{ }^{*}\right)$ or (patients near personal $\left.{ }^{*}\right)$ or $\left(\right.$ consumer* near $^{*}$ tailor $\left.^{*}\right)$ or (consumer* near personal $\left.{ }^{*}\right)$ or (recipient* near tailor*) or (recipient* near personal*) or (tailor* near message*) or (individual* near message*) or (personal* near message*)

2. RISK explode all trees $(\mathrm{MeSH})$

3. (\#1 or \#2)

4. COMMUNICATION single term $(\mathrm{MeSH})$

5. PERSUASIVE COMMUNICATION single term $(\mathrm{MeSH})$

6. COUNSELING single term $(\mathrm{MeSH})$

7. GENETIC COUNSELING single term (MeSH)

8. HEALTH PROMOTION single term (MeSH)

9. PATIENT EDUCATION single term $(\mathrm{MeSH})$

10. HEALTH KNOWLEDGE ATTITUDES PRACTICE single term (MeSH)

11. PATIENT ACCEPTANCE OF HEALTH CARE single term (MeSH)

12. ATTITUDE TO HEALTH single term $(\mathrm{MeSH})$

13. DECISION MAKING single term $(\mathrm{MeSH})$

14. CHOICE BEHAVIOR single term $(\mathrm{MeSH})$

15. INFORMED CONSENT single term (MeSH)

16. ((patient near communicat*) or (patient near educat $\left.{ }^{*}\right)$ or (patient near counsel*) or (patient near inform* $\left.{ }^{*}\right)$ or (patient near discuss*) or (patient near decision*) or (patient near decide* ${ }^{*}$ or (patient near participat ${ }^{*}$ ) or (patient near attitude*) or (patient near accept*) or (patient near choice*))

17. ((patients near communicat $\left.{ }^{*}\right)$ or (patients near educat $\left.{ }^{*}\right)$ or (patients near counsel $\left.{ }^{*}\right)$ or (patients near inform* $\left.{ }^{*}\right)$ or (patients near discuss $\left.^{*}\right)$ or (patients near decision ${ }^{*}$ ) or (patients near decide*) or (patients near participat*) or (patients near attitude $\left.{ }^{*}\right)$ or (patients near accept $\left.t^{*}\right)$ or (patients near choice*))

18. ((consumer* near communicat $\left.{ }^{*}\right)$ or (consumer* near educat $\left.{ }^{*}\right)$ or $\left(\right.$ consumer* near counsel $\left.^{*}\right)$ or (consumer* near inform $\left.{ }^{*}\right)$ or (consumer* near discuss*) or (consumer* near decision ${ }^{*}$ ) or (consumer* near decide ${ }^{*}$ ) or (consumer* near participat*) or (consumer* near attitude*) or (consumer* near accept $\left.{ }^{*}\right)$ or (consumer* near choice*))

19. (\#4 or \#5 or \#6 or \#7 or \#8 or \#9 or \#10 or \#11 or \#12 or \#13 or \#14 or \#15 or \#16 or \#17 or \#18)

20. (\#3 and \#19)

21. MASS SCREENING explode all trees (MeSH)

22. MAMMOGRAPHY single term (MeSH)

23. VAGINAL SMEARS single term $(\mathrm{MeSH})$

24. OCCULT BLOOD single term $(\mathrm{MeSH})$

25. PROSTATE-SPECIFIC ANTIGEN single term (MeSH)

26. COLONOSCOPY explode all trees $(\mathrm{MeSH})$

27. PRECANCEROUS CONDITIONS single term $(\mathrm{MeSH})$

28. CERVIX DYSPLASIA single term (MeSH)

29. EARLY DIAGNOSIS single term (MeSH)

30. (screen* or mammography or mammogram* or (vaginal next smear) or (occult next blood) or (prostate next specific next antigen) or colonoscopy or sigmoidoscopy)

31. neoplasm*

32. (brca1 or brca2)

33. (\#21 or \#22 or \#23 or \#24 or \#25 or \#26 or \#27 or \#28 or \#29 or \#30 or \#31 or \#32)

34. (\#20 and \#33) 


\section{Appendix 2. Search Strategy: CINAHL}

CINAHL (Ovid) (1985 to December 2005)

1. risk\$.mp.

2. ((patient $\$$ or consumer $\$$ or recipient $\$$ ) adj5 (tailor $\$$ or personal $\$)$ ).tw.

3. ((tailor $\$$ or individual $\$$ or personal $\$$ ) adj5 message $\$) . t w$.

4. or/1-3

5. Communication/

6. "GENETIC COUNSELING (IOWA NIC)"/ or "COUNSELING (IOWA NIC)"/ or COUNSELING/ or "HEALTH TEACH-

ING, GUIDANCE AND COUNSELING (OMAHA)”/ or GENETIC COUNSELING/

7. Patient Education/

8. Health Education/

9. Health Promotion/

10. Health Knowledge/

11. ((patient $\$$ or consumer $\$$ ) adj3 (communicat $\$$ or counsel $\$$ or inform $\$$ or discuss $\$$ or decision $\$$ or decide $\$$ or participat $\$)$ ).tw.

12. attitude to health/ or patient attitudes/

13. Health Beliefs/

14. Health Behavior/

15. decision making/ or decision making, patient/

16. informed consent/

17. or $/ 5-16$

18. health screening/ or cancer screening/ or genetic screening/

19. Cervical Smears/

20. mammography/

21. Occult Blood/

22. tumor markers, biological/ or prostate-specific antigen/

23. colonoscopy/ or sigmoidoscopy/

24. Precancerous Conditions/

25. screen $\$$.tw.

26. neoplasms.mp.

27. (BRCA1 or BRCA2).tw.

28. or/18-27

29. randomi?ed controlled trial\$.af.

30. random\$.tw.

31. clinical trial.pt.

32. exp clinical trials/

33. (clin\$ adj25 trial\$).tw.

34. ((singl\$ or doubl\$ or trebl\$ or tripl\$) adj25 (blind\$ or mask\$)).tw.

35. placebos/

36. placebo\$.tw.

37. exp study design/

38. or/29-37

39.4 and 17 and 28 and 38

40. limit 39 to $\mathrm{yr}=1985-2005$ 


\section{Appendix 3. Search Strategy: EMBASE}

EMBASE (Ovid) (1985 to December 2005)

1. risk/ or cardiovascular risk/ or genetic risk/ or high risk patient/ or high risk population/ or population risk/ or risk assessment/ or risk benefit analysis/ or risk factor/ or risk management/

2. cancer risk/ or fetus risk/

3. risk\$.tw.

4. ((patient $\$$ or consumer $\$$ or recipient $\$)$ adj5 (tailor $\$$ or personal $\$)) . t w$.

5. ((tailor\$ or individual\$ or personal\$) adj5 message\$).tw.

6. or/1-5

7. interpersonal communication/ or persuasive communication/ or verbal communication/

8. counseling/ or genetic counseling/ or parent counseling/ or patient counseling/

9. health education/ or health promotion/ or patient education/

10. attitude/

11. decision making/

12. informed consent/

13. ((patient $\$$ or consumer\$) adj3 (communicat $\$$ or counsel $\$$ or inform $\$$ or discuss $\$$ or decision $\$$ or decide $\$$ or participat $\$)$ ).tw.

14. or/7-13

15. screening/ or screening test/ or mass screening/ or cancer screening/ or genetic screening/ or newborn screening/ or prenatal screening/

16. mammography/

17. vagina smear/

18. occult blood/

19. Prostate Specific Antigen/

20. colonoscopy/ or sigmoidoscopy/

21. Precancer/

22. early diagnosis/

23. screen\$.tw.

24. neoplasms.mp.

25. (BRCA1 or BRCA2).tw.

26. or/ $15-25$

27.6 and 14 and 26

28. randomized controlled trial/

29. random $\$$.tw.

30. exp controlled study/

31. double blind procedure/

32. single blind procedure/

33. crossover procedure/

34. latin square design/

35. multicenter study/

36. ((clinical or controlled or comparative or placebo or prospective or random $\$$ ) adj3 (trial or study)).tw.

37. ((single $\$$ or doubl $\$$ or trebl $\$$ or tripl $\$$ ) adj7 (blind $\$$ or mask $\$)$ ).tw.

38. (crossover $\$$ or cross-over $\$$ or (cross adj1 over\$)).tw.

39. ( (allocat $\$$ or allot $\$$ or assign $\$$ or divid $\$$ ) adj3 (condition $\$$ or experiment $\$$ or intervention $\$$ or treatment $\$$ or therap $\$$ or control $\$$ or group\$)).tw.

40. or/28-39

41. exp animal/ or nonhuman/

42. human/

43. 41 and 42

44. 41 not 43

45. 40 not 44

46. 27 and 45 


\section{Appendix 4. Search Strategy: MEDLINE}

MEDLINE (Ovid) (1985 to December 2005)

1. exp risk/

2. risk\$.tw.

3. ((patient $\$$ or consumer $\$$ or recipient $\$$ ) adj5 (tailor $\$$ or personal $\$)$ ).tw.

4. ((tailor\$ or individual\$ or personal\$) adj5 message $\$)$.tw.

5. or/ $1-4$

6. communication/

7. persuasive communication/

8. counseling/

9. genetic counseling/

10. health promotion/

11. Patient Education/

12. health knowledge, attitudes, practice/

13. ((patient\$ or consumer\$) adj3 (communicat\$ or counsel\$ or inform\$ or discuss\$ or decision\$ or decide $\$$ or participat $\$)$ ).tw.

14. "Patient Acceptance of Health Care"/

15. Attitude to Health/

16. decision making/ or choice behavior/

17. Informed Consent/

18. or/6-17

19. exp mass screening/

20. Mammography/

21. Vaginal Smears/

22. occult blood/

23. Prostate-Specific Antigen/

24. colonoscopy/ or sigmoidoscopy/

25. precancerous conditions/ or cervix dysplasia/

26. early diagnosis/

27. screen\$.tw.

28. neoplasms.mp.

29. (BRCA1 or BRCA2).tw.

30. or/19-29

31.5 and 18 and 30

32. clinical trial.pt.

33. random\$.af.

34. placebo\$.af.

35. ((singl\$ or doubl\$) adj25 (blind\$ or mask\$)).af.

36. or $/ 32-35$

37. animals/

38. human/

39.37 and 38

40.37 not 39

41.36 not 40

42. 31 and 41

43. limit 42 to $y r=1985-2005$ 


\section{Appendix 5. Search Strategy: PsycINFO}

PsycINFO (Ovid) (1985 to December 2005)

1. exp RISK PERCEPTION/ or exp RISK ANALYSIS/ or exp RISK FACTORS/ or exp RISK TAKING/

2. risk\$.mp.

3. ((patient $\$$ or consumer $\$$ or recipient $\$$ ) adj5 (tailor $\$$ or personal $\$)$ ).tw.

4. ((tailor $\$$ or individual\$ or personal\$) adj5 message $\$$ ).tw.

5. or/1-4

6. interpersonal communication/ or communication/

7. persuasive communication/

8. counseling/ or genetic counseling/

9. health education/ or client education/ or health promotion/

10. health attitudes/ or health knowledge/ or health behavior/

11. decision making/ or choice behavior/

12. informed consent/

13. ((patient $\$$ or consumer\$) adj3 (communicat $\$$ or counsel $\$$ or inform $\$$ or discuss $\$$ or decision $\$$ or decide $\$$ or participat $\$)$ ).tw.

14. or/6-13

15. screening tests/ or cancer screening/ or health screening/ or screening/

16. mammography/

17. screen\$.tw.

18. (neoplasm $\$$ or cancer $\$$ ).tw.

19. or $/ 15-18$

20. 5 and 14 and 19

21. randomi?ed controlled trial\$.af.

22. random $\$$.tw.

23. (clin\$ adj25 trial\$).tw.

24. ((singl\$ or doubl\$ or trebl\$ or tripl\$) adj25 (blind\$ or mask\$)).tw.

25. placebo/

26. placebo\$.tw.

27. (cross over or crossover).tw.

28. latin square.tw.

29. exp treatment effectiveness evaluation/

30. exp mental health program evaluation/

31. exp experimental design/

32. or/21-31

33. animal.po.

34. (human or inpatient or outpatient).po.

35.33 and 34

36. 33 not 35

37.32 not 36

38. 20 and 37

39. limit 38 to $\mathrm{yr}=1985-2005$ 


\section{FEEDBACK}

\section{Comment from Jeppe Schroll, 30 September 201 I}

\section{Summary}

In the first comparison 1.1.1 the authors include two studies

Personalised risk:

1) Skinner: Mean (SD): 78 (21)

2) Kerman: Mean (SD): $7.74(2.16)$

Combining these results with mean difference results in extreme heterogeneity.

When analysing the large difference in mean and standard deviation (SD) it seems these studies might be using different scales, and a standardized mean difference

might be the right choice for this analysis.

We discuss your specific Cochrane review in a published paper about heterogeneity: http://www.biomedcentral.com/1471-2288/11/ 22

Regards

Jeppe Schroll

\section{Reply}

We thank Dr. Schroll for his comment. We are updating the review at present and will investigate his feedback in detail during the update process.

\section{Contributors}

Adrian Edwards, 8 November 2011

\section{WHAT'S NEW}

Last assessed as up-to-date: 30 December 2005.

\begin{tabular}{ll|l}
\hline Date & Event & Description \\
\hline 8 November 2011 & Feedback has been incorporated & $\begin{array}{l}\text { Feedback from Jeppe Schroll was received in September 2011 (see Feedback } \\
\text { 1). The review authors are updating their review (as at November 2011) and } \\
\text { will investigate his feedback in detail during the update process }\end{array}$ \\
\hline
\end{tabular}




\section{H I S T O R Y}

Protocol first published: Issue 4, 1999

Review first published: Issue 1, 2003

\begin{tabular}{l|l|l}
\hline Date & Event & Description \\
\hline 18 April 2008 & Amended & Converted to new review format. \\
\hline 21 July 2006 & New citation required and conclusions have changed & $\begin{array}{l}\text { Substantive amendment. } \\
\text { The review was updated on Issue 4 } 2006 \text { of The Cochrane } \\
\text { Library. Nine new studies were identified, bringing the total } \\
\text { number of included studies to 22. The reviews conclusions } \\
\text { were amended in light of the new studies included in the } \\
\text { review. }\end{array}$ \\
\hline & $\begin{array}{l}\text { The title of the review also changed slightly. It was first pub- } \\
\text { lished on Issue 1 2003 of The Cochrane Library as "Person- } \\
\text { alised risk communication for informed decision making } \\
\text { about entering screening programs" }\end{array}$ \\
\hline
\end{tabular}

\section{CONTRIBUTIONSOFAUTHORS}

AE developed the protocol for the review, with input from GE; JD conducted the literature searches; AE and one of JD or SH appraised all studies for inclusion of exclusion and for data extraction; $\mathrm{KH}$ gave statistical advice regarding data extraction and synthesis; all authors contributed to discussions and drafting of the review report. AE is the guarantor for the review.

\section{DECLARATIONS OF INTEREST}

None known.

\section{SOURCES OFSUPPORT}

\section{Internal sources}

- No sources of support supplied 


\section{External sources}

- Department of Health, UK.

- Cochrane Health Promotion and Public Health Field, Australia.

\section{N DEX TERMS}

\section{Medical Subject Headings (MeSH)}

${ }^{*}$ Communication; ${ }^{*}$ Decision Making; ${ }^{*}$ Mass Screening; ${ }^{*}$ Risk; Consumer Participation [ ${ }^{*}$ methods]; Patient Education as Topic; Randomized Controlled Trials as Topic

\section{MeSH check words}

Humans 